Portland State University

PDXScholar

1972

\title{
An attitudinal study of selected groups in the city of The Dalles toward the Community Attention Home
}

David Clitheroe

Portland State University

Garrett Long

Portland State University

Follow this and additional works at: https://pdxscholar.library.pdx.edu/open_access_etds

Part of the Family Law Commons, Juvenile Law Commons, and the Social Work Commons Let us know how access to this document benefits you.

Recommended Citation

Clitheroe, David and Long, Garrett, "An attitudinal study of selected groups in the city of The Dalles toward the Community Attention Home" (1972). Dissertations and Theses. Paper 1693.

https://doi.org/10.15760/etd.1692

This Thesis is brought to you for free and open access. It has been accepted for inclusion in Dissertations and Theses by an authorized administrator of PDXScholar. Please contact us if we can make this document more accessible: pdxscholar@pdx.edu. 
AN ATTITUDINAI STUDY OF SELECTED GROUPS

IN THE CITY OF THE DALLES TOWARD

THE CORMUNITY ATTENTION HONE

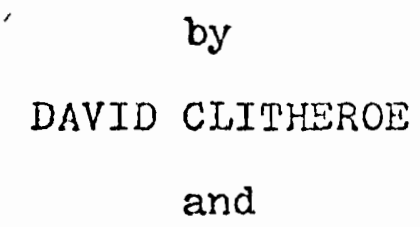

GARRETT LONG
A report submitted in partial fulfillment of the requirements for the degree of
MIASTER OF
SOCIAI WORK

Portland State University

1972 


\section{ACKNOWLEDGNENTS}

We greatly appreciate the help of many interested people and their cooperation in the planning and implementation of this survey.

We would especially like to thank:

Dr. Martha N. Ozawa, Associate Professor of Social Work, Portland State University, School of Social Work, for her guidance and direction throughout the entire study.

Gerald Grey, Social Worker at the Mid Columbia Mental Health Clinic, for serving on our practicum committee. James F. Roth, Director, Wasco County Juvenile Court Department, for his support and suggestions.

Gene Winningham, Assistant Project Director, Volunteer Worker/Student Practicum Project, Corrections Division, for initiating the survey. 
TABLE OF CONTENTS

PAGE

ACKNOWLEDGMENTS

CHAPTER

I HISTORICAL BACKGROUND OF RESIDENTIAL

CARE FOR CHILDREN

The Need for Services in The Nation

and. The State of Oregon

3

The Use of Foster and Group Homes 8

The Original Attention Home 11

Development of An Attention Home In 15

The Dalles, Oregon

II RESEARCH DESIGN 19

Introduction $\quad 19$

Purpose 20

Methodology 21

"III ANALYSIS OF DATA 31

Nethod 31

Philosophy and Concept 32

Awareness and Knowledge $\quad 35$

Need for Home 38

Potential for Involvement 39

Discussion $\quad 42$

IV CONCIUSION $\quad 45$

BIBLIOGRAPHY 48 
Appendix A Financial statements for

Attention, Inc., First Year

of Operation

Appendix B Basic Flow, Source, and Placement Statistics for First Year of Operation

Appendix C Attention Home Rules and Duties for Children

Appendix D Maps of the Surrounding Neighborhood Surveyed

Appendix F Frequency Distributions and

66

Appendix G Questionnaire 
HISTORICAL BACKGROUND

OF

RESIDENTIAL CARE FOR CHILDREN

Institutional care of children has a very long history. Not only is the practice very old but there are some particular institutions that have had a remarkably long existence. Howard W. Hopkirk, writing in his book "Institutions Serving Children," tells of a Japanese orphanage which has been operating for over 1400 years. Hospices (or shelters) monasteries, and convents have been providing care for people in need, including children in western Europe since the fourth century. The first recorded instance of a child care institution in the United States dates back to 1729. An orphanage was founded by a group of nuns for children whose parents had been killed in an Indian attack.

Public care of children like many other social services has developed more slowly than that of private, especially religious, inștitutions. Although social services were for centuries the sole concern of the church, the lack of public response to the needs of children has been influenced by at least two other major considerations. These are, according to Phillipe Aries, (1) the delay in western thought until the twelfth and thirteenth centuries of the special needs of children and (2) the delay in the recognition of the value of 
children until the seventeenth century. In his book, "Centur108 of Chlldhood: A Social History of Family Life", he demonotrates that the concept of childhood as a period of dependency and relative helplessness did not appear until much later than eany other social concepts. He also states that neglect of chlldren was related to the fact that since so many died at an early age it did not make economic sense to invest in thern. In the early days of our nation there were two kinds of care for children separate from their parents, depending upon their ability to work. If they were able-bodied then they were sold in an auction or else indentured to work as apprentices. Apprentices were viewed as extra sons or daughters, educated, clothed, fed, obliged to obedience, forbldden to marry, unpaid, and generally absolutely dependent until they attained the age of twenty-one. Those who were unable to work because they were handicapped in some way were placed in an asylum, almshouse or orphanage. They were supported and housed with other socially dependent persons including paupers and lunatics. These institutions provided lood, clothing and shelter but little else.

The next development was the inclusion of schooling as a function of child caring institutions. At first this was been as a necessity for able-bodied children only, but as ilse went on the value of education for handicapped children - as recognized.

Une of the more recent changes has been the shift from 
large impersonal institutions to smaller cottage type residences with a homelike atmosphere. Another has been the addition of professional staff including psychiatrists, psycologists, social workers and trained house parents. Federal legislation from the $1930^{\circ}$ s onward has made possible the development of highly specialized treatment centers for children, especially those with psychosocial disorders.

The product of this history in the United States is described by William Ni. Bolman as follows:

\begin{abstract}
"In summary, the development of services for children requiring supplementary parenting has gone through a long evaluation resulting in three major instruments for care: (1) the AFDC-supported home, (2) the foster home, and (3) the residential institution. As children's services have developed there has been increasing differentiation among them, and institutions are becoming increasingly treatment-oriented." 1
\end{abstract}

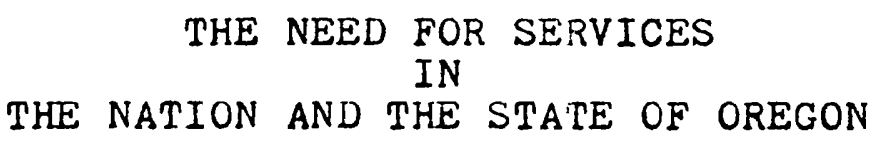

While we as individuals may desire the very best for our children and all the children in our community, there are millions of American children who lack the bare essentials of life. There are still children in this country who, despite our affluence, have not received the necessities for physical, emotional or intellectual growth. The demands of a complex

1 William M. Bolman, The Future of Residential Care for Children, Journal of the Child Welfare League of America, Inc., Vol. XLVIII, No. 5, (May, 1969), pp. 281-282. 
world threaten the solidarity of the family and the welfare of children. When families become overburdened and start to dissolve they frequently come the attention of the court or the welfare department. What happens to them, especially the children, is of the utmost importance.

Approximately 642,000 children came before the court for alleged offenses numbering 745,000, excluding traffic cases, in the United States during 1966. It was an increase of 7 per cent in a year when the estimated population increase for this group was only 2 per cent. There has been an almost continuous upward trend in the rate of juvenile crime since 1949. While the number of adults incarcerated is expected to increase slightly, the alarming fact is that if we continue to confine juveniles at the same rate an increase of 70 per cent between 1965 and 1975 can be expected. These figures suggest that we should investigate alternatives to detention, not only because of the increasing pressures of space available, but, more importantly, because juvenile detention has shown itself to be very expensive and ineffective.

The President's Commission on Law Enforcement and Administration of Justice produced a Task Force Report on Juverile Delinquency and Youth Crime in 1967 which states:

"A study prepared for the Commission reveals that the problem is nationwide. It was found that in 1965, two-thirds of all juveniles apprehended were admitted to detention facilities and held there an average of 12 days at a total cost of more than $\$ 53$ million or an average cost of $\$ 120$ per child. Furthermore, for 93 per cent of the country's juvenile court jurisdiction, serving 44.3 per cent of the 
population, there is no place of detention other than the county jail, and many of the jails used for children are unsuitable even for adult offenders.

To meet this problem, adequate and separate detention facilities for juveniles should be constructed. For children for whom detention is made necessary only by the unavailability of adequate parental supervision, there should be low-security community residential centers and similar shelters."2

The National Commission on Crime and Delinquency recommends a 10 per cent detention figure for juveniles. This recommendation is based on the fact that there are usually insufficient grounds to justify detaining more than 10 per cent of those brought to the attention of the police. There are more effective and appropriate ways of handing the young person either by immediate release, referral without incarceration to the probation department, or referral to another agency.

The NCCD, in their report, "A Balanced Correctional System for Oregon" published in 1966, commented on the need for improving facilities here. They found that of oregon's 36 counties only 5 had detention facilities designed for delinquent children and where there was no detention home children were being held in jail. The lack of foster homes for delinquents was felt to be one of the states' most crucial problems. Juvenile counselors, judges, welfare per-

2 Task Force on Juvenile Delinquency, The President's Commission on Law Enforcement and Administration of Justice, Task Force Report: Juvenile Delinguency and Youth Crime, (U.S. Government Printing Office, Washington D.C., 1967), p. 37. 
sonnel, and police officers all made reference to this need in their communities.

of the four major recommendations for local services and facilities for juveniles, two were specifically related to juvenile homes. They were:

"That a comprehensive and realistic statewide plan for regional juvenile detention be developed; and that such make-shift approaches to this problem as inclusion of juvenile quarters in adult jails and the conversion of old buildings into unsafe 'fire trap' detention homes be abandoned."3

and

\begin{abstract}
"That either the courts or the welfare department be given mandatory legal responsibility for finding and supervising group foster homes for appropriate delinquent children with the state continuing to supplement inadequate county funds appropriated for this purpose."4
\end{abstract}

While the study was not intended to determine what care dependent and neglected children receive, in looking into the situation of delinquents, it also uncovered the fact that in no county was there sufficient care for non-delinquent children either. In short, the state of oregon was not fulfilling its function of "parens patriae."

Greenleigh Associates, Inc., produced a report in 1968 for the Governor's Child Welfare Study Committee, entitled "Child Welfare Needs and Services in Oregon," with similar

${ }^{3}$ National Council on Crime and Delinquency, A Balanced Correctional System for oregon. (1966), pp. 2 and 11 .

4 Ibid.. p. i. 
findings.

The report stated that dependent, neglected, endangered and abused children have been refused public care when county allocations to pay the cost of foster care were exhausted. Services to children were also refused when the workload of child welfare workers reached its limit. Foster homes were found in short supply and there was a lack of staff to recruit and certify additional homes.

once again it was found that the need for more out-ofhome resources for children was repeatedly mentioned by staffs of welfare departments, juvenile departments, private agencies, and mental health agencies.

Some juvenile departments that sought care for dependent children from the county welfare were refused. Not only was the juvenile department left with the responsibility for these dependent children but delinquent children as well. The juvenile departments are not subject to certification. Some of their homes do not even meet minimum requirements. Two recommendations of Greenleigh Associates, Inc., were as follows:

"It is recommended that the State of Oregon accept its responsibility to provide care and protection for all children in the state who are dependent, neglected, endangered or who are without parental care or support, or who have been determined to be in need of the protective services of the state." 5

${ }^{5}$ Greenleigh Associates, Inc., Child Welfare Needs and Services in oregon: Report to The Govermor's child Welfare Study Committee, (New York, 1968), p. 17. 
and

"It is recommended that efforts to recruit more foster family and group homes be intensified." 6

The need for these kinds of services in the state of Oregon have been well established. What is needed now is appropriate action to obtain them.

\section{THE USE OF FOSTER AND GROUP HONES}

Foster and group homes differ from detention halls in that they have no physically restricting features, such as locked outer doors, bars, or high walls. This kind of shelter care is used by the juvenile court and other child welfare service agencies, both public and private.

Young people in a variety of situations may be best served by a foster or group home if they do not require the controls of an institution. This may include:

1. Young people who committed an offense but were not almost certain to run before the court disposition.

2. Neglected, dependent and non-delinquent emotionally disturbed young people.

3. Delinquent young people who do not require secure custody but because of physical or moral danger at home need to be removed from their parents or siblings.

4. Young people who were being held for court referral.

5. Young people held for police or social investigation.

6. Young people who need clinical study and treatment.

6 Ibid., p. 18. 
7. Young people who have become uncontrollable at home and their parents have been unable or unwilling to be responsible for them.

While not every child in all of these categories needs to be removed from his home, these are some of the situations that may make it necessary. When it is necessary, the foster and group home is preferable to detention. Detention should be the last resort; but, unfortunately, all too often it is used when a foster or group home would be more appropriate. One of the questions that arises is, 'Should delinquent and non-delinquent young people live together?' Alfred J. Kahn says with regard to this issue:

"There is often confusion about this point and a failure to make use of shelters for delinquents. In part, it derives from a desire not to expose the (often younger) dependent and neglected children in shelters to the influence of delinquents. To some degree, however, there is a failure to appreciate the possibilities of nonrestrictive shelter, as appropriate, for some delinquents. Classification within a shelter facility to separate out the more aggressive or more disturbed older children, even among the allegedly neglected and dependent, is necessary under any circumstances. The tendency of shelters to be closed to delinquents provides one more illustration of the undesirable consequences of labeling."?

The use of a foster or group home has real advantages. The young person stays in the community. His ties with friends, school, and work need not be broken. He is not stigmatized so he does not develop a sense of criminal identity or have it reinforced if it already exists. An important

7 Alfred J. Kahn, Planring Community Services for Children in Trouble, (Columbia University Press, New York, 1963), p. 281 . 
advantage to the taxpayer is that the cost of care is usually much lower.

Children labeled "delinquent" are often as much neglected as they are delinquent. The homes many of them come from are so badly deteriorated that delinquent behavior is a means of survival physically, mentally or emotionally. Sometimes the family situation can be improved to the point where the young person is able to return home without the pressure to break the law. If the child has been in a foster or group home rather than an institution while adjustments were made, he will not have been exposed to the socialization of more "hardened criminal" types. ("Institution" here refers to a detention facility.)

This is why foster home placement is one of the most common alternatives to institutionalization. of 233 probation departments surveyed by the National survey of Corrections, 42 per cent used foster home placements.

Many states are developing group homes in addition to foster homes. These are used for youths who do not adjust well to family life in the home of foster parents but do not need the full controls of an institution. The Wisconsin Division of Corrections has used group homes extensively. In 1966 they operated 33 homes for boys and girls with 4 to 8 in each home. When they compared the cost of care with their other juvenile institutions it was found to be from onefourth to one-third less. 
A recent development in the state of Oregon is the Youth Care Center. This is a group home for young people between the ages of 12 and 18 who have to leave their own home but do not need to be sent to the state Correctional School. It is the first venture in state-county shared funding in the field of juvenile delinquency. In March 1968 ten counties either had or were in the process of developing Youth Care Centers.

\section{THE ORIGINAL ATTENTION HOME}

The first Attention Home was begun in the city of Boulder, Colorado. This is a middle and upper middle class community. The average family income is considerably higher than the national average. It is about 25 miles on the freeway from Denver. The University of Colorado is located here. The citizens of Boulder are largely professional and skilled workers. Only one per cent of the county's population is non-white.

It all started in the Adult Study Group at the Methodist Church during 1966. The group discussion leader, John E. Hargadine, was describing the problems of placing children who come to the attention of the court. The group decided to make a study of resources in Boulder County available to children in trouble who for one reason or another had to leave home. They learned only three alternatives were available. There were a limited number of foster homes known to 
the county welfare department and the juvenile court. These were filled to capacity. Many of them were not available to older teenagers, however, even when they were not taken. There was temporary housing available at the Denver Juvenile Hall but this was almost entirely restricted to girls. Since there were more boys needing the service and it meant transportation out of town this was of questionable value. Finally there were the juvenile quarters of the county jail. For those who needed to be locked up, a minority indeed, this was adequate, but for the rest it was felt to be a very undesirable place. It was also learned that there were many other children in the community who could benefit from the services of the court if temporary shelter care were available. There were many children who ran away because of severe family conflicts but had no place to go. The study group concluded that if a child had a "neutral" place to go until things could be straightened out at home there would be fewer runaways. Runaways and other children who sought to escape an intolerable home life were frequently arrested for violations of the law.

The group decided that while many young people in their community were getting "detention", what they really needed was "attention". They felt a new and positive approach was needed. In response to the need they made plans to sponsor a community supported group foster home for the care of delinquent and other youth with problems. Since "detention" 
had the unpleasant connotation of community rejection, they chose to call the shelter an Attention Home.

A nonprofit tax-exempt organization called "Attention, Inc." was formed by several members in the adult study class, court representatives, and interested citizens. The first Methodist Church turned their old Parsonage over to the corporation. It was a three story brick home near the downtown area. The house was furnished comfortably through donations from the community. There was no local, state or Federal money involved. Everything came from the community. Horace B. Holmes, the judge of the juvenile court, expressed the philosophy when he said that participation by the community must be that of total involvement. He felt that the local community should be responsible for the needs of its children, and not the state, as long as the comnunity was financially able, as Boulder certainly was. Contributions of money, goods and services made it possible for the home to operate for one year on $\$ 7,300.00 .^{8}$

- While administration of the home was the responsibility of the Board of Directors, intake for the home was controlled by court personnel. During the first year the home was occupied by delinquent and dependent children, children in need of supervision and children with a variety of other problems. 9

${ }^{8}$ See Appendix A.

${ }^{9}$ See Appendix B. 
The houseparents chosen by the board for the home were only a few years older than the older young people the home served. It was felt they would be best able to relate to the children and also be most willing to incorporate and experiment with new ideas. They were paid $\$ 200$ per month plus room and board. They had considerable background as volunteers and in administration of volunteer programs. The Board knew that the house parents would have problems because of their inexperience, but they felt the gain would be worth the risk. The children in the home had duties and were expected to obey the rules, ${ }^{10}$ but these were at a minimum. When the Attention Home was established the Boulder County court already had an extensive volunteer program in operation. The children in the home were encouraged to participate in these ongoing Court sponsored activities. Even though some of the children were not delinquent, it was felt they could benefit from the program. The volunteer programs included discussion groups, tutoring, arts and crafts, classes on health, grooming and hygiene, job training and a friendship program manned by adult volunteers. The volunteers participated in the individual work with the child, group activities, entertainment, and homemaking responsibilities. The home had the appearance at times of a teenage center. 
DEVELOPMENT OF AN ATTENTION HOME

IN THE DALLES, OREGON

Like many other communities around the country, the city of The Dalles, Oregon, found that there was a need for temporary child care facilities.

of the 679 cases handled in 1970 by the Juvenile Court in Wasco County, 221 were for offenses applicable to both juveniles and adults. For the same category in 1969 there were 152 cases. This means there has been an increase of 69 cases or 45 per cent. Offenses applicable to "juveniles only" totaled 378 in 1970 and 286 in 1969. This is an increase of 19 or 86 per cent. Dependency and neglect cases decreased from 64 in 1969 to 36 in 1970. This represents a decline of 28 cases or 43 per cent. There were 3 "special cases" for both 1969 and 1970.

While statistics are only a small part of the picture, it is interesting to note that offenses applicable to juveniles only (such as run away, truancy, curfew, ungovernable, minor in possession, etc.) from the year 1965 through 1970 are as follows: 253 in 1965; 235 in 1966; 284 in 1967; 264 in 1968; 286 in 1969; and 378 in 1970. There has been no expansion of facilities during this period. The increase in the number of cases has placed great stress on existing facilities.

The Correctional Feasability Study for Region 9 states regarding juvenile detention and temporary shelter care problems : 
"The number of youth detained was nearly as large in Hood River County (108) as in Wasco County (132). Although not very many children were being detained on any particular day, the total number for the two counties for the entire year, 240 , means that juvenile detention is a problem which needs attention in this area, particularly in that juveniles are currently being detained in the county jails. ...these figures suggest that most of the youngsters who are detained are relatively minor cases, so that alternatives to putting them in jail ought to be vigorously sought out."

Statistics show that 164 children were detained overnight or longer in the juvenile detention quarters of the Wasco County Jail and only 24 children were placed in overnight or longer care at a foster family shelter. The Public Welfare Department has one or two homes that can accommodate one or two children and the Court must share these limited facilities.

The basic problems presented by the lack of appropriate facilities in The Dalles are as follows:

1. Often children who allegedly committed acts of delinquency need to be removed from a harmful home environment but there is no place to put them except in jail.

2. Children under 14 years of age are not permitted in the juvenile quarters of the county jail so when they need shelter by the Court they must be taken to a distant county.

3. Dependent children are housed in the juvenile quarters of the county jail when it is necessary for the Court to hold them for evaluation.

4. There is no neutral setting for children who run away or are urimanageable at home, where they can go to live while the Court or other agency attempts to work out the family conflict.

In resporse to these needs it was felt that an Attention 
Home similar to the one in Boulder, Colorado, would be a real solution. A facility of this kind would provide temporary child care for up to eight children of either sex.

In this secure but unthreatening atmosphere community volunteers and professional personnel in the Attention Home would have the opportunity to contribute to the evaluation of the children's needs. The Attention Home would also tend to minimize adjustment problems by keeping the children in the community and allowing them to continue, as much as possible, their regular activities. It has been found that the Attention Home approach has been very successful in coordinating the resources of the community with the needs of its children.

To accomplish this, a non-profit corporation with a nine member Board of Directors has been formed. The name of the corporation is "Community Attention, Inc.". Members of the Board of Directors include: Robert $w$. Close, principal of The Dalles Junior High School; Gerald Grey, Psychiatric Social Worker at Mid-Columbia Mental Health Clinic; Philip Hammond, owner and operator of Hand Out Drive-In Restaurant; Jim Kribs, Director of Guidance, Wahtonka High School; James F. Roth, Director, Wasco County Juvenile Department; and Robert A. Taylor, Director, Vocational Center at The $D_{\Re}$ lles High School; Rosemary Wolfe, Superintendent of Children and Family Services, Wasco County Public Welfare Department; San Van Vactor, District Judge for Wasco County; and Rev. C. 
18

Emerson Vedell, Pastor of Zion Lutheran Church.

Agencies participating in the project include those providing clients and those providing services. Those providing clients are the Waco County Juvenile Department, the Waco County Welfare Department, and the Mid-Columbia Mental Health Clinic. Those providing services are the Sheriff, Waco County; the Juvenile Court, Wasco County; and the Public Welfare Department. 


\section{RESEARCH DESIGN}

\section{INTRODUCTION}

The Board of Directors has described its organization, responsibility and purpose as follows:

"Community Attention Home, Inc., is a nonprofit, non-governmental corporation located in The Dalles, Oregon. It is composed of interested citizens of the community who volunteer their services and support. Community participation and support at all levels of the program is encouraged and sought. The name of the corporation was chosen to demonstrate this founding principle: Active community involvement at the local level in recognizing, meeting and resolving the problems of the community, particularly those related to the youth, is an essential building block in a stable and humane society that is responsive to the needs of its individual members.

The responsibility of the program of Community Attention Home, Inc., rests with the Board of Directors chosen from the membership at large. They have the authority to determine and direct the content of the program and to designate com-

- mittees, individual members and employees of the corporation in carrying out those parts of the program they so designate. The Board is composed of nine members. A term of office is three years and one third of the Board membership changes each year, assuring continuity of the program as well as enabling the Board to be responsive to the membership and community.

Community Attention Home, Inc., was established after recognition of a very great need and scarcity of alternatives in the community other than jail for youth in disrupted family and/or home environments that precipitate a crisis and need for temporary care and shelter. This situation was considered intolerable. Community Attention Home, 
Inc., chose to reflect another basic principle in its name with emphasis on attention rather than detention as a method in dealing with many of the individual and social problems besetting our families and our youth. The word "attention" was borrowed from a program in Boulder, Colorado, and their work was used as a guide in establishing our own Attention Home program.

The house is equipped to handle both boys and girls in the general age range of 12-1? for a period not exceeding 30 days for a child. The capacity of the home is 8 children at any one time. It is anticipated that the youth will fall into three general areas of classification or a component of the three basic areas: Children experiencing family breakdown ard/or unresolved parent-child conflict; neglected and dependent children; and children involved in delinquent behavior."

\section{PURPOSE}

The Board of Directors, after considering a number of alternatives, decided upon an attitudinal study of various local groups regarding the Community Attention Home and its underlying philosophy. The groups were selected arbitrarily but with the thought that they would be diverse and among those groups likely to be most influential in the operation of the home. The population studied consisted of six groups: the Interagency Council; the immediate neighborhood around the home; the local Carpenters' Union; the Kiwanis Club; the Hot Line Youth Group; and the local Police Departments. The purpose of the study is to determine whether or not the individuals in these groups:

1. support the basjc concepts and philosophies of the Community Attention Home. 
2. were aware of and knowledgeable about the Attention Home,

3. perceived the need for the Attention Home in The Dalles, and

4. were willing to become involved with the program.

This is a two part study. Part one establishes baseline data of attitudes prior to the opening of the home. Part two is a follow-up study of the attitudes nine months to one year later. A comparative evaluation of the two surveys will be undertaken to determine what attitudinal changes, if any, have taken place between the first and second surveys.

\section{METHODOLOGY}

In this chapter the methodology of the research will be discussed, including (1) populations, (2) construction of the questionnaire, and (3) the administration of the questionnaire. This is basically an exploritory study for administrative purposes. A review of journals of the past four years, the period during which this concept has been implemented, failed to uncover any similar studies.

\section{Populations}

The group populations are not the total memberships, but rather the number of members present at a particular time and place unless otherwise specified. An effort was made to obtain seventy-five per cent of the actual total group membership. However, this goal was not completely 
obtained in all of the populations. For detailed breakdowns of the groups by age, sex, marital status, and number of children, see the results in the appendix. ${ }^{1}$ A description of the populations are presented below.

1. Interagency Council. The Nasco County Interagency Council is composed of professional people (the majority being women and about two-thirds in the age range of 31-50) working in various areas of social service in Wasco County. The membership includes representatives of such agencies as the Department of Public Nelfare, the Mental Health Clinic, the Juvenile Court, the Cooperative Extension Service, and the public schools. This group attempts to facilitate better communication and planning between agencies and promote needed community programs and services. At the time of the survey the group included four members who were also members of the Community Attention Home Board of Directors. The group was surveyed on June 8,1971 . They met informally in the conference room of the public library during the noon hour. All members of the council present answered the questionnaire.

2. Immediate Neighborhood. The immediate neighborhood was arbitrarily defined by the surveyors to include the area enclosed by the following boundaries (see appendix $D$ for map): a. both sides of E. 7 th Place between Case Street and Court Street,

${ }^{1}$ See Appendix E. 
b. both sides of Case Street between E. 7th Place and E. 8 th Place,

c. both sides of E. 8 th Place between Case Street and Washington Street,

d. both sides of Washington Street between E. 8th Place and E. 9th Street (Washington dead ends before reaching 9th Street.).

e. both sides of 9 th Street between Washington and Court Streets,

f. both sides of Court street between 9 th and loth Streets

g. the north side of 10 th street between Court and Union Streets,

h. the east side of Union between 10 th and 7 th Streets,

i. both sides of 7 th Street between Union and court Streets, and

j. both sides of Court Street between 7 th Street and E. 7th Place.

The survey was conducted on Saturday, June 19, 1971. The survey took from mid morning to late afternoon to complete. The population consisted of one adult person from each of the fifty-five buildings occupied within the defined boundaries. Forty-three persons were contacted in the area. Twenty-five persons responded to the questionnaire and eighteen refused. Although no record was kept of demographic data on the people who refused to answer the questionnaire, it was the opinion of the surveyors that there was a relatively even distribution of men and women contacted. Many more women than men actually responded to the questionnaire. The ages appear to cluster in two groups, those thirty and under and those sixty-one 
and above.

3. Carpenters' Union. The local Carpenters' Union was surveyed on June 15, 1971. The secretary advised the surveyors that the attendance at the union meetings was usually very low in proportion to the total membership. The group surveyed was considered an average sized attendance. A large attendance is assured only when a fine is threatened. The reader should keep in mind when considering the findings of the group that this is the active portion and may not be typical of the total membership. However, one would suspect that this portion has a greater likelihood of becoming involved in the Community Attention Home. This was a totally male population, almost entirely over the age of forty-one. All present at the meeting responded to the questionnaire.

4. Kiwanis Club. This is an international organization for business and professional men with two local service clubs in The Dalles. The club surveyed was the Downtown Chapter of the club. The club was surveyed on June 10, 1971 at a Thursday noon Iuncheon. There were thirty members present. Twenty-one questionnaires were returned. The majority of the men present were over the age of fifty.

5. Hotline Youth Group. This is a voluntary group of young boys and girls of approximately high school age. The young people are involved in a "hotline" telephone answering service for youth with problems, combined with a drop-in center at the Methodist Church. The group meets in the base- 
ment of the church on Saturday nights. The survey was conducted on May 27, 1971. Gerald Grey, M.S.W. of the Mental Health Clinic, acts as an advisor and instructor to the group. 6. Police. The survey of the police departments was conducted on June 19, 1971. Both the Wasco County Sheriff's Department and The Dalles City Police Department were surveyed. These two departments were chosen because of their likelihood of involvement with the home. Many of the youth served by the home are apt to be handled by or referred by the police department. Prior to the opening of the home many of the young people were housed in the County Jail. Twenty questionnaires were obtained from the combined police departments.

\section{The Questionnaire}

The questionnaire was constructed to determine the attitudes of the groups in the areas mentioned earlier. The questionnaire consisted of fixed alternative responses. The opportunity was given for open ended responses following each question. This was to allow the respondent to explain his response if he felt confined by the fixed nature of the question. The questions did not contain a category for a neutral response, with the exception of question eight. The rationale being that everybody has an attitude (positive or negative). The attitudes may be mild or strong, but they exist. This type of forced choice question makes the respondent choose one way or the other. 
Questions 1 through $2 f$, and question 5 dealt with the general area of support or non-support of the basic concepts and philosophies of the Community Attention Home. A profile of total support would include the following attitudes:

1. There should be alternative methods for handling youthful offenders, adolescents removed from their homes due to family conflict, dependent and neglected youths other than placing them in jail or detention facilities. ('yes' responses to questions $1 a, b$, and $c$ )

2. Community volunteers should be involved in the handling of adolescents in need of temporary shelter care, as opposed to only paid officials. ('agree' response to question 2a)

3. Generally speaking, delinquent youth should not be isolated from non-delinquent youth. ('disagree' response to question $2 \mathrm{~b}$ )

4:. Jail or detention facilities should not be used for temporary shelter care facilities for dependent or neglected youth. ('disagree' response to question $2 \mathrm{c}$ )

5. It is not a poor plan to house youth who have broken the law and youth who are neglected by their parents together in the same facility. ('disagree' response to question 2d)

6. The major responsibility for providing facilities for the youth in the community who need temporary shelter care lies with the community rather than the state or federal government. ('agreement' response to question 2c)

7. Funding for programs such as the Community Attention 
Home should come mainly from within the community rather than from outside the community. ('agreement' response to question 2f)

Questions 1 through $2 f$ ask about support or non-support of specific concepts underlying the program. Question 5 asks for a general conclusion to the question, "Are you in favor of the Community Attention Home type of program?" A comparison be iween these questions serves as a check on the internal consistency of the responses.

Questions 3 and 4 dealt with the area of knowledge about the Community Attention Home. A knowledgeable response would include:

1. hearing of the home,

2. knowing it serves delinquert and non-delinquent youth ('yes' response),

3. knowing it is not a profit making organization ('no' response),

4. knowing it allows the youth to remain in the community ('yes' response),

5. knowing it relies partially on volunteer services from the community ('yes' response),

6. knowing the age range served is not 18-21 ('no' response),

7. knowing there is a treatment emphasis as opposed to a punishment emphasis ('yes' response),

8. knowing it does not isolate the youth from his peers ('no' response), and 
9. knowing it is not controlled by a government agency •

These questions were used to measure the effectiveness of the various facets of the Home's publicity program.

The issue of the need for the Attention Home in The Dalles is covered by questions 6 and 9 . Question 6 deals with whether or not there is a real need for the home in The Dalles. Question 9 asks if the respondent knows what facilities are presently available in The Dalles for youth in need of temporary shelter care. Question 9 helps determine whether the response to question 6 was an informed response.

The potential for community involvement is explored in questions 7 and 8 . Question ? deals directly with the issue of willingness to support the home. Those willing to support the home are asked to specify how. Question 8 deals with how willing the respondent would be to have the home in his immediate neighborhood. The home was identified but not occupied at the time this survey was conducted. The board of directors was concerned with the possibility of resistance to the home in the immediate neightorhood.

The remaining question, question 10 , was not included for statistical evaluation, but to give the respondent an opportunity to give any suggestions he may feel would be helpful.

Administration of the Questionnaire 
The questionnaire was administered in three ways. It was administered to (1) the total group at once, (2) part of population in group, part individually, and (3) the total population individually. The instructions and explanations about the survey were basically the same for all methods of administration. The Kiwanis Club, the Carpenters' Union, the Interagency Council, and the Hot Iine Youth Group were each surveyed as a group. Ne attended a regular meeting of each of these groups and administered the questionnaire at that time. After a brief introduction and explanation of the survey the questionnaire was distributed to the members. The questions were read aloud, with time allotted for answering each question. If the respondents had not heard of the Attention Home they were encouraged not to guess at the questions related specifically to the home. They were, however, encouraged to respond to the opinion questions not specifically related to the home.

The survey of the police population was conducted on a group and individual basis. An effort was made to survey ali three shifts of both departments. Because the police are scattered throughout the area, it was felt the best time to contact them was during the shift changes. It should be noted that one entire shift of the city police department did not complete the questionnaire. The sergeant in charge would not distribute the questionnaire unless directed to do so by the chief of police. While we had permission from the chief of police, the sergeant had not received direct communication 
from the chief.

The questionnaires were administered individually to the immediate neighborhood population. Basically the same procedure of administration was followed. The person was contacted, introductions made and a brief explanation was given. The surveyor read the questions aloud while the respondent answered. 


\section{ANALYSIS OF DATA}

\section{METHOD}

Frequency distributions were made for the demographic data and the structured responses to the knowledge and attitude questions. These results were translated into percentages. The percentages were illustrated graphically in the form of bar graphs (see appendix). Intragroup and intergroup comparisons were made for each general area of investigation. To aid in these comparisons the following quotients were developed: a support quotient and a knowledge quotient.

The support quotient reflects the group's attitude toward the philosophy and concept of the Attention Home. A support quotient of 1.00 would indicate that every person in the group had a positive attitude toward the philosophy and concept of the Home and responded to every question as the total support profile of the previous chapter states.

The knowledge quotient reflects the group's awareness and knowledge of the Home. A knowledge quotient of 1.00 would indicate that every member of the group had heard of the Home and was able to answer the questions about it correctly. A knowledgeable response is also defined in the previous chapter. 
The quotient is made of the number of responses compatible with the home, divided by the total number of responses in the area under consideration. A compatible response refers to a response which is supportive or knowledgeable.

Example: The support quotient for the Interagency Council is .81 . This was determined as follows:

Actual Number of Supportive Responses (121) divided by Number of persons in group (15) times Number of Questions in Category (10) equals Support Quotient (.806).

Number of persons surveyed $=15$

Number of questions involved with questions on philosophy and concept $=10$

Total possible supportive responses $=150$

Actual supportive responses $\quad=121$

121 divided by $150=.806$

No comparable quotient was employed for the area's "need for home" and "potential for involvement" discussed below because the questions dealt with under these headings need to be considered individually. Each question deals with a separate and distinct issue.

\section{PHILOSOFHY AND CONCEPT}

The following questions are analyzed in Table 1.

1. Do you feel there should be alternative methods for handling the following youths other than placing them in jail or detention facilities?

a. Youthful offenders

b. Adolescents removed from their home because of family conflict

c. Dependent or neglected youths 
2. Please indicate whether you agree or disagree with the

following statements, and why.

a. Community volunteers should be involved in the handling of adolescents in need of temporary shelter care (as opposed to only paid officials).

b. Generally speaking, delinquent youth should be isolated from non-delinquent youth.

c. Jail or detention facilities should be used for temporary shelter care facilities for dependent or neglected youth.

d. It is a poor plan to house youth who have broken the law and youth who are neglected by their parents, together in the same facility.

e. The major responsibility for providing facilities for the youth in the community who need temporary shelter care lies with the community rather than the state or federal government.

f. Funding for programs such as the Community Attention Home should be mainly from within the community rather than from outside the community.

5. Are you in favor of the Community Attention Home type of program?

Table 1: A. Percentage of Responses Supporting and

B. Percentage of Responses Opposing the Philosophy and Concept of the Attention Home

(Questions 1, 2 and 5)

\begin{tabular}{|c|c|c|c|c|}
\hline $\begin{array}{l}\text { Inter- } \\
\text { agency } \\
\text { Council }\end{array}$ & $\begin{array}{l}\text { Immediate } \\
\text { Neighbor- } \\
\text { hood }\end{array}$ & $\begin{array}{l}\text { Carpen- } \\
\text { ters } \\
\text { Union }\end{array}$ & $\begin{array}{l}\text { Kiwanis } \\
\text { Club }\end{array}$ & $\begin{array}{l}\text { Hot Line } \\
\text { Youth } \\
\text { Group }\end{array}$ \\
\hline
\end{tabular}

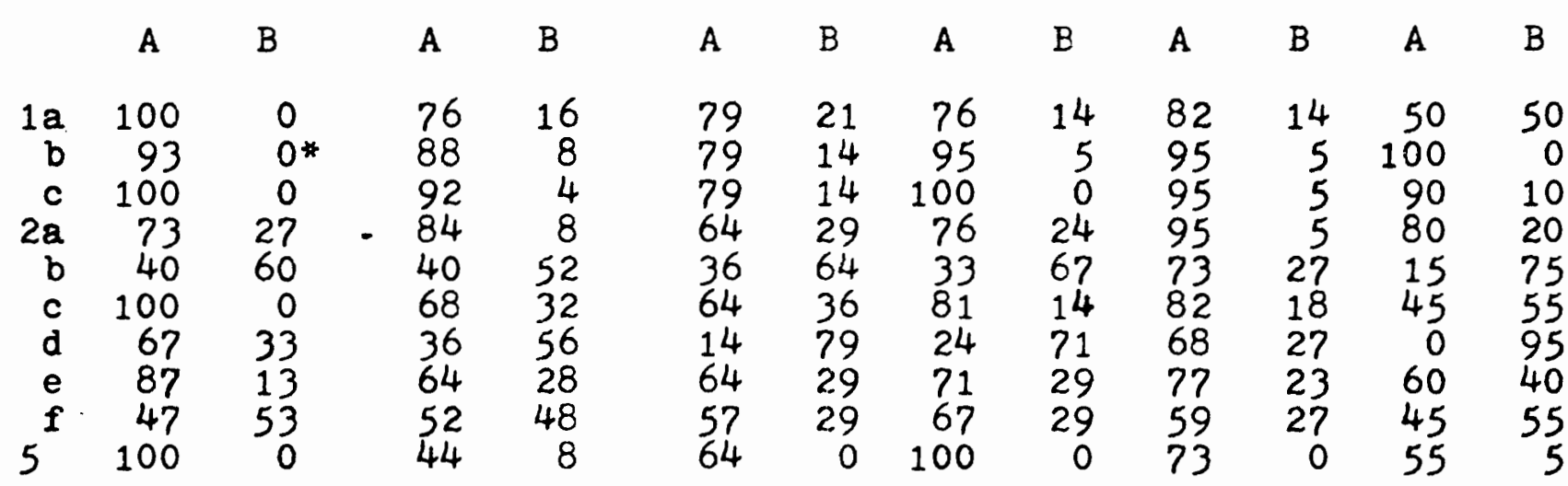

* Combined figures $A(93)$ and B (0) total less than $100 \%$ because some $(7 \%)$ did not answer question.

Interagency Council. The council was the group most supportive of the basic concept and philosophy of the home. This group had a support quotient of .81 . There were two areas of 
the home's philosophy which the majority of the council did not support. These were: (1) the isolation of delinquent youth from non-delinquent youth (40\%), and (2) the idea of local funding rather than outside funding for the program $(47 \%)$.

Immediate Neighborhood. From the response received this group seemed generally in favor or supportive of the concepts, with the exception of favoring isolation and opposing the housing of delinquent youth with non-delinquent youth $(40 \%$ and $36 \%$ respectively). The support quotient for the group was .64 .

Carpenters' Union. A support quotient of .59 indicates the Carpenters were generally in favor of the basic concepts behind the home. The exceptions to this were the questions concerning the integration and housing of delinquent and nondelinquent youth ( $36 \%$ and $14 \%$ respectively).

Kiwanis Club. With a support quotient of .69 , the Kiwanis Club shows good support of the philosophy. The exceptions are to the idea of integrating or housing delinquent and non-delinquent youth together (33\% and $24 \%$ respectively).

Hot Line Youth Group. The Hot Line Youth Group had the second highest support quotient which was .79. The lowest area of support was on the issue of funding the home from local sources $(59 \%)$. This was the only group that showed majority support for every relevant issue.

Police Department. This was the lowest group in supporting the concept and philosophy. There was lack of majority support for questions concerning integrating or housing delinquent 
and non-delinquent youth ( $15 \%$ and $0 \%$ respectively), the use of the jail as a temporary shelter care facility (45\%), and the idea of local funding for the program (45\%). The police were divided evenly on the idea of having some altemative method of treatment other than jail for youth who have broken the law $(50 \%)$. The support quotient was .54 .

All Groups. The groups were generally supportive of the philosophy and concept of the Attention fiome. The range of the support quotients ran from .54 to .81 . There were three exceptions to the general support. The majority of all the groups, except the Hot line youth group, felt that delinquent youth should be isolated from non-delinquent youth. The majority of the Hot Line group and the Interagency Council supported the idea of housing youth who have broken the law with youth who were neglected by their parents, whereas the other four groups did not. The majority of the Interagency Council and the police group did not support the concept of funding the program mainly from within the community.

\section{ANARENESS AND KNONLEDGE}

The following questions are analyzed in Table 2.

3. Have you heard of the Community Attention Home planned for the Dalles?

4. Which of the following items apply to the Community Attention Home? (check yes or no)

a. Serves delinquent and non-delinquent youth

b. Profit making organization

c. Allows youth to remain in the community (public schools, etc.) 
d. Relies partially on volunteer services from community

e. Age range served 18-21

f. Treatment as opposed to punishment emphasis

g. Isolates youth from his peers

h. Controlled by government agency

Table 2: A. Percentage of Responses that Indicate Knowledge and Awareness of the Community Attention Home, and

B. Percentage of Responses that Indicate Inaccurate Knowledge and Lack of Awareness. (Questions 3 and 4 )

\begin{tabular}{|c|c|c|c|c|}
\hline $\begin{array}{l}\text { Inter- } \\
\text { agency } \\
\text { Council }\end{array}$ & $\begin{array}{l}\text { Immediate } \\
\text { Neighbor- } \\
\text { hood }\end{array}$ & $\begin{array}{l}\text { Carpen- } \\
\text { ters } \\
\text { Union }\end{array}$ & $\begin{array}{l}\text { Kiwanis } \\
\text { Club }\end{array}$ & $\begin{array}{l}\text { Hot Iine } \\
\text { Youth } \\
\text { Group }\end{array}$ \\
\hline
\end{tabular}

$\begin{array}{rrrrrrrrrrrrr} & \text { A } & \text { B } & \text { A } & \text { B } & \text { A } & \text { B } & \text { A } & \text { B } & \text { A } & \text { B } & \text { A } & \text { B } \\ 3 & 100 & 0 & 44 & 45 & 50 & 43 & 81 & 19 & 59 & 41 & 75 & 25 \\ 4 \mathrm{a} & 93 & 0 * & 24 & 12 & 64 & 7 & 86 & 0 & 45 & 9 & 60 & 5 \\ \text { b } & 100 & 0 & 32 & 0 & 64 & 0 & 86 & 0 & 55 & 0 & 55 & 5 \\ \text { C } & 100 & 0 & 36 & 0 & 71 & 0 & 90 & 5 & 50 & 5 & 60 & 5 \\ \text { d } & 87 & 13 & 28 & 8 & 43 & 14 & 86 & 10 & 50 & 0 & 50 & 10 \\ \text { e } & 100 & 0 & 20 & 12 & 29 & 50 & 86 & 5 & 50 & 5 & 40 & 20 \\ \text { f } & 100 & 0 & 28 & 8 & 57 & 7 & 95 & 0 & 45 & 9 & 60 & 5 \\ \text { g } & 87 & 13 & 28 & 8 & 50 & 21 & 81 & 14 & 36 & 5 & 40 & 20 \\ \text { h } & 60 & 40 & 32 & 4 & 57 & 7 & 71 & 24 & 36 & 9 & 45 & 15\end{array}$

* Combined figures A (93) and B (0) total less than $100 \%$ because some $(7 \%)$ did not answer question.

Interagency Council. The group as a whole seemed quite aware of the program and their knowledge was accurate. They received by far the highest knowledge quotient of .92 . Of the media listed, the newspaper $(47 \%)$ was the most effective method of transmitting the information to the group. However, a majority of the group stated they heard of the home through some source other than was specifically listed on the questionnaire $(93 \%)$.

Immediate Neighborhood. In this group only 44 per cent heard of the home. The ones who responded to the knowledge questions seemed knowledgeable concerning the home. It 
appeared this group was more uninformed (i.e. they had not heard of the home) rather than misinformed. The knowledge quotient was .29.

Carpenters' Union. Fifty per cent of the group had heard of the home at the time of the interview. There were a considerable number of "no responses" to the knowledge questions. They had a knowledge quotient of .54 .

Kiwanis Club. The media most effective in communicating information to the Kiwanis Club were the newspapers (71\%) and the radio (43\%). The club had accurate knowledge of the home. Scores ranged from a low of 71 per cent to 95 per cent. With the exception of the one 71 per cent, the rest were above 80 per cent. The knowledge quotient was .74 . Hot Line Youth Group. None of the media listed was very effective in reaching the youth at the time of the survey. There were some knowledgeable responses; however, approximately 50 per cent did not respond. The knowledge quotient was .47 .

- Police Departments. The radio (45\%) and newspaper (45\%) were fairly effective in reaching this group. However, the responses to the knowledge questions by this group were not as accurate as one might expect. The knowledge quotient was .54 .

All Groups. The knowledge quotient ranged from .29 to 92. The immediate neighborhood had the lowest quotient while the Interagency Council had the highest. I'he general conclusion from examining the six groups is that of the 
groups who scoz=三 low in this area, it appeared they were more uninformec rather than misinformed. It was not that they were rece it, but that tiney were not receiving the information necessary. The mass Iraia was presenting clear information, however, the $i=s=$ mation had not been received by many of the people surt છed.

NEED FOR HOME

The following ${ }_{2}$ setions are analyzed in Table 3.

6. Do you feez zhere is a need for the Community Attention Home in The jalles?

9. Do you knciv virat facilities are presently available in The Dalles zar youth who are in need of temporary shelter caz”?

Table 3: A. Ėaentage of Persons who Feel There Is A

$Y=2$ for The Community Attention Home, and

B. Ėzentage of Fersons who Do Not (2estion 6)

A. Ezcentage of Persons who know what Facilities

$\therefore=$ Available for Youth who Need Temporary

Er Ilter Care, and

B. $Z=$ eentage of Fersons who Do Not iuestion 9)

Inter- Inmediate Carpen- Kiwanis Hot Line Police agency - NeighborCouncil nood ters' Club Union

$\begin{array}{llllllllllll}\text { A } & \text { B } & \text { A } & \text { B } & \text { A } & \text { B } & \text { A } & \text { B } & \text { A } & \text { B } & \text { A } & \text { B }\end{array}$

$\begin{array}{lllllllllllll}6 & 100 & 0 & 76 & 12 * & 64 & 21 & 71 & 29 & 68 & 0 & 60 & 10 \\ 9 & 100 & 0 & 24 & 72 & 21 & 71 & 19 & 81 & 41 & 45 & 60 & 35\end{array}$

- Combined figurzs A (76) and B (12) total less than 100\% because some $(12 \%)$ dic net answer questions.

Interagerc: zouncil. The entire group felt strongly

that there was seed for the home. The council was also 
aware of the existing facility for temporary shelter care. Immediate Neighborhood. This group (76\%) definitely felt there was a need for this kind of program in The Dalles. However, very few people (24\%) knew about the existing facility. Carpenters' Union. Although not many (21\%) knew of the home or were aware of existing facilities, they (64\%) felt there was a need in The Dalles for this type of program. Kiwanis Club. The Kiwanians (71\%) felt strongly that there was a need for the home in The Dalles. They (19\%) were not generally aware of what the existing facilities were.

Hot Line Youth Group. The majority of the group (68\%) felt strongly about the need for the home in The Dalles, but a large portion of the group (41\%) was not well informed of the existing facilities prior to the Attention Home.

Police Departments. The majority of this group (60\%) felt there was a need for the home. A majority (60\%) of the group knew of the existing facility for temporary shelter care.

All Groups. There was strong conviction in all the groups that there was a need for the home. However, only the Interagency Council was well informed of the existing facilities. The entire Interagency Council knew of existing facilities, whereas the police group was second with only sixty per cent. Need and knowledge percentages were congruent only in these two groups.

\section{POTENTIAL FOR INVULVEMENT}

The following questions are analyzed in Table 4. 
Table 4: A. Percentage of Persons who Would Support the Community Attention Home, and

B. Percentage of Persons who Would Not (Question 7)

A. Percentage of Persons who Favor Placing the Community Attention Home In Their Immediate Neighborhood, and

B. Percentage of Fersons who Oppose Placing It In Their Neighborhood (Question 8)

Inter- . Immediate Carpen- Kiwanis Hot Iine Folice agency NeighborCouncil hood ters' Union
Youth

Group

$\begin{array}{llllllllllll}\text { A } & \text { B } & \text { A } & \text { B } & \text { A } & \text { B } & \text { A } & \text { B } & \text { A } & \text { B } & \text { A } & \text { B }\end{array}$

$\begin{array}{rrrrlrrrrrrrr}? & 100 & 0 & 64 & 24 * & 57 & 21 & 86 & 0 & 73 & 0 & 55 & 10 \\ 8 & 60 & 7 & 64 & 16 & 43 & 14 & 19 & 38 & 64 & 0 & 40 & 15\end{array}$

*Combined figures A (64) and B (24) total less than $100 \%$ because some (12\%) did not answer the questions.

Interagency Council. The Interagency Council was quite willing to support the home. The majority irdicated support in all ways except through extra taxes (33\%).

Immediate Neighborhood. The majority of the group said they would support the home and would not mind having it located in their own neighborhood. However, only one person said he would support the home through cash donations.

Carpenters Union. The majority of the group said they would support the program. Support through extra taxes was not a favored method. Only 7 per cent (or one person) said they would support the home in this manner. Nost of the group were either undecided or opposed to having the home in their own neighborhood.

Kiwanis Club. The group was willing to support the home. The most favored means of support was through extra taxes, 
and with goods and services. Almost half (43\%) of the Kiwanians were undecided about having the home in their own neighborhood. Thirty-eight per cent were opposed to the idea. Only nineteen per cent were in favor of it.

Hot Line Youth Group. This group was willing to support the home mainly through volunteering their time. Sixty-eight per cent said they would donate time.

Police Departments. About fifty-five per cent of the group said they were willing to support the home in some way. The donation of time was the most popular way (35\%) to support the home. Sixty-five per cent were willing to have the home in their immediate neighborhood.

All Groups. In the area of potential involvement with the home all the groups indicated they were willing to become involved. However, there was considerable variation in the types of involvement preferred by the different groups. Generally the idea of supporting the home by extra taxes was not looked upon favorably. Oniy the Kiwanis Club showed a slight majority $(52 \%)$ in favor of tinis type of support. When considering having the home located in their immediate neighborhood three of the groups showed a majority in favor of the idea. The three groups were the Interagency Council $(60 \%)$, the immediate neighborhood $(64 \%)$, and the Hot Line Youth Group (64\%). Of the remaining groups a substantial number of respondents were undecided. Recorded opposition was limited. The Kiwanis Club showed the most with thirty-eight per cent opposing the home in their neighborhood. 


\section{DISCUSSION}

Police Attitude Toward Youthful Offenders

The police' response to the question, "Do you feel there should be alternative methods for handing the following youth other than placing them in jail or detention facility? Youthful offenders," stands out in relation to the other groups surveyed. Fifty per cent of the police were opposed to finding alternative methods. In the other five groups the opposition was under twenty-one per cent. In fact, in the Interagency Council there was no opposition recorded. It would seem, in contrast to the other groups, that a large proportion of the police feel that jail or detention is an appropriate way of handling youthrul offenders. This opposition by the police appeared to be confined specifically to youthful offenders. They were overwhelmingly in favor of alternative methods for the other two categories of adolescents (dependent or neglected adolescents and adolescents removed from home because of family conflict) listed. Since the Community Attention Home incorporates youthful offenders in their treatment program, one would wonder if their attitude toward the youthful offender might adversely influence their attitude toward the home. Another indication that this may be a problem area is evidenced by the fact that not one of the members of the police group disagreed with the statement, "It is a poor plan to house youth who have broken the law and youth who are neglected by their parents together 
in the same facility."

Hot Line Youth Group Attitudes Toward Delinquents

Over seventy per cent of the Hot Line Youth Group disagreed with the statement, "Generally speaking delinquent youth should be isolated from non-delinquent youth." In all other groups the majority agreed with the statement. In other words, the Hot line group was the only group supportive of the Attention Home's philosophy of integrating delinquent and non-delinquent youth in their treatment program. Apparently the Hot Line youth don't see the delinquent as having an adverse influence upon the non-delinquent, or perhaps they don't see these as two distinct groups. This would be congruent with the fact that this group was organized to help youth with a variety of problems. Their disagreement $(68 \%)$ with the statement, "It is a poor plan to house youth who have broken the law and youth who are neglected by their parents together in the same facility", tends to confirm this assumption.

Effectiveness of Publicity

Over forty-three per cent of each group had heard of the home at the time of the survey. The television publicity campaign had not begun at the time so the potential for this media is unknown. The radio was effective in reaching at least one member of each group, but in no group did it reach fifty per cent. The newspaper reached over thirty-five per cent of each group except the Hot Line Youth Group. At the 
time of the survey there had been several articles, including two pictures on the front page, of the local newspaper. The best informed group was the Interagency Council. The most effective means of communicating this information to this group was through the "grapevine". When one considers the fact that the survey was conducted during the initial phase of the publicity campaign, it appears that the campaign was relatively successful in reaching these groups.

\section{Questions Arising from Research}

1. There are many more people who feel there is a need for the Attention Home than there are who know what the existing facilities are. This raises the question of why they feel there is a need for the home. One possible explanation is that this may be seen as a more socially acceptable response. Another possibility may be that it was for many people simply a positive emotional response to an idea that sounded good to them.

2. The majority of the police group agreed with the statement, "Jail or detention facilities should be used for temporary shelter care facilities for dependent or neglected youth." They were the only group with a majority responding in this way. This appears to be ircongruent with their earlier overwhelming support of finding alternative methods for handing dependent or neglected youth other than placing them in jail or detention facilities. One possible explanation is that the police see this as an alternative when nothing else is available: 


\section{CONCLUSION}

The investigation of attitudes of selected groups in the community of The Dalles toward the Community Attention Home has led the researchers to the following conclusions and recommendations.

1. Generally there was support from all the groups for the philosophy and concepts of the Community Attention Home. One exception to this general support was in the area of mixing delinquent and non-delinquent youth. The home may experience some resistance in this area from the community, or at least to the idea as presented in these terms (i.e. delinquent and non-delinquent). Therefore, the researchers recommend that the similarities of the youth served be emphasized as opposed to their differences.

2. The respondents who had heard of the home had accurate knowledge; however, a substantial portion of each group, except the Interagency Council, had not heard of the home. The publicity campaign seems to be presenting clear information to the public and is penetrating each group. However, at the time of the survey it had not reached a substantial portion of each group. It should be noted that the survey was conducted during the initial phase of the publicity campaign. It is felt that this type of publicity is effective and should be continued and expanded upon with 
the existing media and in addition the local television ne twork.

3. The findings show a large segment of the police population who felt that there should be no alternative method of handling youth who have broken the law other than jail or detention. Since the cooperation of this group is critical to the operation and success of the home, we recommend that the board of directors develop a public relations program to eliminate any potential barriers.

4. The surveyed populations see the major responsibility for providing temporary shelter care facilities for the youth as resting with the community rather than the state or federal governments. However, when it comes to the issue of who should provide the majority of the funding for this type of program the results are less conclusive. This presents a potential problem when one assumes that outside funding will diminish in the near future. We recommend that a plan be initiated to clarify the community's future responsibility for funding. Otherwise the board may find when the outside sources of funding are diminished or eliminated, the community may not be prepared or willing to provide the majority or total funding for the home.

5. A majority of each group said they would support the home in some concrete way. The groups varied in the manner of support preferred. Therefore, it appears the home can expect good support from the community through volunteer activities, donations of money, goods, or services, etc.. 
Community involvement is at the heart of the Attention Home program. Therefore, we recommend that this kind of support from individuals and groups be cultivated to insure its continuance. It is felt that with increased community involvement there is less likelyhood of community rejection due to unexpected negative events or situations which may develop. In addition, institutions tend to become isolated from their community over time. The Community Attention Home cannot necessarily expect support to continue without some programmed method to foster it. 
Bibliography

Allen, Donald E., and Harjit S. Sandhee, "A Comparative Study of Delinquents and Non-delinquents, Family Affect, Religion, and Personal Income," Social Forces, 46, (February, 1967), 263-9.

Babst, Dean V., and John W. Mannering, "Probation Versus Imprisonment for Similar Types of Offenders--A Comparison by Subsequent Violation," Journal of Research in Crime and Delinquency, 2 (July, 1965), 60-72.

Beggs, The Reverend Larry, Huckleberry's for Runaways, New York, Ballantine Books, Inc., c. 1969.

Brenner, Joseph H., M.D., Robert Coles, M.D. and Dermot Meager, Drugs and Youth, New York, Liveright Publishing Corporation, c. 1970.

Clinard, Marshall B., Sociology of Deviant Behavior, third edition, New York, Holt, Rinehard and Winston, Inc., c. 1968 .

Cloward, Richard A., and Lloyd E. Ohlin, Delinguency and Opportunity, Glencoe, Ill., Free Press, 1960.

Cohen, Sidney, The Drug Dilemma, New York, McGraw-Hill Book Company, c.1969.

Dunham, H. Warren, "The Juvenile Court: Contradictory Orientations in Processing Offenders," Juvenile Delinquency, edited by Rose Giellombardo, New York, John Wesley and Sons, Inc., 337-55.

Eldefonso, Edward, Law Enforcement and the Youthful Offender: Juvenile Procedures, New York, John Wiley and sons, Inc., 1967.

Elliott, Mabel A., "Trends in Theories Regarding Juvenile Delinquency and Their Implications for Treatment Programs," Federal Probation, XXXI (September, 1967), 3-111.

England, Ralph W., Jr., Criminology, fourth edition, New York, The MacMillan Company, c. 1964.

Finkelstein, Harry, "The Use of Court Commitment in the Residential Treatment of Disturbed Children," Social Casework, XLV (December, 1965), 603-10. 
Garrett, James E., M.S.W., and Peter O. Rompler, M.A., Community Resocialization, A New Perspective, Washington, D.C., The Catholic University of America Press, Inc.. c. 1966.

Gilpin, Ruth, "Foster Home Care for Delinquent Children," The Problem of Delinquency, edited by Sheldon Glueck, Boston, Houghton-Mifflin Company, 1959.

Hoffman, Lois Wladis and Martin L. Hoffman, Review of Child Development Research, Volume One, New York, Russell Sage Foundation, 1964.

Kahn, Alfred J., Planning Community Services for Children in Trouble, New York, Columbia University Press, c. 1963.

- Studies in Social Policy and Planning, New York, Russell Sage Foundation, 1969

Norman, Sherwood, Detention Practice, Significant Developments In The Detention of Children and Youth, New York, National Probation and Parole Association, c. I960.

Passingham, R. E., "A Study of Delinquents with Children's Home Background," British Journal of Criminology, 8 (January, 1968), 32-45.

Phillips, Harold M., Child Welfare Needs and Services in Oregon, Report to The Governor's Child Welfare Study Committee, New York, Greenleigh Associates, Inc., (December, 1968).

Rinck, Jane E., "Supervision of The Juvenile Delinquent," The Problem of Delinquency, edited by Sheldon Glueck, Boston, Houghton-Mifflin Co., 1959.

Smith, David E., The New Social Drug, Cultural, Medical, and Legal Perspectives on Marijuana, Englewood Cliffs, N.J., Prentice-Hall, Inc., c. 1970.

Spray, Charles, M.D., Doctor Outlandish: Drug Scene \pm Sundry Subjects, Beaverton, Oregon, An Outside-In Publication in Cooperation with Criterion, Inc., Publishers, c. 3.970.

Stricker, George, Ph.D., Kicking It, New York, Pyramid Books, c. 1.971 .

United Nations, The Young Adult Offender, A Review of Current Practices and programmes in Prevention and Treatment, New York, 1965. 
United States Department of Health, Education and Welfare, Social and Rehabilitation Services, Office of Juvenile Delinquency and Youth Development, Volunteer Programs In Courts, Washington, D.C., U.S. Government Printing Office, I969.

United States Department of Justice, Bureau of Prisons, Re-Educating Confined Delirquents, El Reno, Oklahoma, Federal Prisons Industries, July, 1965.

United States Task Force Report: Corrections, Washington, D.C., The President's Commission on Law Enforcement and Administration of Justice, U.S. Government Printing Office, 1967.

- Juvenile Delinquency and Youth Crime, Report on Juvenile Justice and ConsuItants' Papers, The President's Commission on Law Enforcement and Administration of Justice, Washington, D.C., U.S. Government Printing Office, 1967.

- Narcotics and Drug Abuse, Annotations and Consultants: Papers, The President's Commission on Law Enforcement and Administration of Justice, Washington, U.S. Government Printing Office, 1967.

Vaz, Edmund W., Middle-Class Juvenile Delinquency, New York, Harper \& Row Publishers, c. 1.967.

Williams, Herbert D., "Foster Homes for Juverile Delinquents," The Problem of Delinquency, edited by Sheldon Glueck, Boston, Houghton-Mifflin Co., 1959.

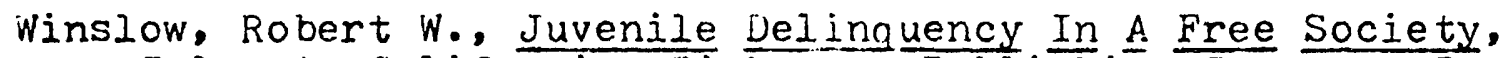
Belmont, California, Dickenson Publishing Company, Inc., - c. 1968 .

Witherspoon, Arthur W., "Foster Home Placements for Juvenile Delinquents," Federal Probation, XXX (December, 1966), $128-53$. 
APPENDICES 
APPENDIX A

FINANCIAL STATEMENTS FOR ATTENTION, INC. FIRST YEAR OF OPERATION (1967)

Balance Sheet

Assets

Cash

Furniture and equipment.

furniture and equipment..............1,641.50

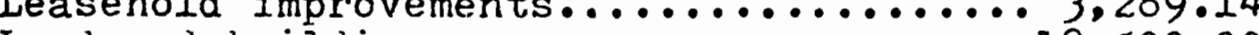

Land and building........................500.00

$23,403.64$

Less: Accumulated depreciation........1,296.73

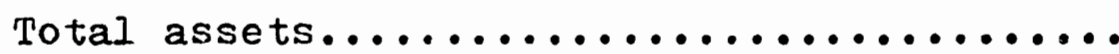

$\$ 3,334.57$

$22,106.91$

$25,441.48$

\section{Iiabilities and Equity}

Payroll taxes withhel...............\$114.06 Mortgage payable (home No. 2)...........11,128.56

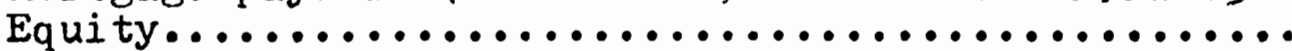

Total liabilities and equity............ $\$ 11,242.62$ $14,198.86$

25.441 .48

Statement of Receipts, Expenses, and Equity

(for the 12 months ended Sept. 30, 1967)

Receipts:

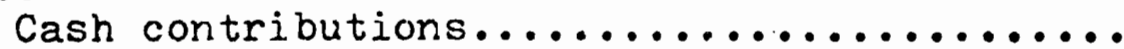

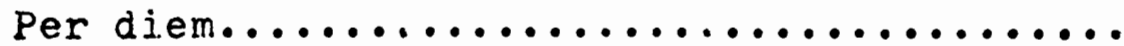

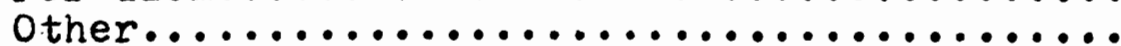

Total cash receipts.................

$\$ 9,872.71$

$2,277.00$

79.28

$12,228.99$

Expenses :

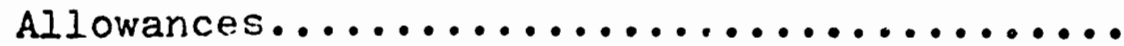

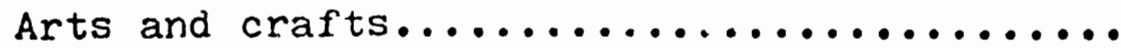

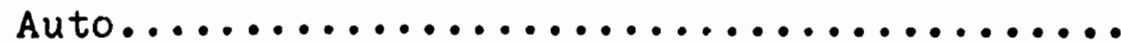

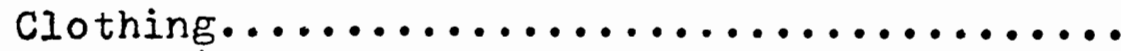

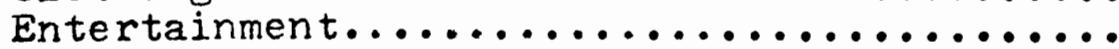

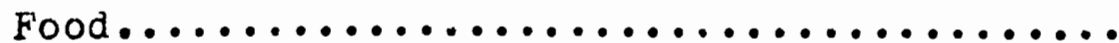

Insurance.

$\$ 73.00$

25.02

311.17

34.34

364.22

$1,957.99$

67.00 
Laundry............................ Medical.............................

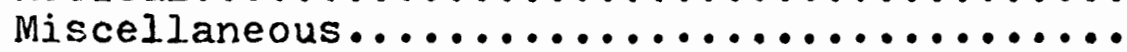
Office............................

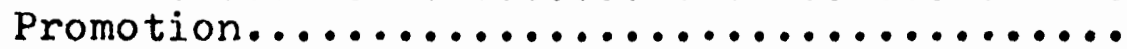

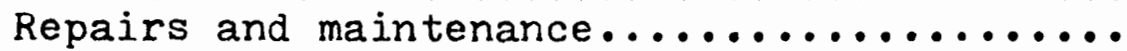

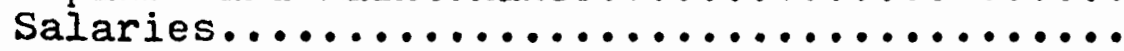

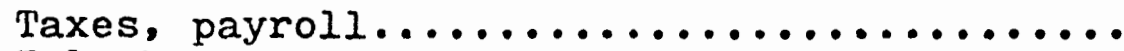

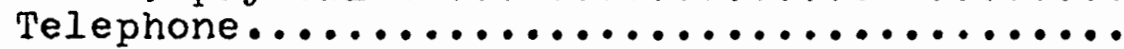
Utilities..........................

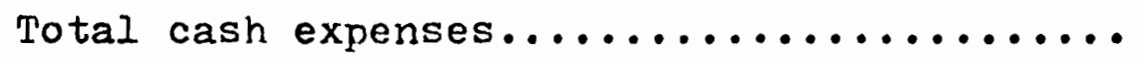

19.89

17.65

178.24

34.95

10.00

209.29

$3,339.66$

114.59

374.53

179.14

$7,310.68$ 


\section{APPENDIX B}

BASIC FLOW, SOURCE, AND PLACEMENT STATISTICS

FOR FIRST YEAR OF OPERATION, ATTENTION HOME NO. 1

Total children passing through the home during the year: 65 . From - City of Boulder, 34; outside city of Boulder, 31. Type of Case - Delinquent, 29; dependent, 11; child in need of supervision, 11; other 14.

Age in years (Number of children in parentheses) - 12 (3), $13(6), 14(6), 15(9), 16(18), 17(21), 18(2)$.

Sex - Girls, 40; boys, 25 .

Average Length of Stay - 23 days.

Total child-days: 1,518 at average cost of $\$ 5.67$ per child-day.

\section{Summary of placement, after home}

Returned home-1...- 30 Referred back to court-...- 3 Placed in foster home-.-- 15 Niental institution-.......- 1 Placed in group home-..- 7 Job Corps-_. Placed in private school- $2 \mathrm{still}$ in home-... 6 
APPENDTX C

ATTENTION HONE RULES AND DUTIES FOR CHILDREN

Since each child that is placed in the Attention Home has a different problem, each operates at the home under somewhat different rules. Some are allowed many privileges, while others may not be allowed out of the house without supervision. All the children, however, are expected to:

1. Obey the houseparents at all times.

2. Take showers or baths at least every other night.

3. Make beds and clean room every day as well as helping with meals, dishes, general cleanup, etc., as assigned.

4. Reach and return from work or school without delay unless special permission is granted.

5. Take the responsibility of making sure that one of the houseparents knows his or her whereabouts at all times.

6. Show respect for the other children in the home.

7. Fix breakfast and lunch for self and handle all washing and ironing if possible. Breakfast is at $7: 30 \mathrm{a} \cdot \mathrm{m} . ;$ I unch, noon; dinner, $6 \mathrm{p.m}$. Meals are served family style and a blessing is said before each meal.

8. Smoking: Smoking will be permitted as directed by the houseparents. Jt is illegal for a minor under 16 years of age to smoke without parents' consent.

9. All personal property is kept in such places as designated by the houseparents. A child may not borrow any items from other occupants unless prior approval is granted by the houseparents. 
MINIMUM REQUIREMENTS FOR CHILDREN

A Message From the Hous'eparents

To Volunteers Working in The Home

\section{Food Preparation}

The children are expected to $f i x$ their own breakfast and lunch and help with the preparation of supper. Our food bill usually averages $\$ 30$ per week. This figure is low because we receive all dairy products as donations and we receive damaged canned goods from a local grocery store.

\section{House cleaning}

The housecleaning duties are equally divided, with the majority of the work being done by those children who are not working or attending school. All children, however, do share in the work. My wife and I have found that the children enjoy the work if we pitch in and do our share along with them.

3. Home Repairs and Maintenance

The members of our board of directors volunteer their time to repair and maintain the home.

4. Church Requirements

We have no church requirements here at the home. Any child who desires to attend church may do so, but no real pressure is put on the children to attend.

5. Daily Requirements

Here again daily requirements are impossible to outline. 
Some of the children work, some go to school and some must stay around the home and work, engage in recreational activities, etc. An attempt is made to keep the children busy, but often it is impossible to do so.

\section{Guests: Visiting}

It has always been a policy of ours to encourage as many guests as possible to visit our home. Interested members of the community are encouraged to come by at any time of the day or night to talk to us and the children. They often do. The children may have guests over when arrangements can be made. Their friends may stay for an hour and must stay on the main floor. The guest situation must be handled properly in order to avoid the "zoo" effect. Visiting hours for parents are Wednesday, 4 to $6 \mathrm{p} . \mathrm{m}$. If special arrangements are needed, permission must be granted by the houseparents. No telephone calls will be allowed unless permission is given by the houseparents.

\section{Penalties ard Rewards}

Perhaps one of the most unique things about our program is the fact that placement at the Attention Home is a privilege. The children who come to stay with us are always informed that they are being placed here instead of juvenile quarters (jail). The ultimate in punishment then is referral to juvenile quarters. Punishments of a less serious nature include assignment to a week of dishes, witharawal of television privileges, 
etc. When a child comes to the home, he is granted privileges which the Juvenile Department feels he is capable of handing. The child's privileges are increased and decreased from then on, according to behavior. 


\section{APPENDIX D}




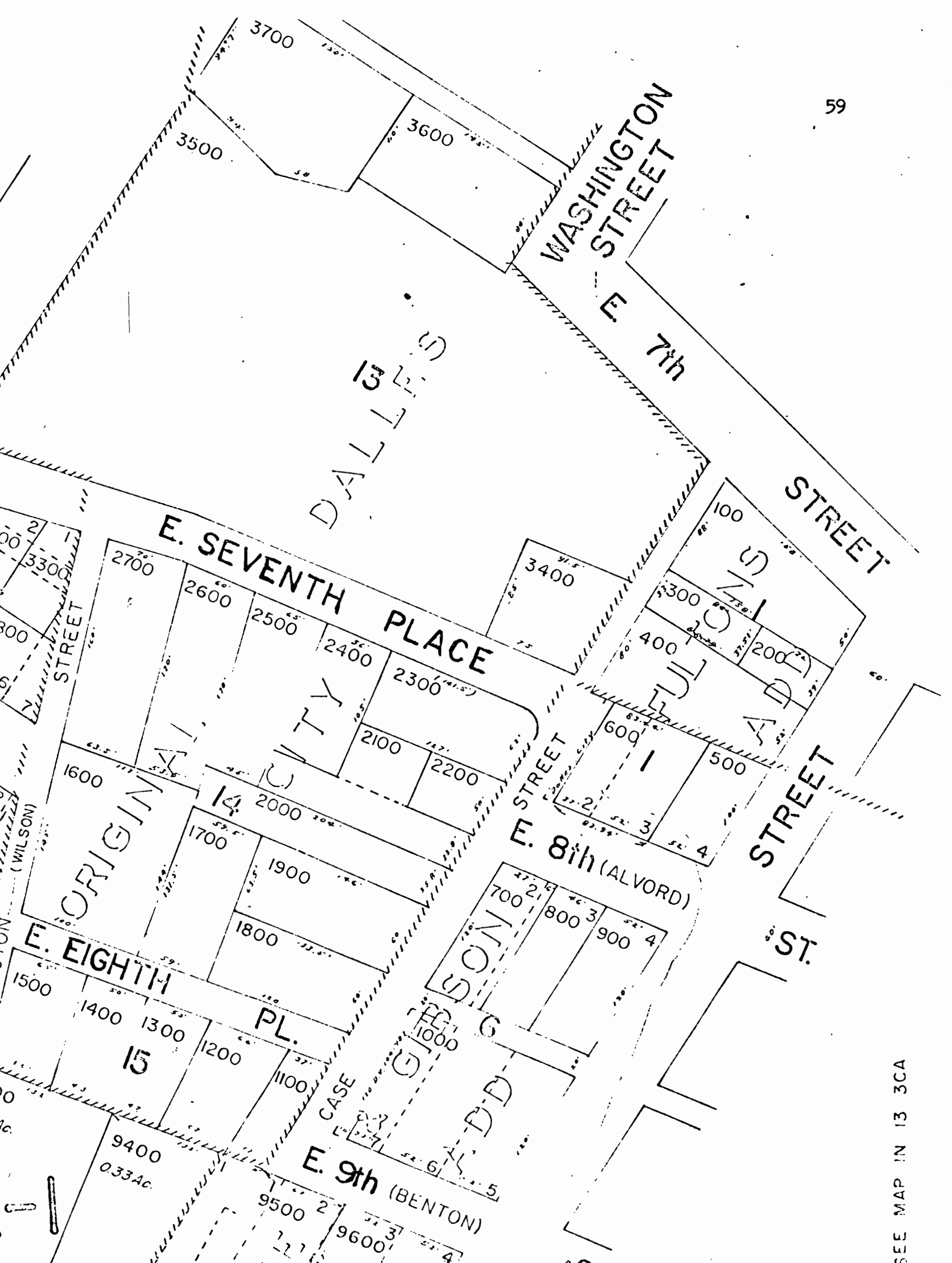


APPENDIX E 


\section{QUESTION}

Age category

Number of respondents according to age category.

RESULTS

$$
\begin{aligned}
& 1 \text { Interagency Council }
\end{aligned}
$$

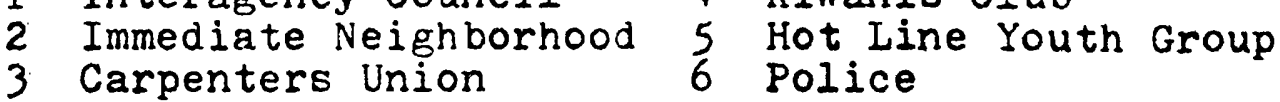

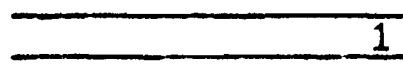

Age $11-20$

0

2

4

5

2

0

2

15

25

22

21

1

5

4

0

9

4

0

5

6

0

1

11

3

6

0

0

0

Total

15

14

21

0

0

1

Percentage of responses according to age category.

\begin{tabular}{lrrrrrr}
\hline & 1 & 2 & 3 & 4 & 5 & 6 \\
Age $11-20$ & 0 & 8 & 7 & 0 & 95 & 0 \\
Age $21-30$ & 13 & 36 & 7 & 5 & 5 & 25 \\
Age $31-40$ & 28 & 4 & 0 & 19 & 0 & 45 \\
Age $41-50$ & 33 & 4 & 44 & 19 & 0 & 25 \\
Age $51-60$ & 13 & 4 & 21 & 28 & 0 & 5 \\
Age $61-$ up & 0 & 44 & 21 & 29 & 0 & 0 \\
No response & 13 & 0 & 0 & 0 & 0 & 0 \\
Total & $100 \%$ & $100 \%$ & $100 \%$ & $100 \%$ & $100 \%$ & $100 \%$
\end{tabular}


QUESTION

$\operatorname{sex}$

Number of respondents according to sex category.

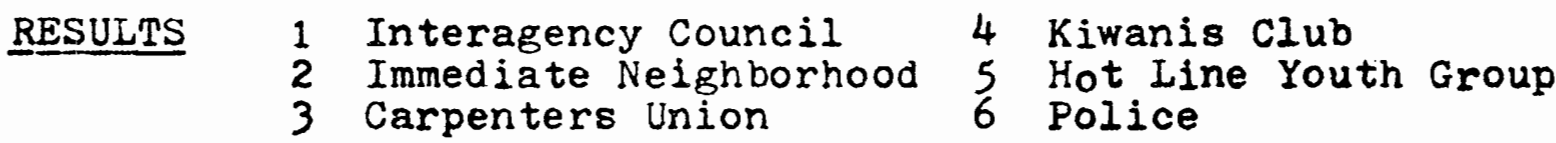

$-\frac{1}{2}$

1 Male 3

$6 \quad 14$

3

4

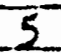

8

11

3

8

Total

15

25

14

21

22

20

Percentage of Responses according to sex.

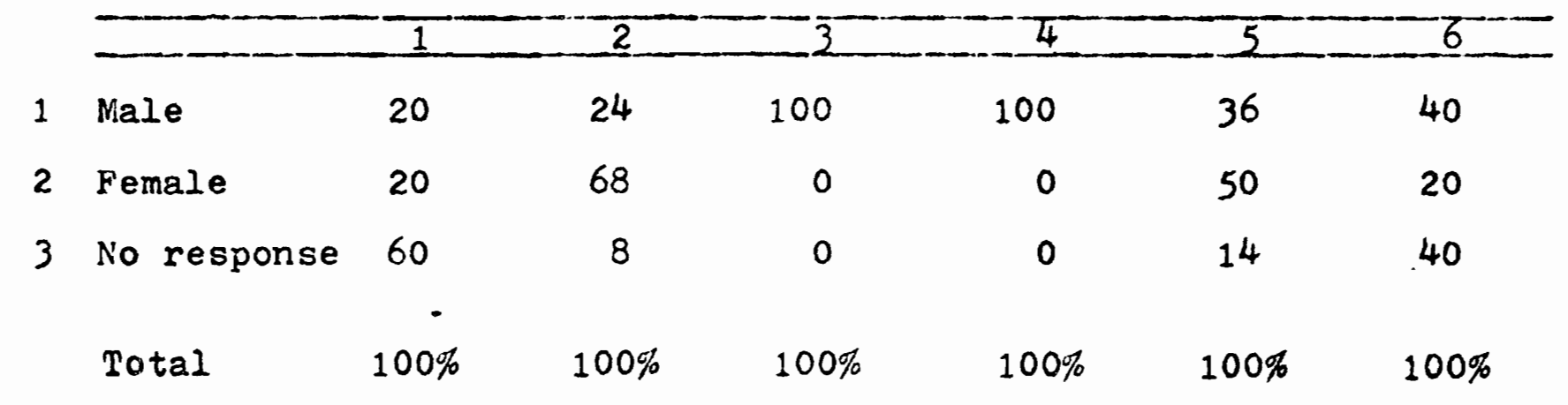




\section{QUESTION}

Marital status

Number of respondents according to marital status.

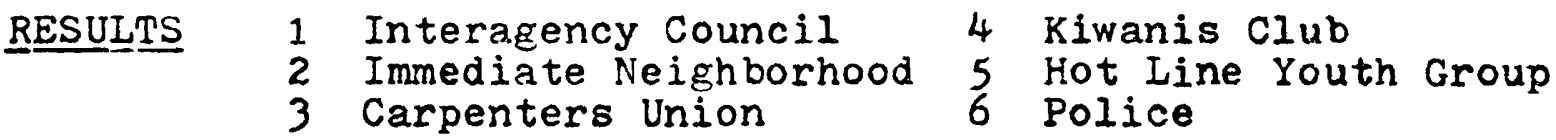

$\begin{array}{lllllll} & 1 & 2 & 3 & 4 & 5 & 6 \\ \text { Single } & 2 & 9 & 0 & 1 & 18 & 0\end{array}$

2 Married

10

12

18

15

3 Divorced

1

2

1

0

0

2

4 Widowed

1

3

1

0

0

0

5 Separated

2

0

0

0

1

6 No response 2

1 . 0

2

3

2

Total

15

$25 \quad 14$

21

22

20

Percentage of responses according to marital status.

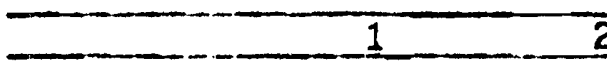

1 Single

2 Married

3 Divorced

4 Widowed

5 Separated

6 No response

Total
13

47

7

7

13

13

$100 \%$
36

40

8

12

0

4

$100 \%$

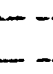

0

86

7

7

0

0

$100 \%$

$-4$

5

85

0

0

0

10

14

10

81

5

0

0

0

5 
QUESTION

Number of respondents with children under 13.

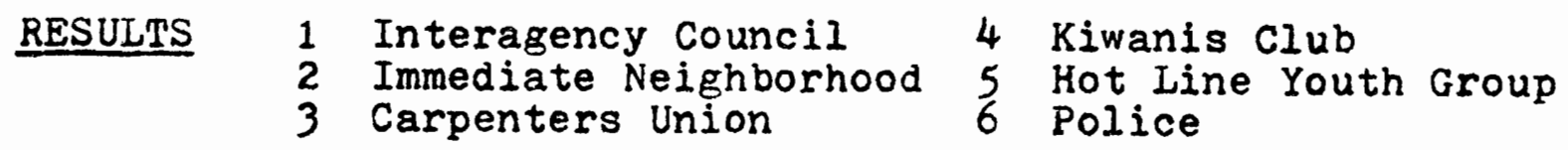

\begin{tabular}{lrrrrrrr}
\hline & 1 & 2 & 3 & 4 & 5 & 6 \\
\hline 1 & Yes & 5 & 7 & 2 & 6 & 1 & 14 \\
2 & No & 8 & 10 & 10 & 14 & 21 & 6 \\
3 & No response & 2 & 8 & 2 & 1 & 0 & 0 \\
& Total & 15 & 25 & 14 & 21 & 22 & 20
\end{tabular}

Percentage of respondents with children under 13.

\begin{tabular}{|c|c|c|c|c|c|c|}
\hline & 1 & 2 & 3 & 4 & 5 & 6 \\
\hline Yes & 33 & 28 & 14 & 29 & 5 & 70 \\
\hline No & 54 & 40 & 72 & 66 & 95 & 30 \\
\hline No response & 13 & 32 & 14 & 5 & 0 & 0 \\
\hline Total & $100 \%$ & $100 \%$ & $100 \%$ & $100 \%$ & $100 \%$ & $100 \%$ \\
\hline
\end{tabular}




\section{QUESTION}

Number of respondents with children between 13 and 21 years of age.

RESULTS

1 Interagency Council

2 Immediate Neighborhood

3 Carpenters Union
4 Kiwanis Club

5 Hot Line Youth Group Police

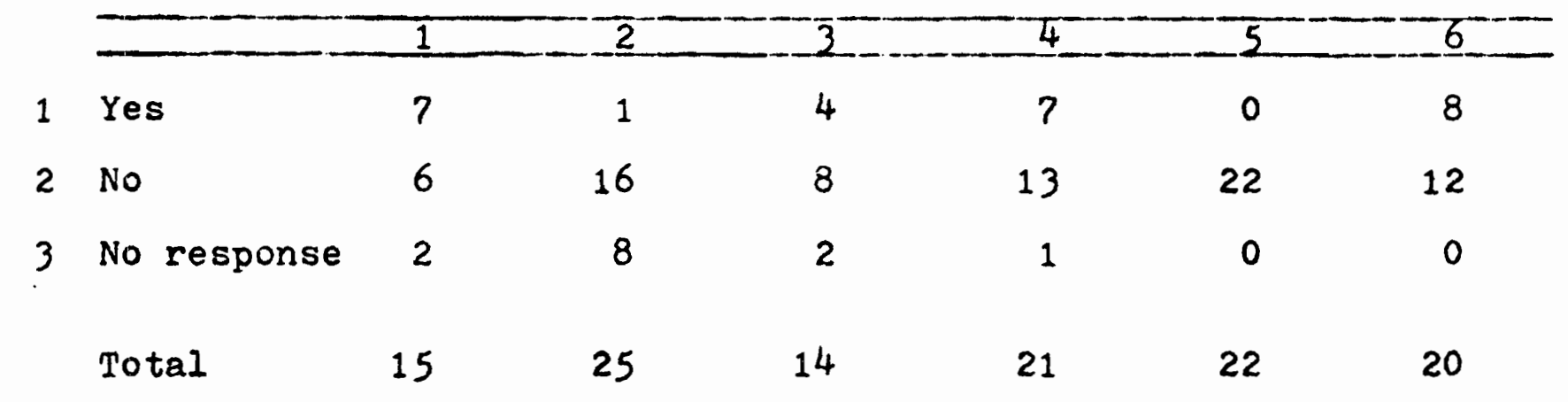

Percentage of respondents with children between 13 and 21 years of age.

\begin{tabular}{llcccccc}
\hline & 1 & 2 & & 2 & 4 & 5 & 6 \\
\hline 1 & Yes & 47 & 4 & 29 & 33 & 0 & 40 \\
2 & No & 40 & 64 & 57 & 62 & 100 & 60 \\
3 & No response & 13 & 32 & 14 & 5 & 0 & 0 \\
Total & $100 \%$ & $100 \%$ & $100 \%$ & $100 \%$ & $100 \%$ & $100 \%$
\end{tabular}


QUESTION

Number of respondents with children over 21 years of age. RESULTS 1 Interagency Council 4 Kiwanis Club 2 Immediate Neighborhood 5 Hot Line Youth Group 3 Carpenters Union 6 Police

\begin{tabular}{lrrrrrr}
\hline & 1 & 2 & 3 & 4 & 5 & 6 \\
\hline Yes & 2 & 6 & 7 & 12 & 0 & 5 \\
No & 11 & 11 & 5 & 8 & 22 & 15 \\
No response & 2 & 8 & 2 & 1 & 0 & 0 \\
Total & 15 & 25 & 14 & 21 & 22 & 20
\end{tabular}

Percentage of respondents with children over 21 years of age.

\begin{tabular}{llllllll}
\hline & & 1 & 2 & 3 & 4 & 5 & 6 \\
\hline Yes & 13 & 24 & 50 & 57 & 0 & 25 \\
3 & No & 74 & 44 & 36 & 38 & 100 & 75 \\
No response & 13 & 32 & 14 & 5 & 0 & 0 \\
Total & $100 \%$ & $100 \%$ & $100 \%$ & $100 \%$ & $100 \%$ & $100 \%$
\end{tabular}




\section{APPENDIX F}


QUESTRION

Do you feel there should be alternative methods for handing the following youths other than placing them in jail or detention facilities? A. Youthful offenders

RESULTS

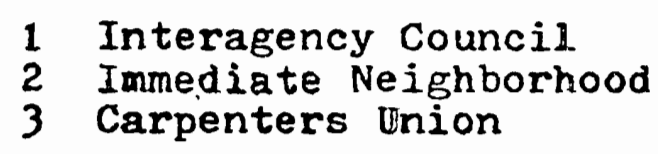

4 Kiwanis Club

5 Hot Line Youth Group 6 Police

\begin{tabular}{|c|c|c|c|c|c|c|c|}
\hline & & 1 & $1-2$ & 3 & 4 & 5 & 6 \\
\hline * & Yes & . 15 & 19 & 11 & 16 & 18 & 10 \\
\hline 6 & No & & 4 & 3 & 3 & 3 & 10 \\
\hline 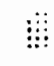 & No response & & 2 & 0 & 2 & 1. & 0 \\
\hline & Total & 15 & 25 & 14 & 21 & 22 & 20 \\
\hline
\end{tabular}

GRAPHIC ILLUSTRATION (number code above)

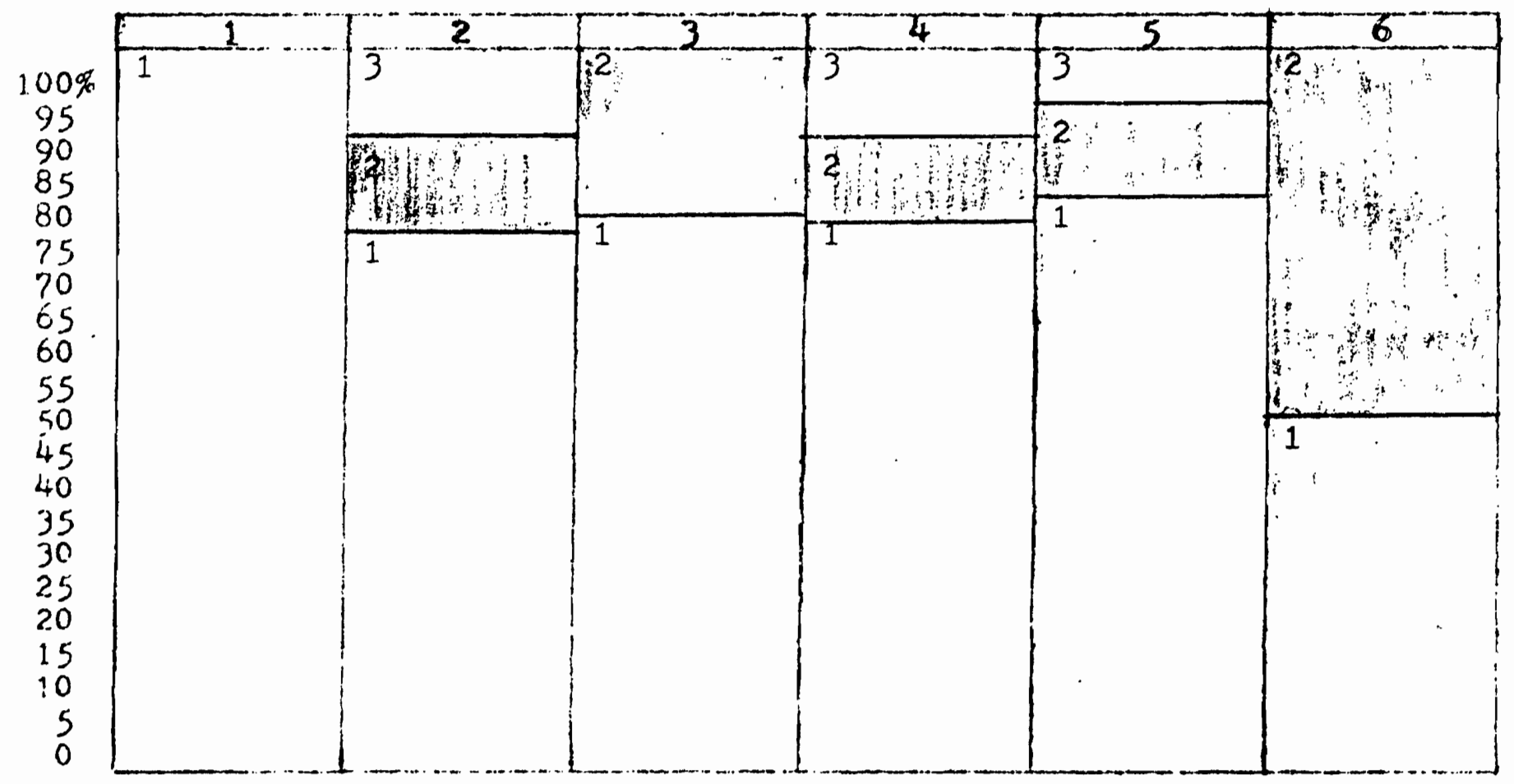


QUESTION

Do you feel there should be alternative methods for handing the following youths other than placing them in jail or detention facilities? B. Adolescents removed from their home because of family conflict

RESULTS

$$
\begin{aligned}
& 1 \text { Interagency Council } 4 \text { Kimanis Club } \\
& 2 \text { Inmediate Neighborhood } 5 \text { Hot Line Youth Group } \\
& 3 \text { Carpenters Enion } 6 \text { Police }
\end{aligned}
$$

\begin{tabular}{lrrrrrr}
\hline & 1 & 11 & 20 & 21 & 20 \\
\hline Yes & 14 & 22 & 2 & 3 & 5 & 0 \\
No & 0 & 2 & 3 & 1 & 1 & 0 \\
No response & 1 & 1 & 0 & 0 & 0 & 0 \\
Total & 15 & 25 & 14 & 21 & 22 & 20
\end{tabular}

GRAPHIC ILIUSTRATION (number code above)

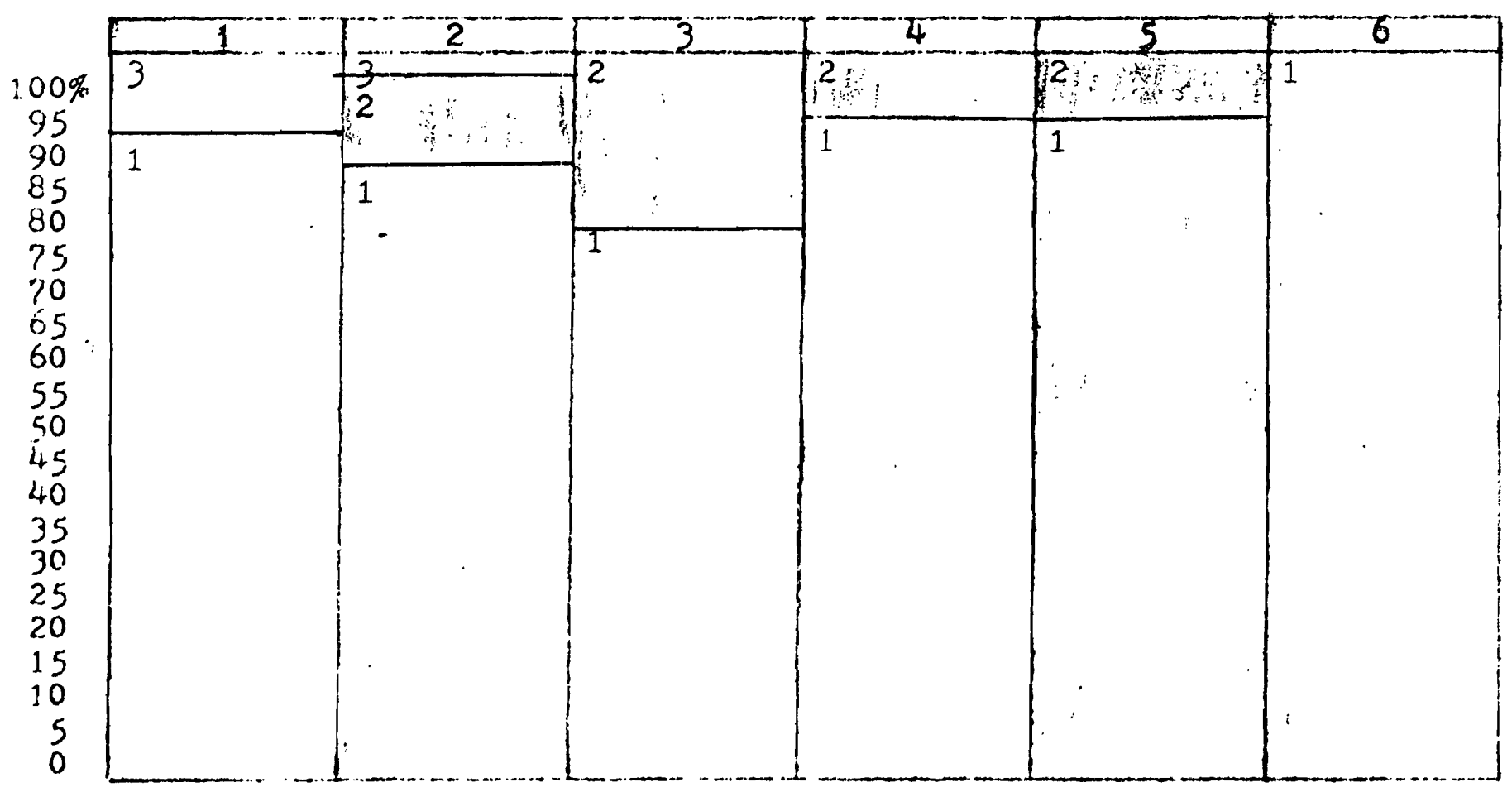




\section{QUESTION}

Do you feel there should be alternative methods for handling the following youths other than placing them in jail or detention facilities? C. Dependent or neglected youths

RESULTS

1 Interagency Council

2 Immediate Neighborhood

3 Carpenters Union
4 Kiwanis Club

5 Hot Line Youth Group

Police

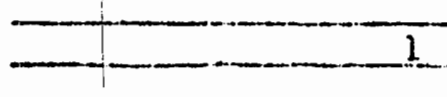

1 Yes

15

0

0

15

Total

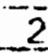

23

1

1

25

14

$4-5$

21

21 18

2

0

1

2

0

0

0

22

20

GRAPHIC ILLUSTRATION (number code above)

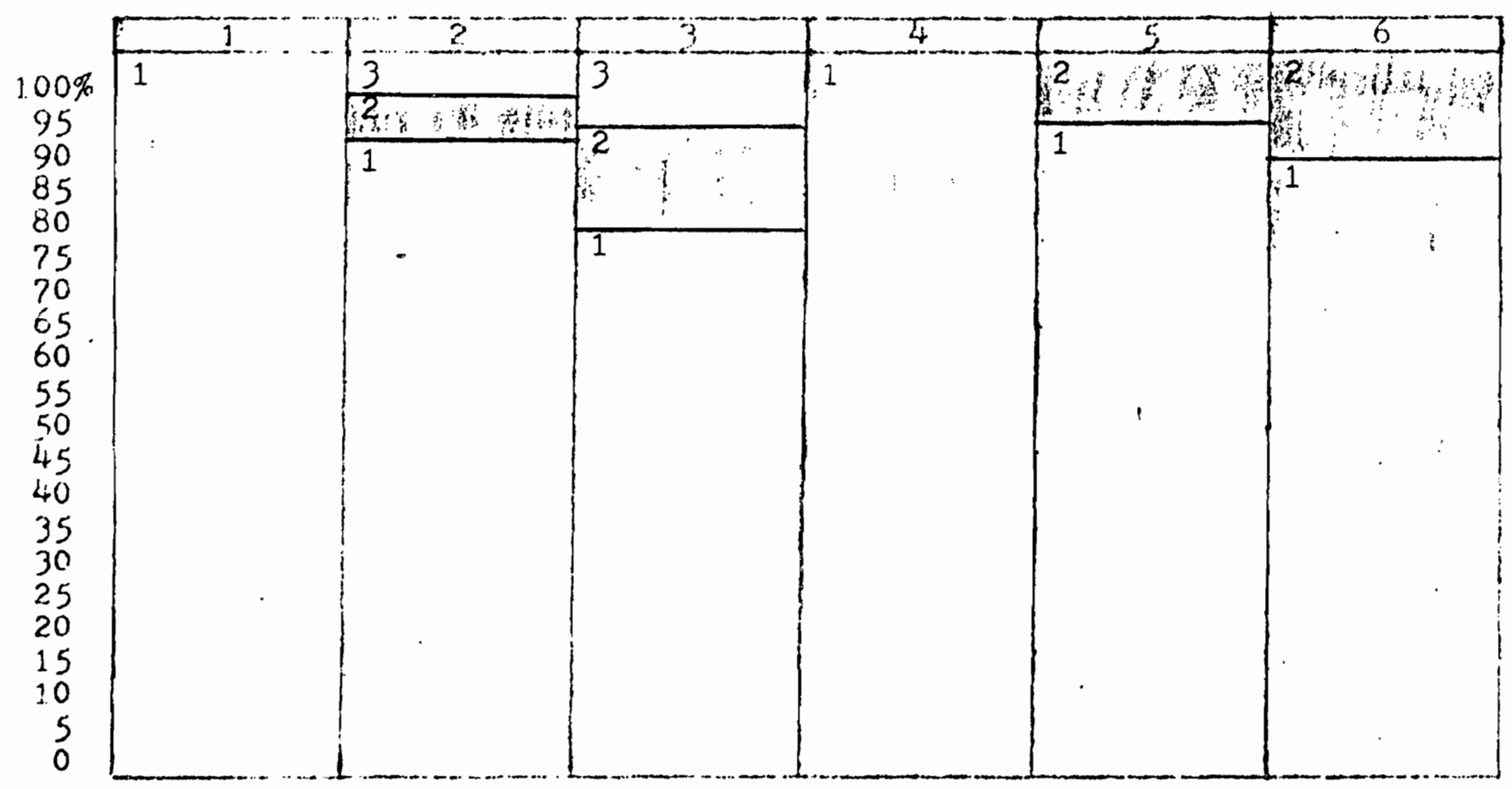


Please indicate whether you agree or disagree with the following statements, and why. A. Community volunteers should be involved in the handling of adolescents in need of temporary shelter care (as opposed to only paid officials.)

RESULTS

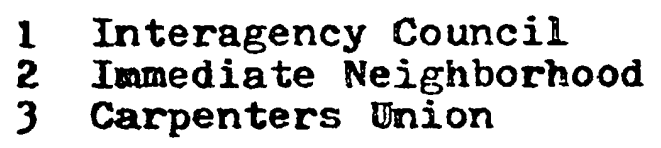

4 Kiwanis Club

5 Hot Iine Youth Group Police

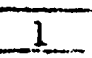

1 Strongly agree 9

2 Mildly agree 2 3

12

4

4

5

12.

6

3

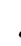

Strongly
Mijidy

disagree

3

1

disagree

No response

Total

15

25

14

21

22

10

12

9

1

2

3

1

0

2

0

0

0

GRAPHIC ILIUSTRATION (number code above)

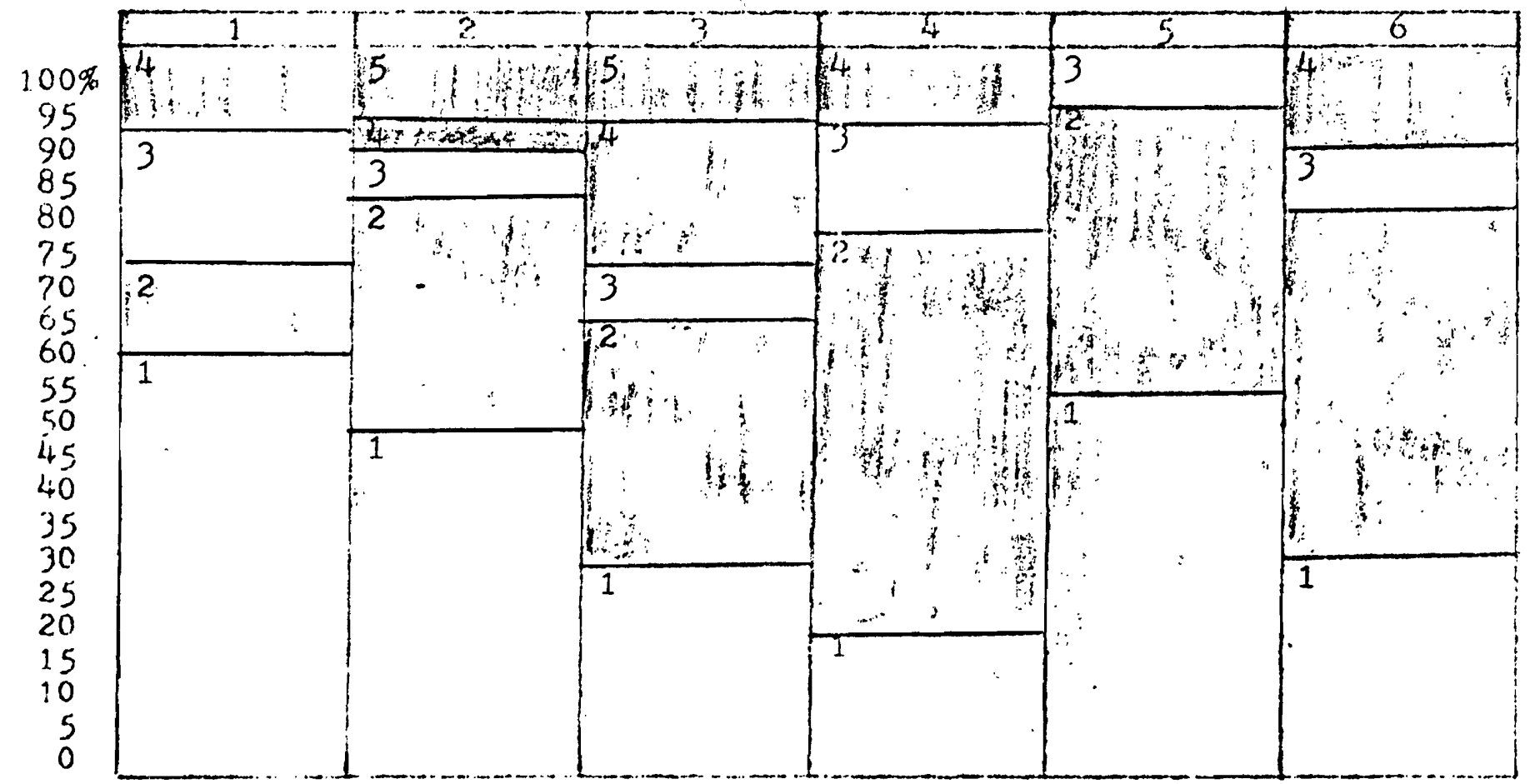


QUE:STION

Please indicate whether you agree or disagree with the following statement, and why. B. Generally speaking, delinquent youth should be isolated from non-delinquent youth.

RESULTS

$$
\begin{aligned}
& 1 \text { Interagency Council } 4 \text { KIwanis CIub } \\
& 2 \text { Immediate Neighborhood } 5 \text { Hot Line Youth Group } \\
& 3 \text { Carpenters Union } \\
& \text { Police }
\end{aligned}
$$

1

2

4

4

6

(w) Strongly

agree

3

4

$?$

7

2

11

- Mildlir agree 6

9

2

7

4

4

1!. Mildly

disagree

4

3

2

3

3

1

- Strongly

disagree

2

7

3

4

13

2

No response

0

2

0

0

0

2

Total

15

25

1t

21

22

20

GRAPHIC ILLUSTRATION (number code above)

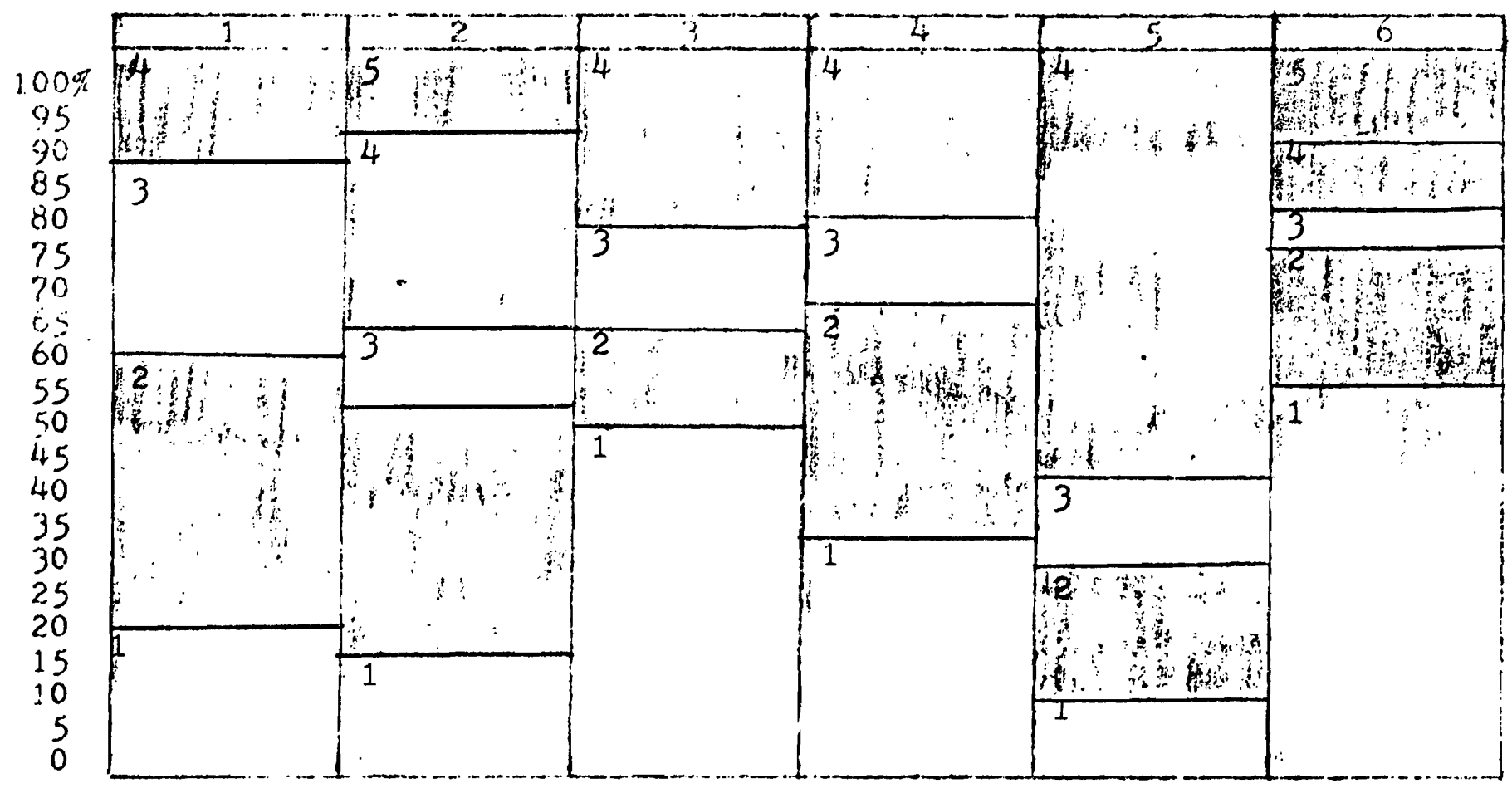




\section{QUESTION}

Please indicate whether you agree or disagree with the following, statement, and why, C. Jail or detention facilities should be used for temporary shelter care facilities for dependent or neglected youth.

RESULTS

$$
\begin{aligned}
& 1 \text { Interagency Council } 4 \text { Kiwanta Club } \\
& 2 \text { Immediate Neighborhood } 5 \text { Hot Iine Youth Group } \\
& 3 \text { Carpenters Union } \\
& \text { Police }
\end{aligned}
$$

1

$1 \quad \begin{gathered}\text { Strongly } \\ \text { agree }\end{gathered}$

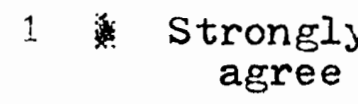

2. Mildly agree 0

;.

disagree

0

15

13

14

25

15

Total
9

0

4

0

1

3

2

5

2

1

9

8

6

1

$\begin{array}{lll}9 & 12 & 8\end{array}$

10

0

21

22

20

GRAPHIC ILLUSWRATION (number code above)

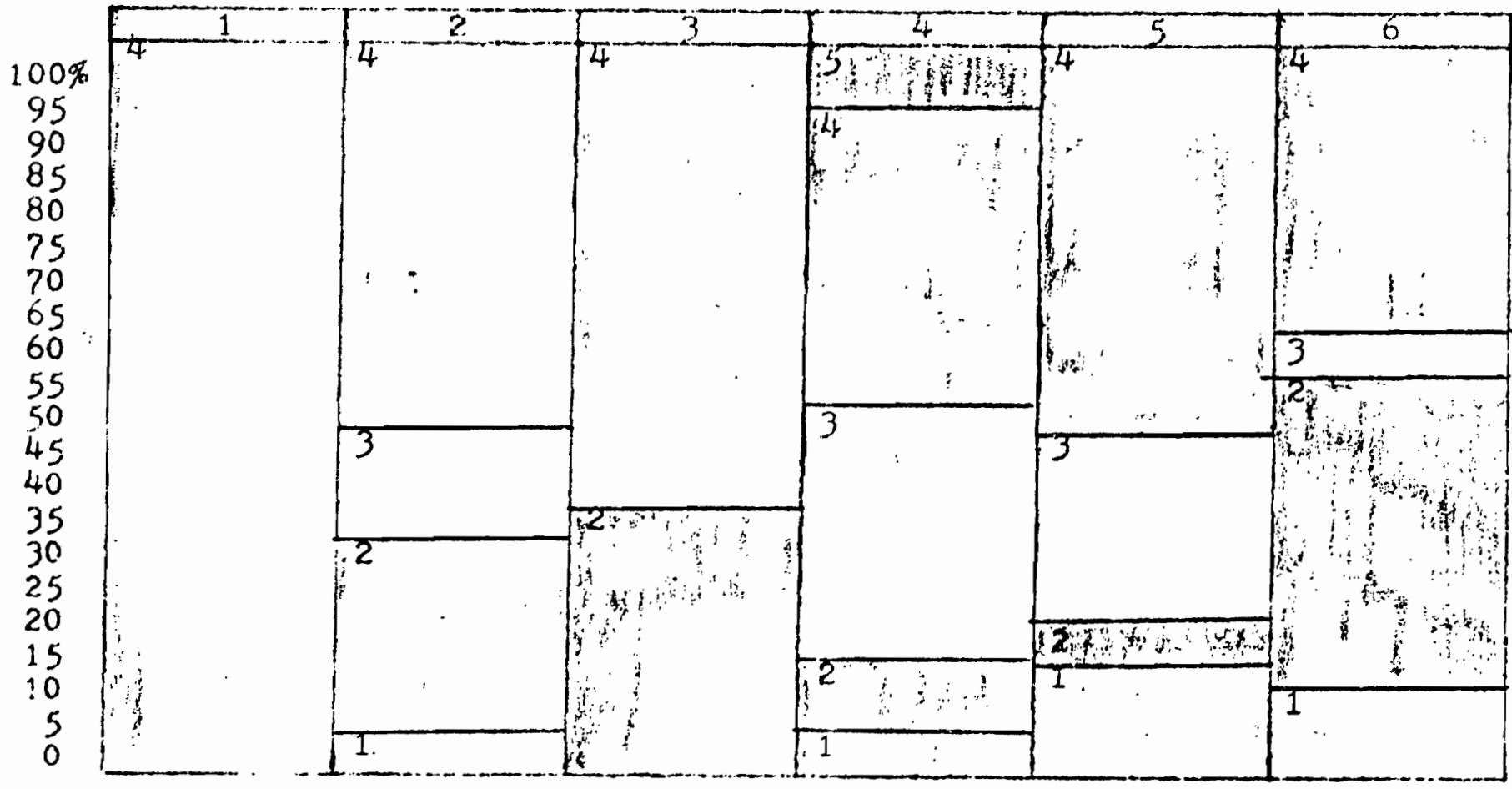


QUESTION

Please indicate whether you agree or disagree with the following statement, and why. D. It is a poor plan to house youth who have broken the law and youth who are neglected by their parents, together in the same facility.

RESULTS 1 Interagency Council

2 Immediate Neighborhood

3 Carpenters' Union

4 Kiwanis Club 5 Hot Iine Youth Group
6 Police
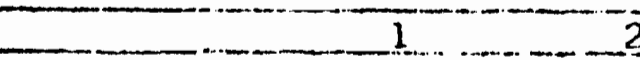
$\overline{3}$

4

9

11

2

15

agree

2 Mildly agree 5

4

2

4

4

4

$3:$ Mildly

disagree

5

5

4

9

1

6

1

21

22

20

GRAPHIC ILLUSTRATION (number code above)

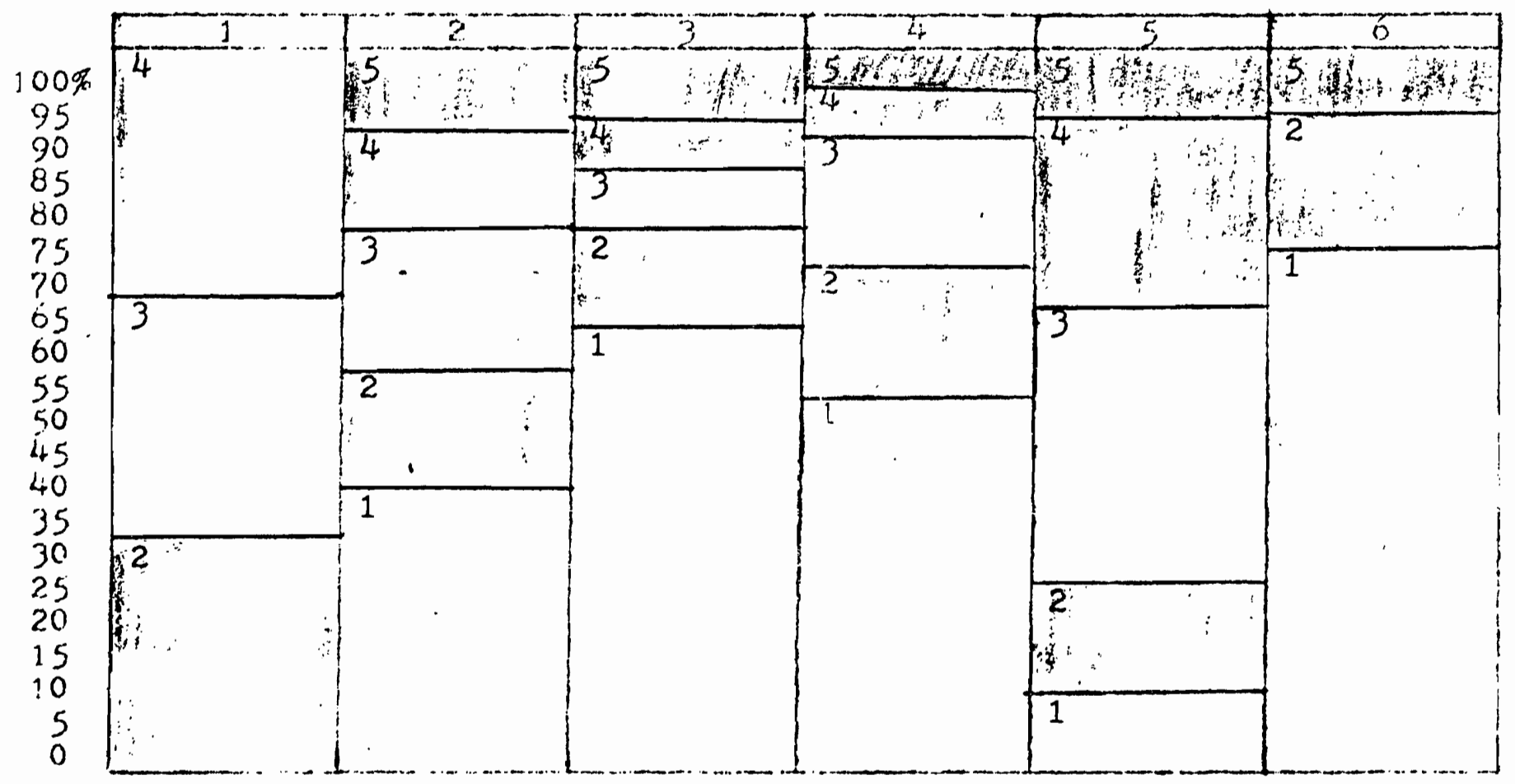


SUESTION

Please indicate whether you agree or disagree with the following statement, and why. E. The major responsibility for providing facilities for the youth in the community who need temporary shelter care lies with the community rather than the state or federal government

RESULTS $\quad 1$ Interagency Council 2 Immediate Neighborhood 5 Hot Line Youth Group $-1-\frac{3}{2}-4$

1 Strongly

agree

7

12

8

9

8

5

2. Mildily agree 6

4

6

9

7

3 Mildiy

disagree

2

4

0

5

4

7

4 Strongly

disagree

0

3. 4

1

1

1

5 No response

0

2.

1.

0

0

0

Total

15

25

14

21

22

20

GRAPHIC ILLUSTRATION (number code above)

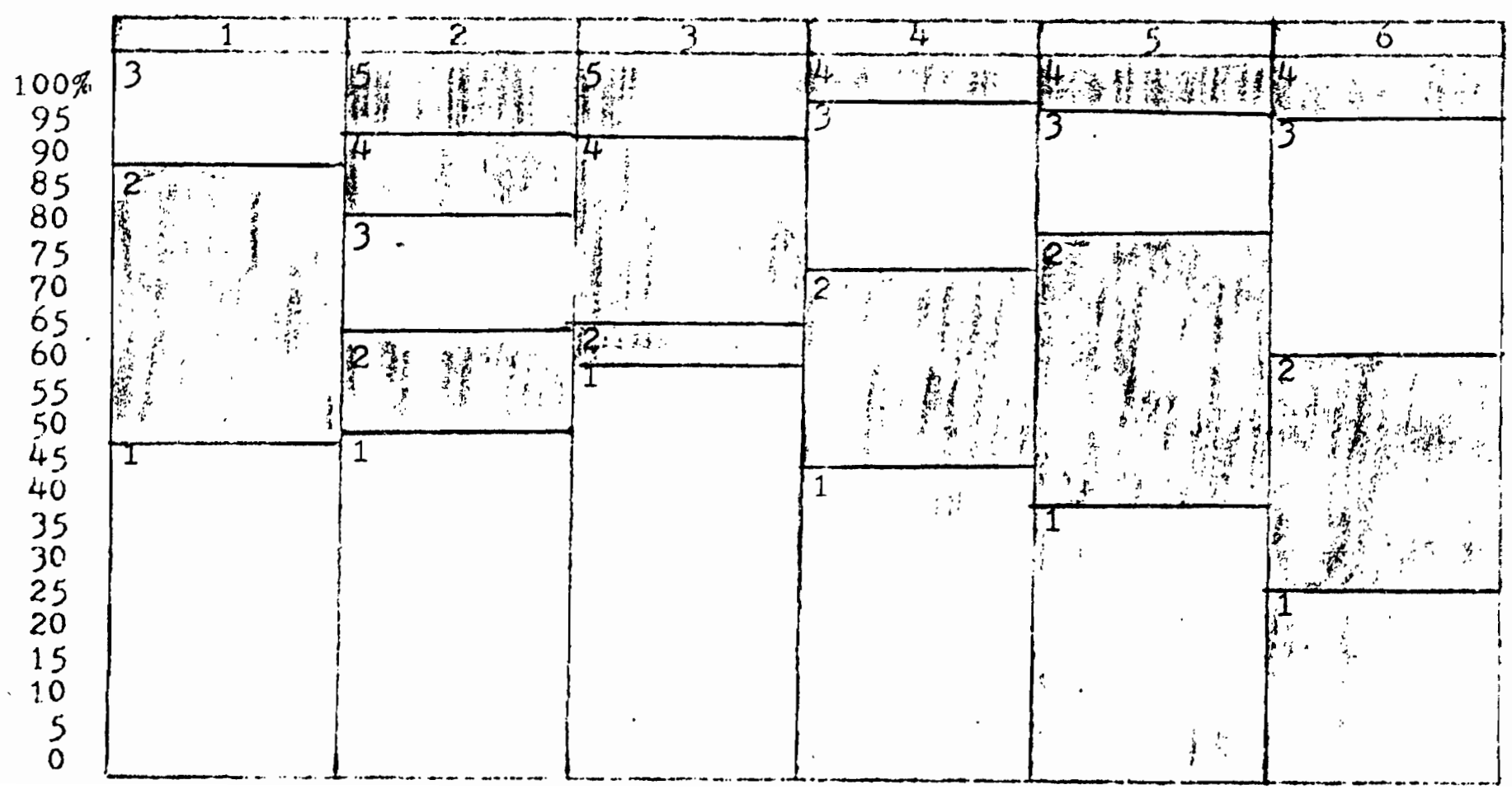


GUESTION

Please indicate whether you agree or disagree with the following statement, and why. F.' Funding for programs such as the Community Attention Home should come mainly from within the community rather than from outside the community.

RESULTS

$$
\begin{aligned}
& 1 \text { Interagency Council } \\
& 2 \text { Immediate Neighborhood } \\
& 3 \text { Carpenters' Union }
\end{aligned}
$$

4 Kiwanis Club

5 Hot Line Youth Group 6 Police $+\ldots+1$

Strongly

agree

2. Mildly agree 4

3 : Mildly

disagree

4 Strongly

disagree

$5 \quad$ No response

Total

6

2
9

4

8.

0

25

14
21

7

7

3

3

1

2

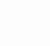

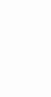

4

5

$5-6$

6


QUESTION

Have you heard of the Community Attention Home planned for The Dalles?

RESULTS 1 Interagency Council

2 Immediate Neighborhood

3 Carpenters' Union

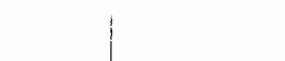

4 Kiwanis Club

5 Hot Line Youth Group 6 Folice i. Yes

2. No

3 No response

Total
15

15

0

0

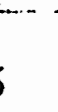

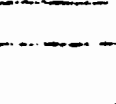

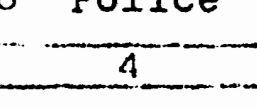

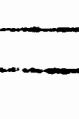

$-$

5

13

15

11

17

9

5

0

6

4

0

0

GRAPHIC ILIUSTRATION (number code above)

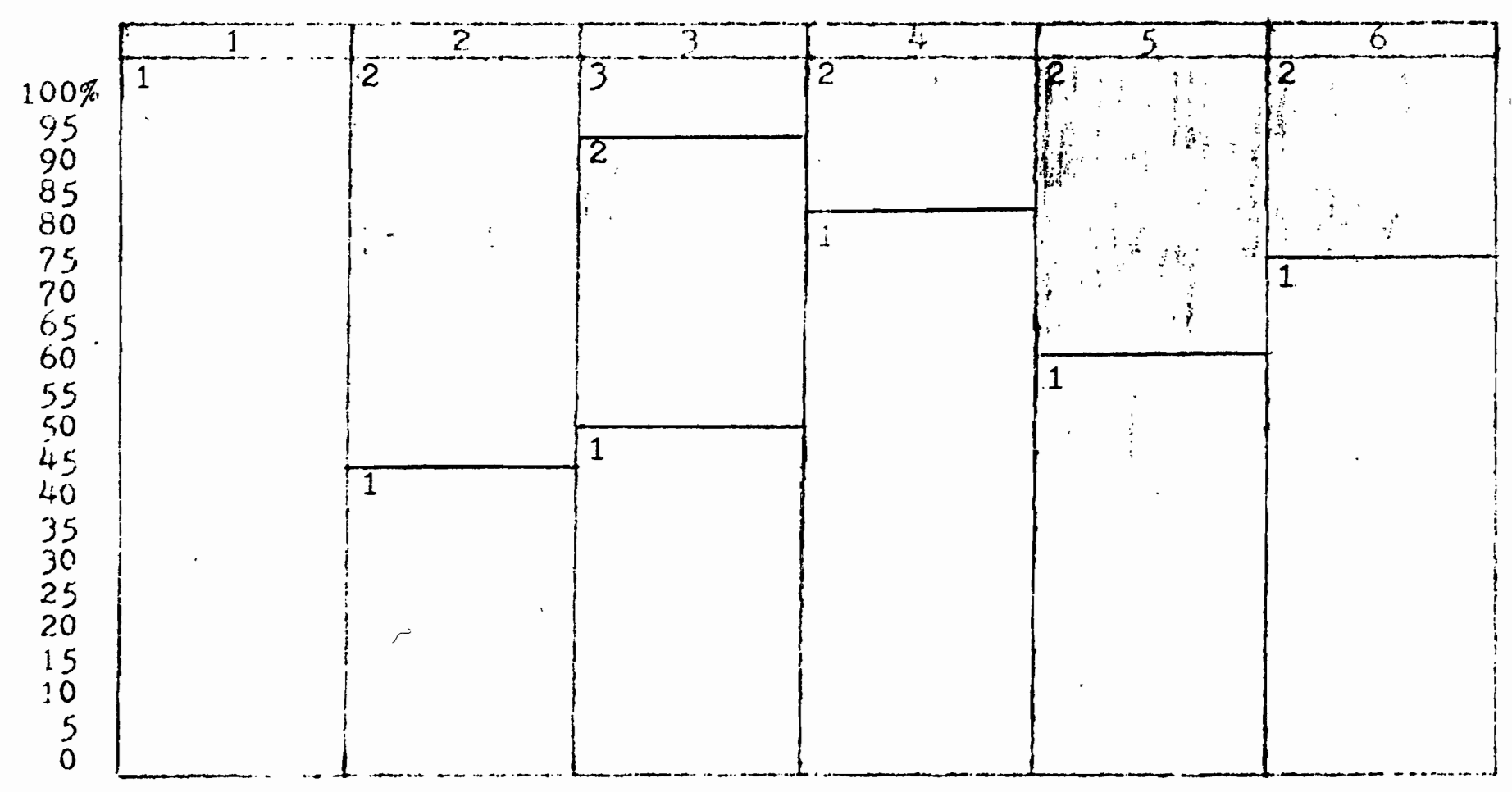


QUESTION

Have you heard of the Community Attention Home planned for The Dalles? If yes, did you hear of it on T.V.?

$\begin{array}{lllll}\text { RESULTS } & 1 & \text { Interagency Council } & 4 & \text { Kiwanis Club } \\ & 2 & \text { Immediate Neighborhood } & 5 & \text { Hot Iine Youth Group } \\ & 3 & \text { Carpenters Union } & 6 & \text { Police }\end{array}$

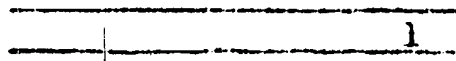

3

Yes

0

15

0

15

Total
0

13

1

14
0

21

0

21

22

21
6

0

20

1

0

20

GRAPHIC ILLUSTRATION (number code above)

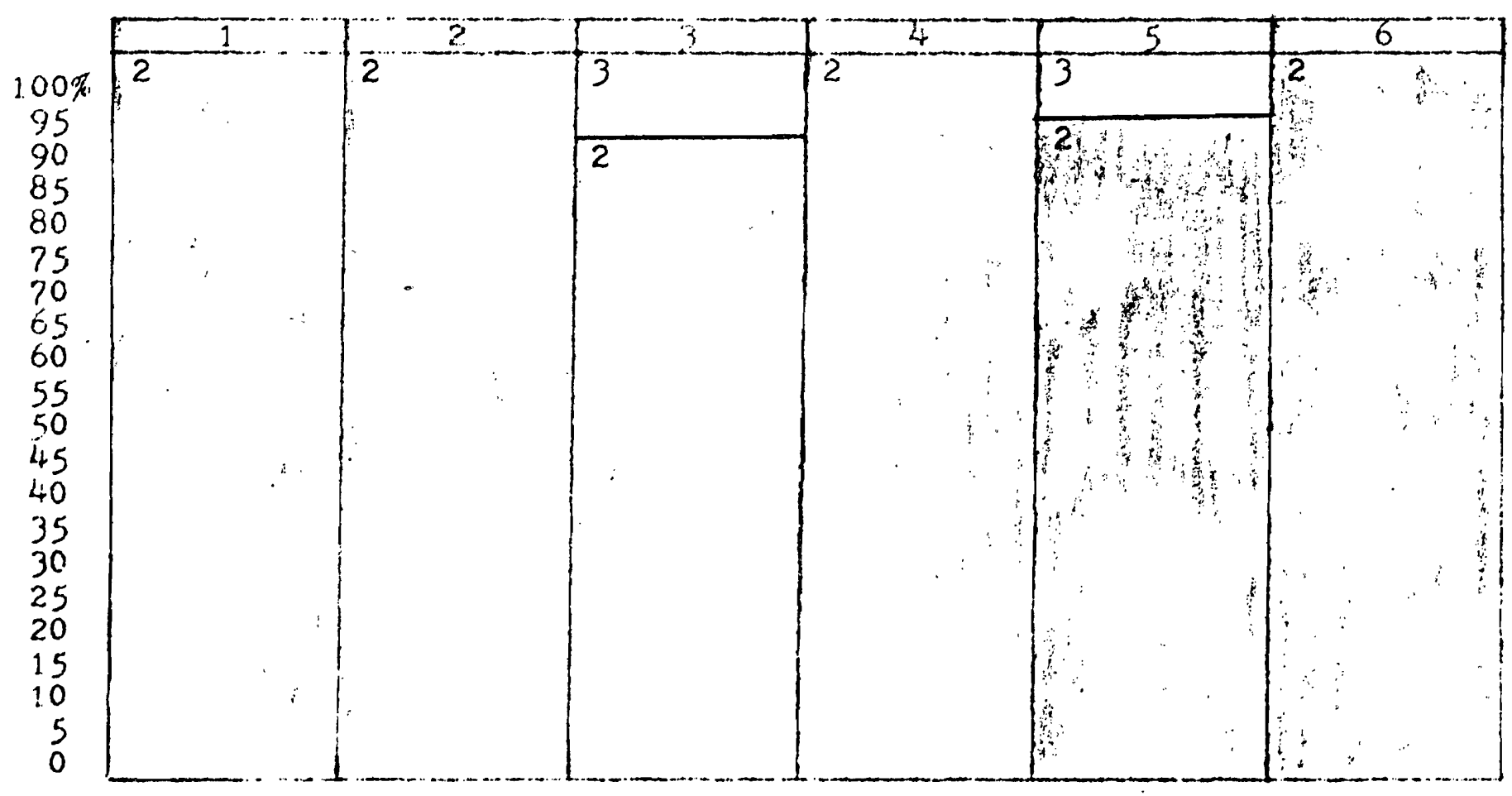


QUESTION

Have you heard of the Community Attention Home planned for The Dalles. If yes, did you hear of it on the radio?

RESULTS 1 Interagency Council 2 Immediate Neighborhood 3 Carpenters' Union

4 Kiwanis Club

5 Hot Iine Youth Group Police
-

Yes

No

1

14

4

1

21

12

0

1

14

25

15

Total

21

12

0

19

1

22

20

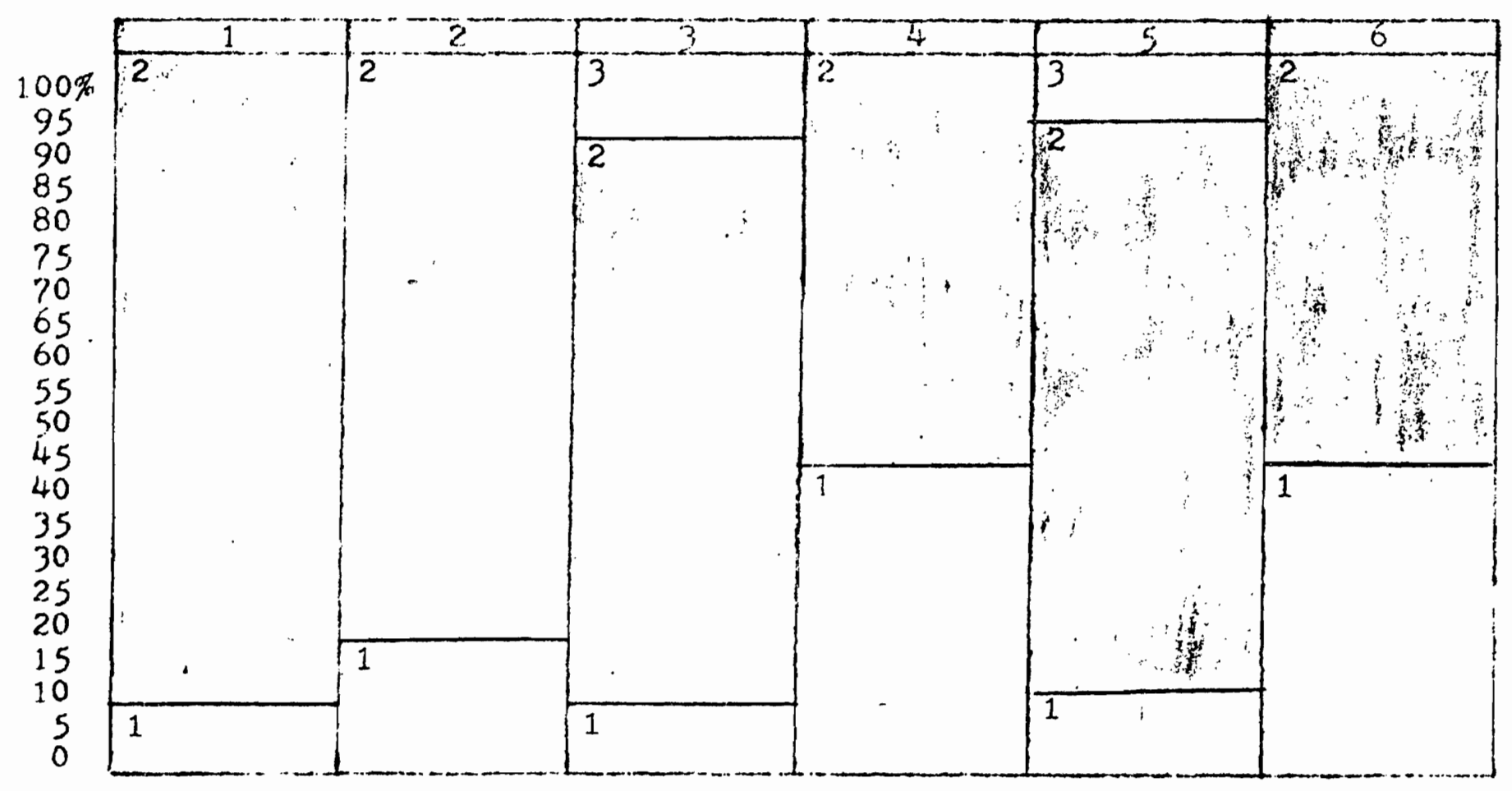


QUESTISN

Have you heard of the Community Attention Home planned for The Dalles? If.yes, did you hear of it through the newspaper?

RESULTS 1 Interagency Council 2 Immediate Neighborhood 3 Carpenters' Union

4 Kiwanis CIub

5 Hot Iine Youth Group 6 Police

\begin{tabular}{lrrrrrr}
\hline & 1 & 6 & 5 & 5 & 5 \\
\hline Yes & 7 & 9 & 15 & 1 & 9 \\
No & 8 & 16 & 7 & 6 & 20 & 11 \\
No response & 0 & 0 & 1 & 0 & 1 & 0 \\
Total & 15 & 25 & 14 & 21 & 22 & 20
\end{tabular}

GRAPHIC ILIUSTRATION (number code above)

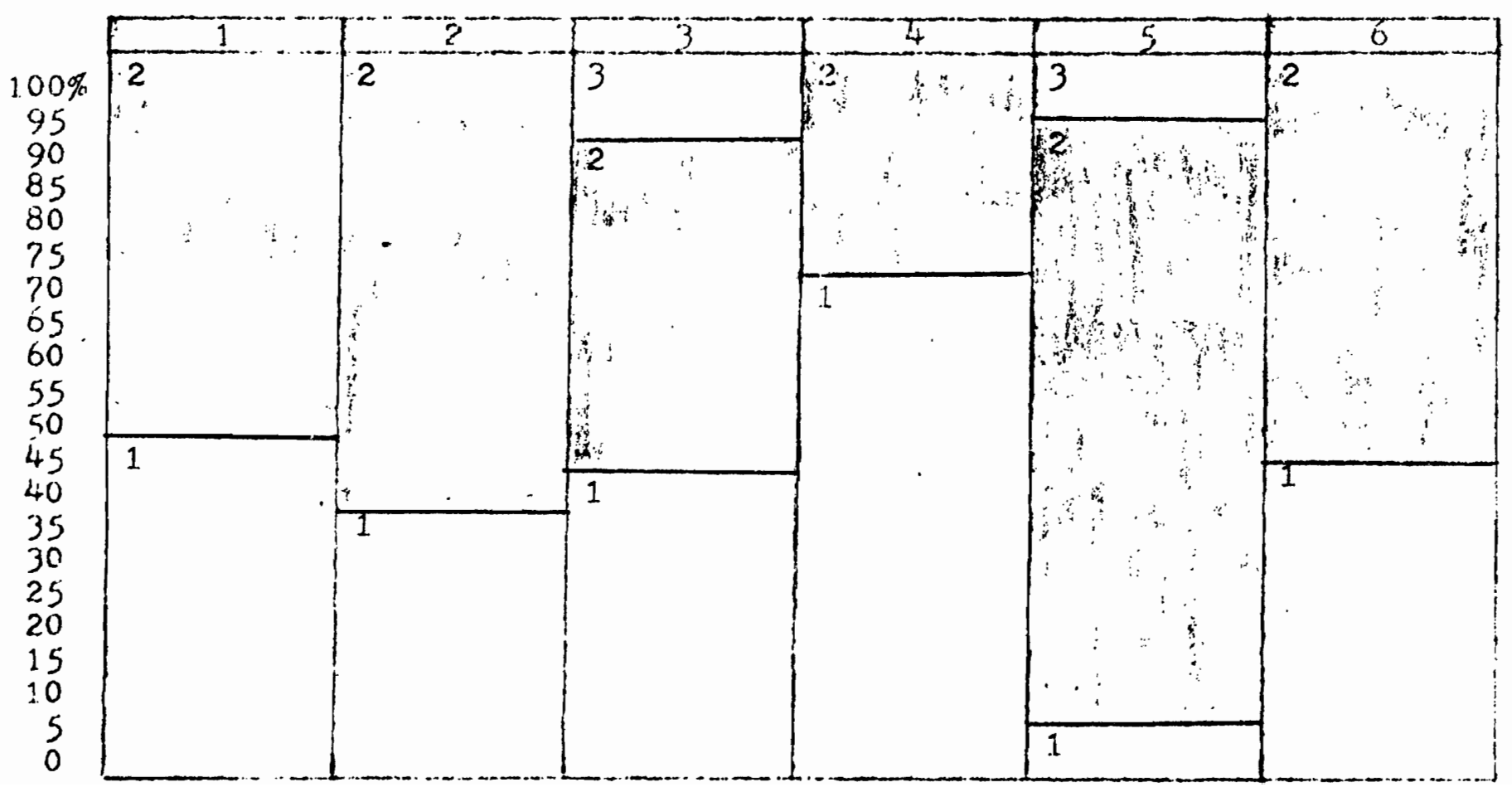


QUE:STION

Have you heard of the Community Attention Home planned for the Dalles? If yes, did you hear of j.t through a source other than T.V., radio, or the newspaper?

RESULTS

1 Interagency Council

2 Immediate Neighborhood

3 Carpenters' Union
4 Kiwanis Club

5 Hot Iine Youth Group Police

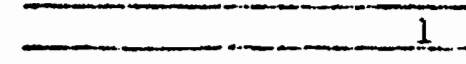

1 Yes

2 No

3 : No response

Total
14

1

0

15

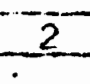

5

20

0

25

3

1

12

1

$1^{1 / 4}$
21

4

2

19

0

4

2

0

9

21

5


QUESTION

Which of the following items apply to the Community Attention Home? A. Serves delinquent and non-delinquent youth

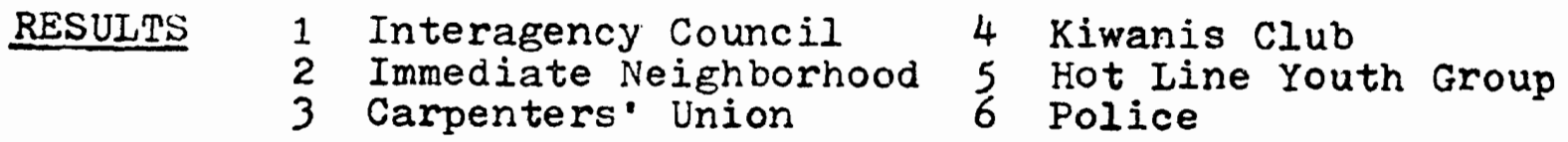

\begin{tabular}{lrrrrrr}
\hline & 1 & -2 & 3 & 4 & 5 & 6 \\
\hline Yes & 14 & 6 & 9 & 18 & 10 & 12 \\
No & 0 & 3 & 1 & 0 & 2 & 1 \\
No response & 1 & 16 & 4 & 3 & 10 & 7 \\
Total & 1.5 & 25 & 14 & 21 & 22 & 20
\end{tabular}

GRAPHIC ILIUSTRATION (number code above)

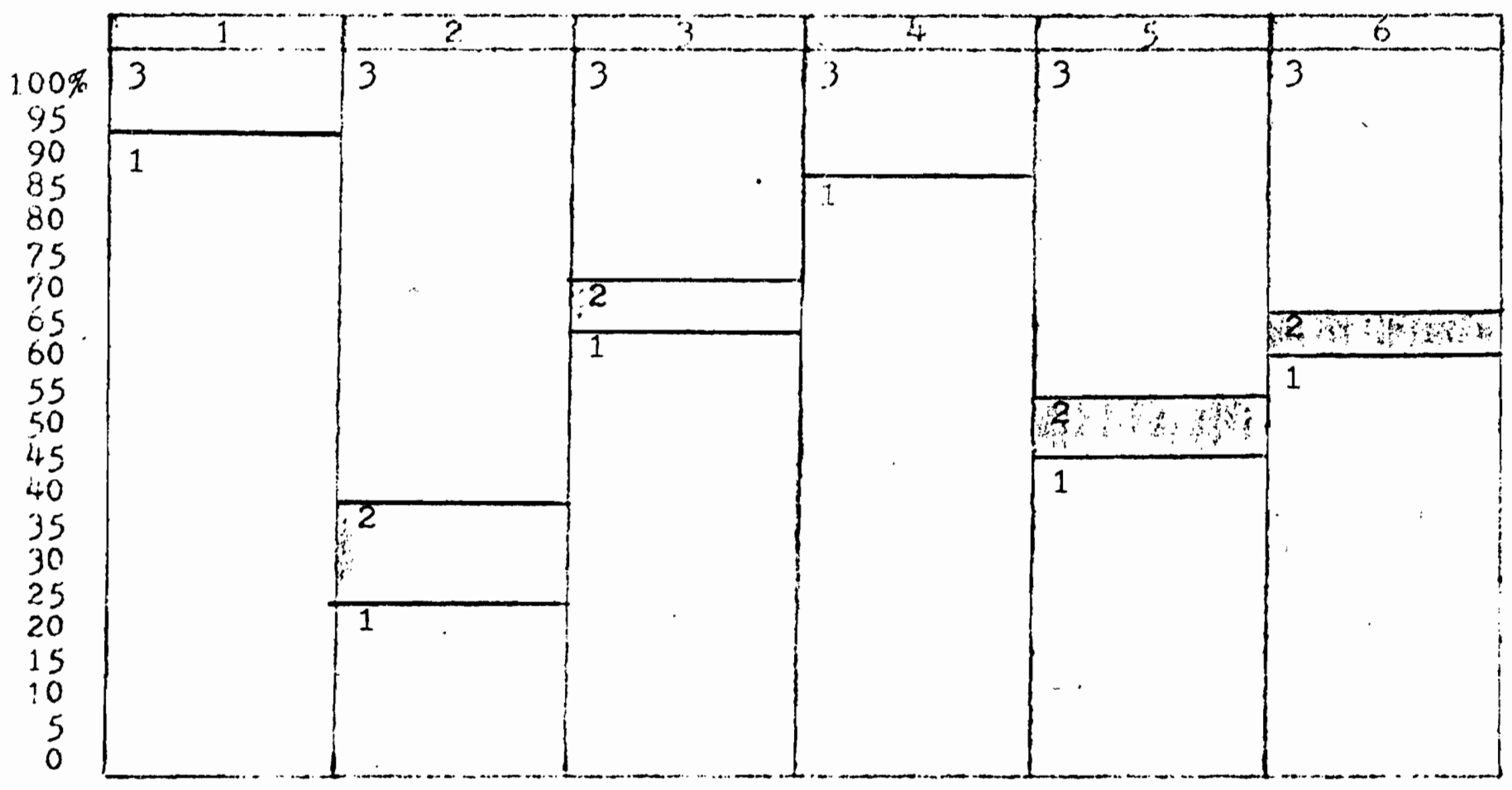


GUESTION

Which of the following items apply to the Community Attention Home? B. Profit making or ganization

RESULTS

$$
\begin{aligned}
& 1 \text { Interagency Council } \\
& 2 \text { Immediate Neighborhood } \\
& 3 \text { Carpenters Union }
\end{aligned}
$$

4 Kiwanis club 5 Hot Line Youth Group

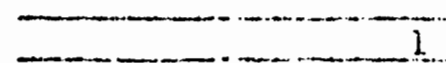

Yes
0

15

0

15

Total
0

8

17

2.5

1 it

0
9

5

3

...... $1-1$

0

0 1 11 8 3 21 22 20

\section{GRAPHIC ILLUSTRATION (number code above)}

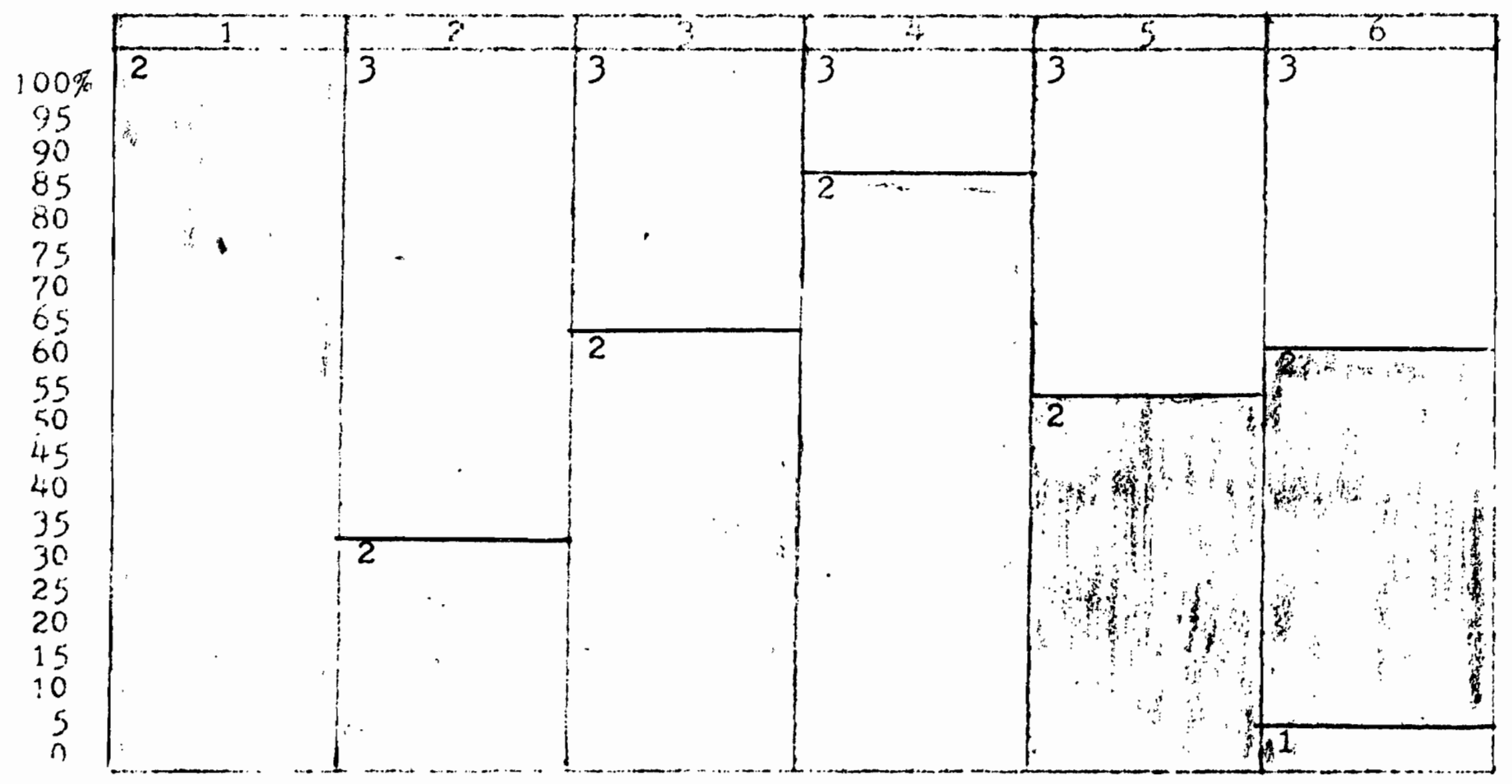



QUESTION

Which of the following items apply to the Community Attention Home? D. Relies partially on volunteer services from community

RESULTS 1 Interagency Council

4 Kiwanis Club

2 Immediate Neighborhood 5 Hot Line Youth Group
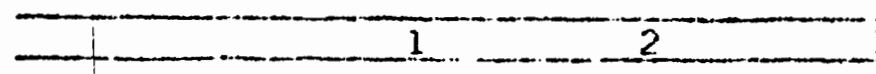

1 Yes

13

7

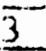

4

5

6

$?$ No

2

2

6

18

11

10

3 : No response 0

16

2

2

0

2

Total

15

25

14

21

22

20

GRAPHIC ILLUSTRATION (number code above)

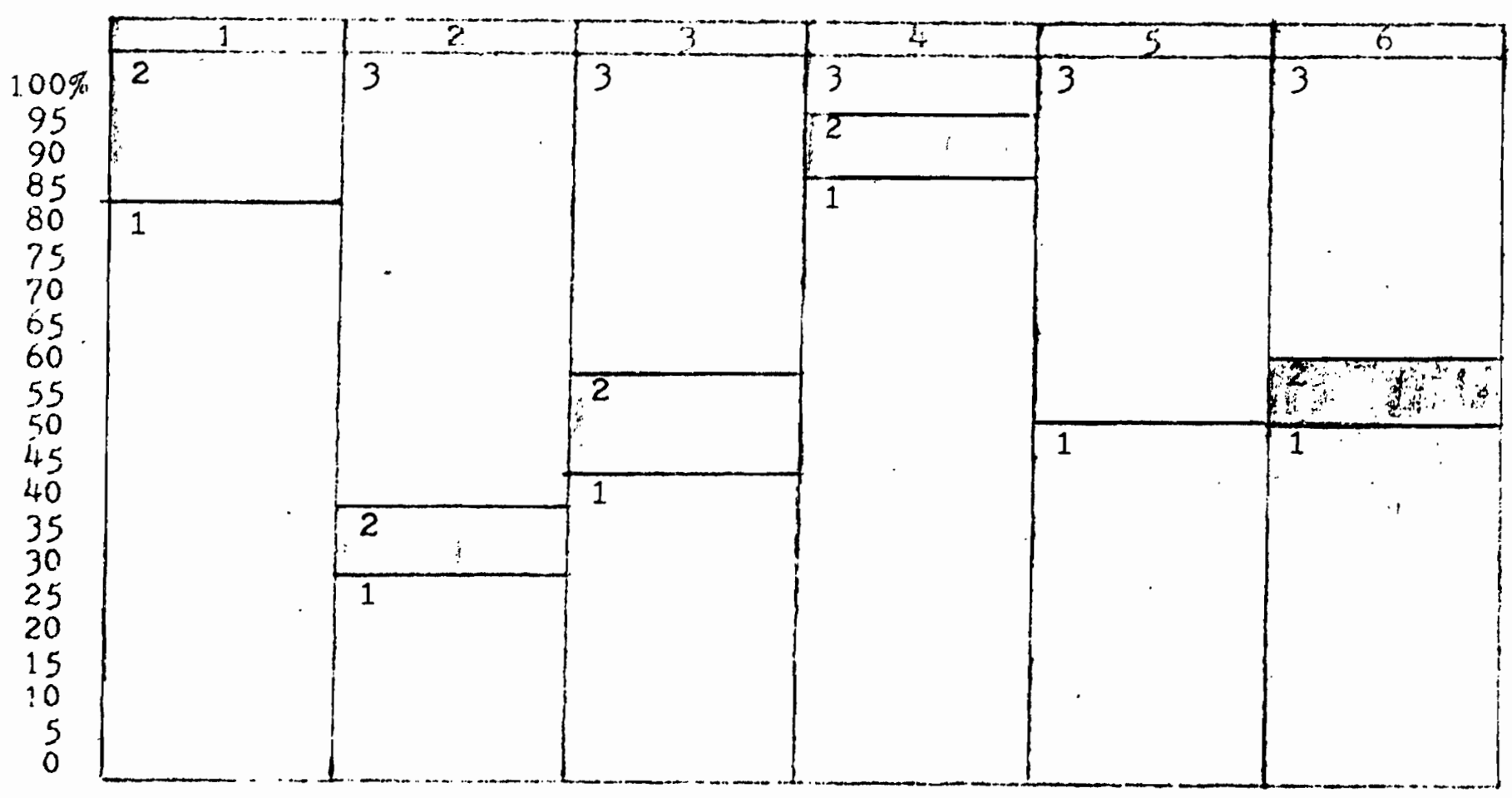


QUESTION

Which of the following items apply to the Community Attention Home? E. Age range served 18-21

RESULTS

1 Interagency Council

2 Immediate Neighborhood

3 Carpenters' Union
4 Kiwanis Club

5 Hot Iine Youth Group Police

-

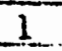

0

15

0

15

Total
0

3

5

17

25

14
1

18

2

21
6

4

8

8

10

22

20

\section{GRAPHIC ILLUSTRATION (number code above)}

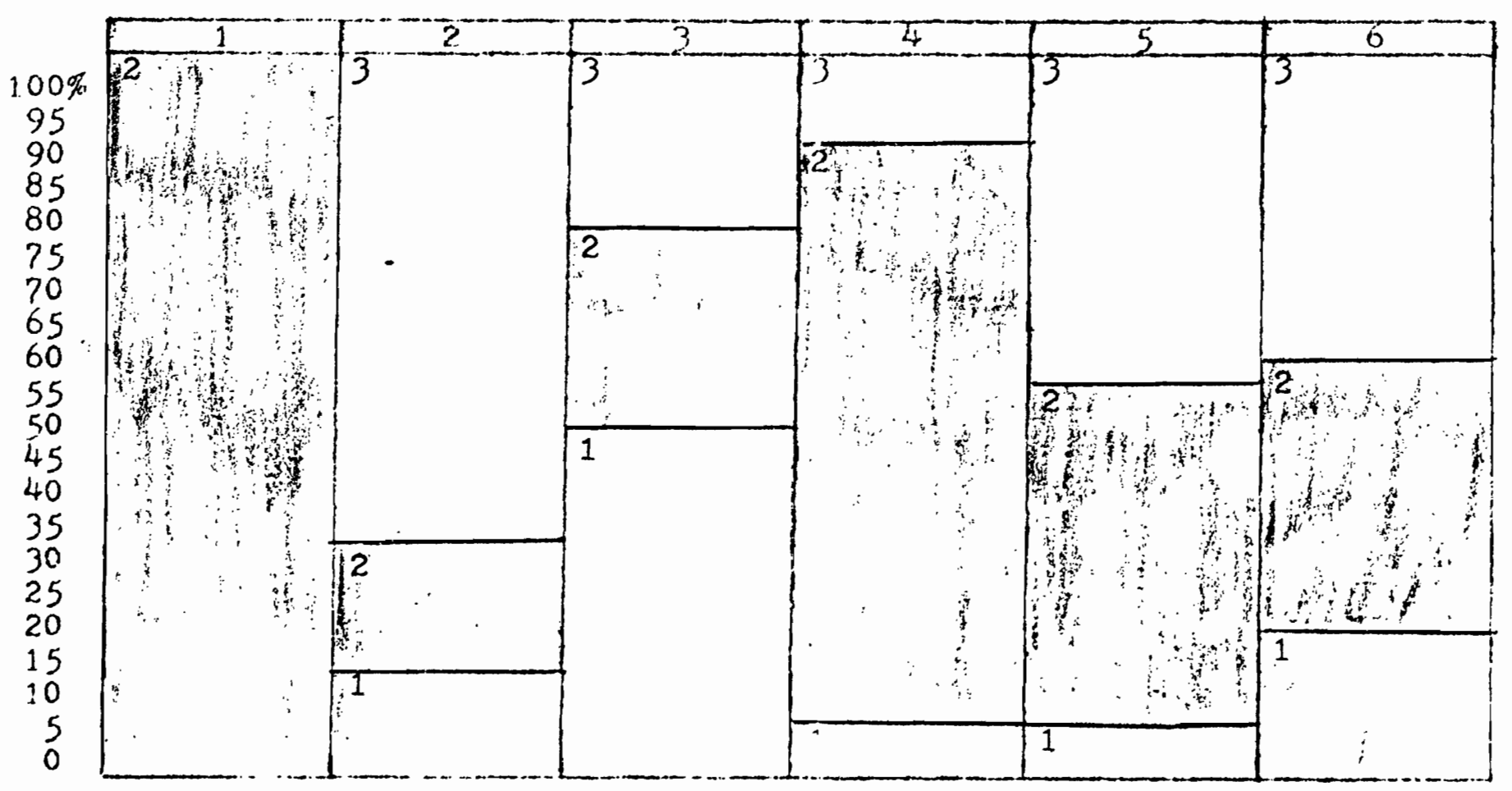


QUESTION

Which of the following items apply to the Community Attention Home? F. Treatment as opposed. to punishment emphasis

RESULTS 1 Interagency Council 2 Immediate Neighborhood 3 Carpenters' Union
4 Kiwanis Club 5 Hot Line Youth Group $\longrightarrow$

Yes

15

0

0

15

Total

2

7

2

16

25 $\overrightarrow{3}$

8

1

5

14

4

20

0

1

21
6

12

10

2

1

10

7

25

14

(

10

22

20

GRAFHIC ILLUSTRATION (number code above)

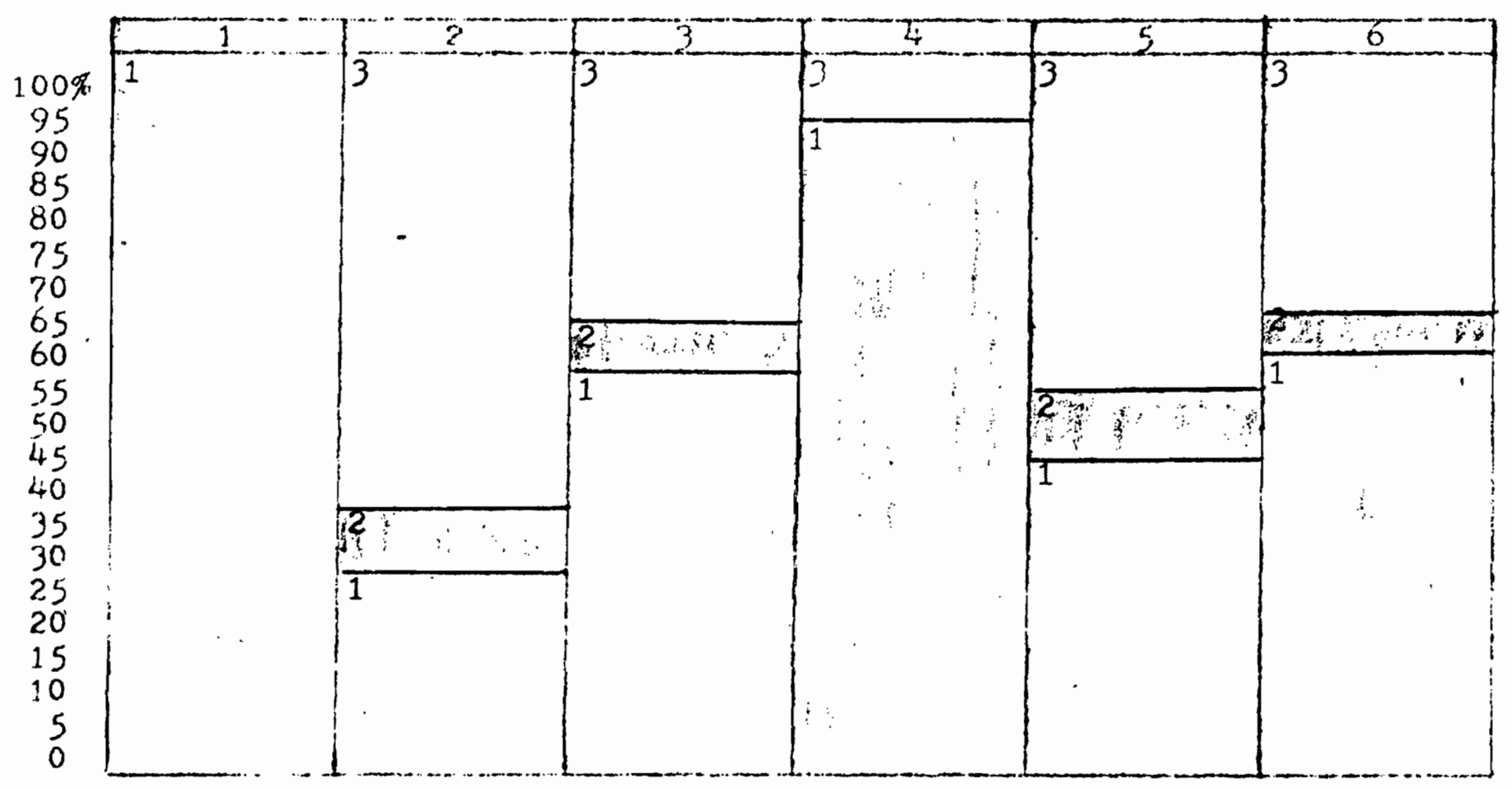


QUESTION

Which of the following items apply to the Community Attention Home? G. Isolates youth from his peers

RESULTS

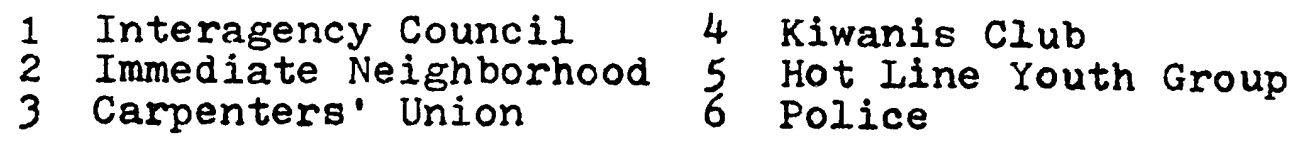

1

Yes

No

No response

Total

\section{2}

1.3

0

15

25

14
4

3

17

1

21

5

1

8

13

22
6

4

8

8

20

\section{GRAPHIC ILLUSTRATION (number code above)}

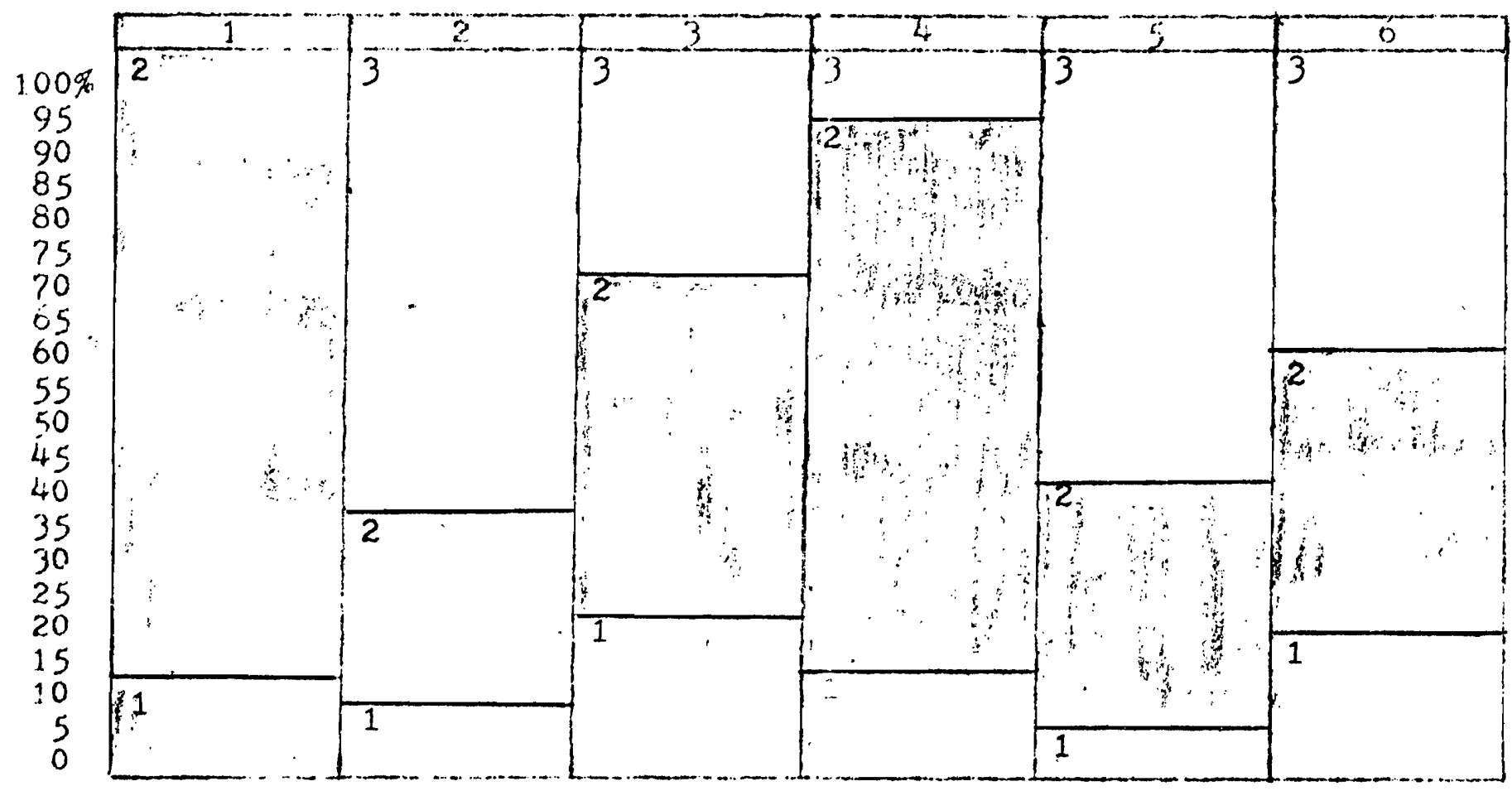


QUE:STION

Which of the following items apply to the Community Attention Home? H. Controlled by government agency

RESULTS 1 Interagency Council

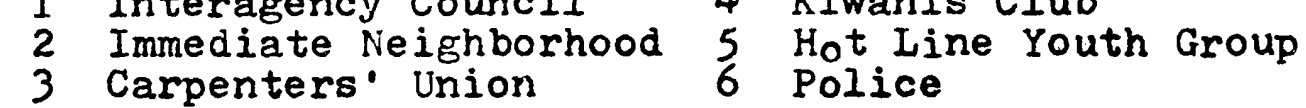

\begin{tabular}{|c|c|c|c|c|c|c|}
\hline & 1 & 2 & 3 & 4 & 5 & 6 \\
\hline Yes & 6 & 1 & 1 & 5 & 2 & 3 \\
\hline No & 9 & 8 & 8 & 15 & 8 & 9 \\
\hline No response & 0 & 16 & 5 & 1 & 12 & 8 \\
\hline Total & 15 & 25 & 14 & 21 & 22 & 20 \\
\hline
\end{tabular}

GRAPHIC ILIUSTRATION (number code above)

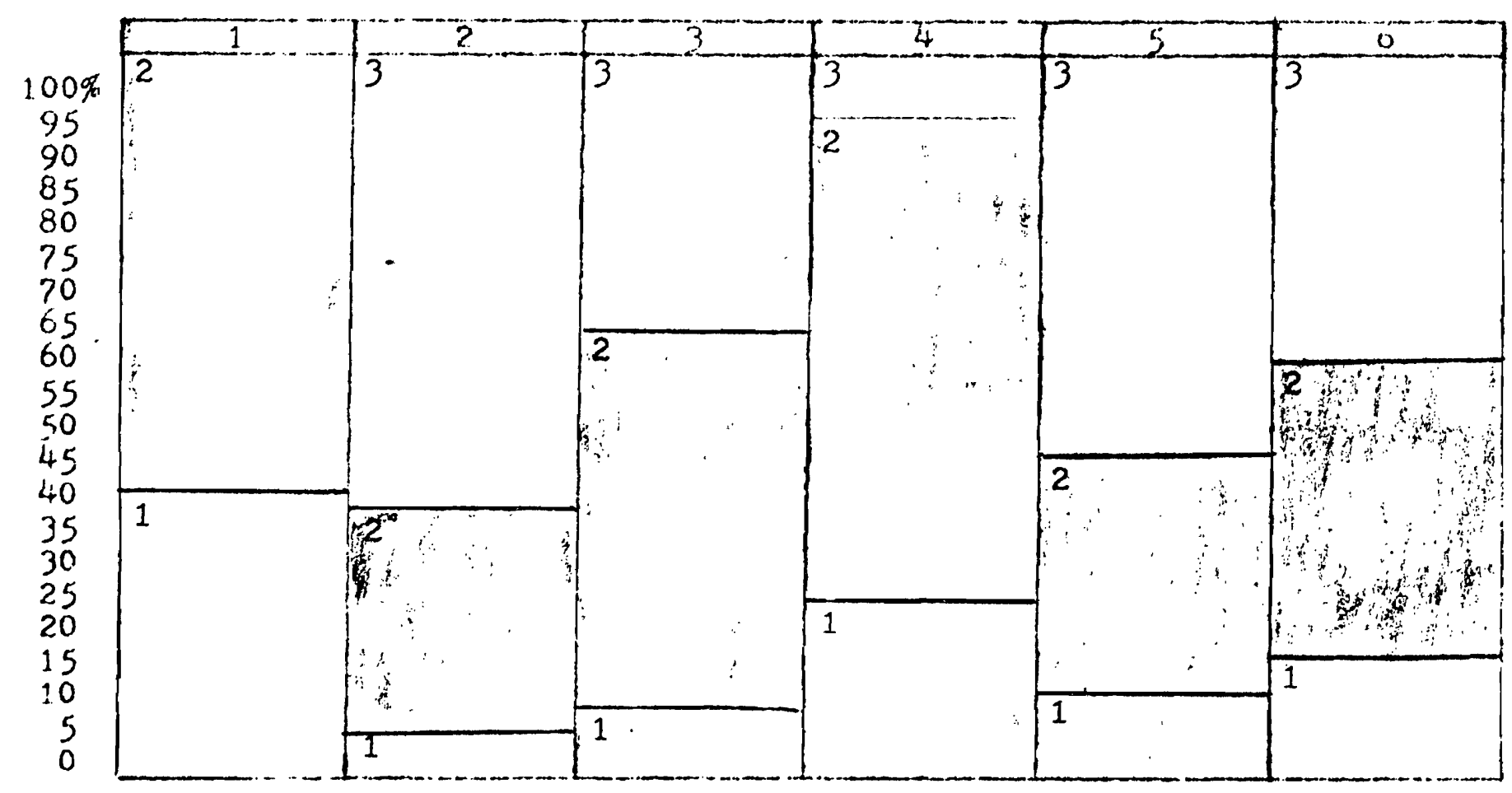


QUESTION

Are you in favor of the Community Attention Home type of program?

RESULTS

$$
\begin{aligned}
& 1 \text { Interagency Council } \\
& 2 \text { Immediate Neighborhood } \\
& 3 \text { Carpenters. Union }
\end{aligned}
$$

4 Kiwanis Club

5 Hot Line Youth Group 6 Police

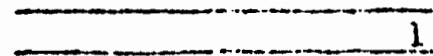

$1+-2$ 3 4

1 Strongly in favor $\quad .14$

11

?

6

14

8

2 Mildiy in favor

10

2

15

2.

3

3 No opinion

0

2

2.

0

0

3

4. Not in favor 0

2

0

0

0

1.

5 No response

0

10

0

6

5

Total

15

25

14

21.

22

20

\section{GRAPHIC ILLUSTRATION (number code above)}

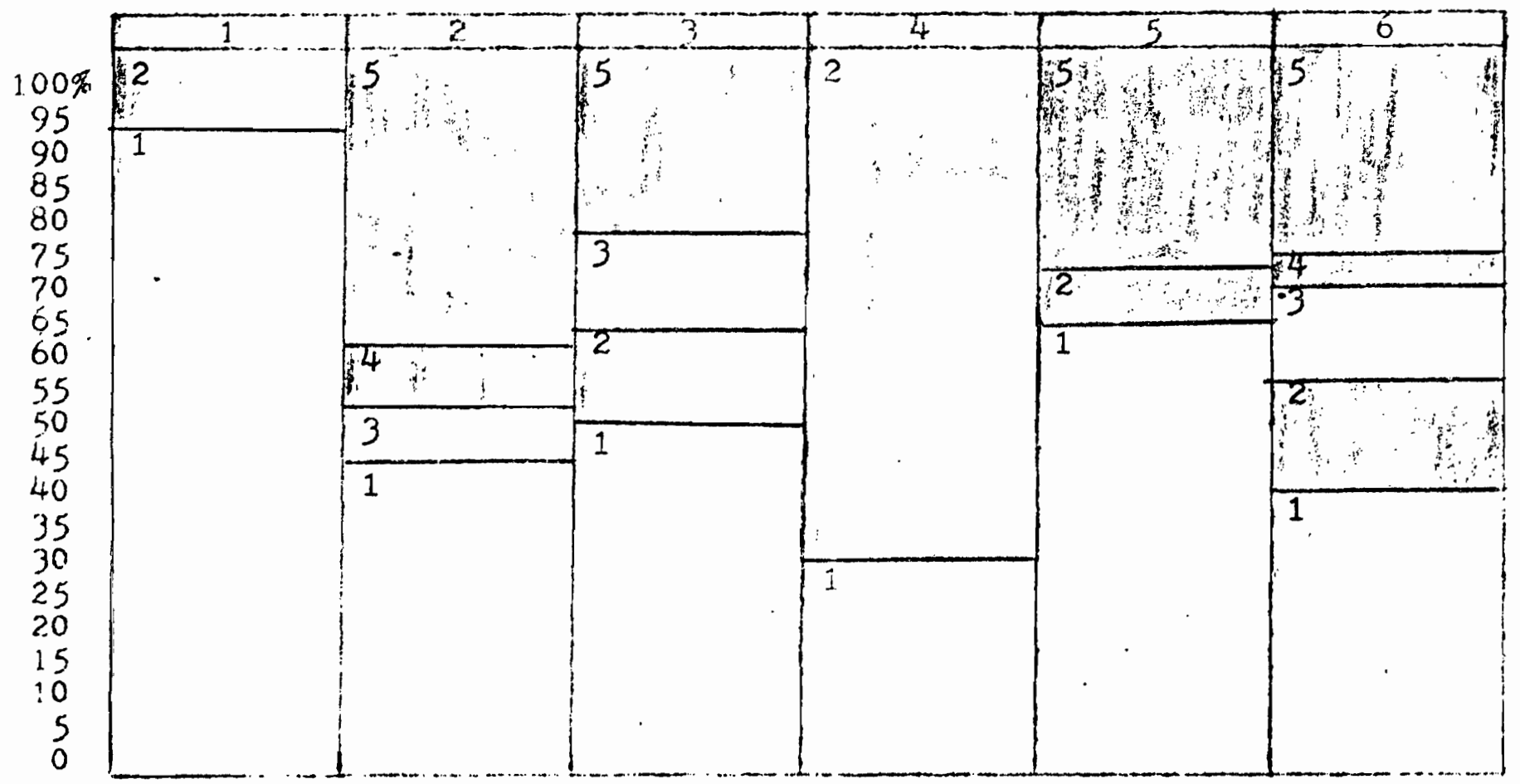


Gerisides

Do you feel there is a need for the Community Attention Home in The Dalles?

RESULTS 1 Interagency Council

2 Immediate Neighborhood

3 Carpenters' Union
4 Kiwanis Club

5 Hot Line Youth Group 6 Police

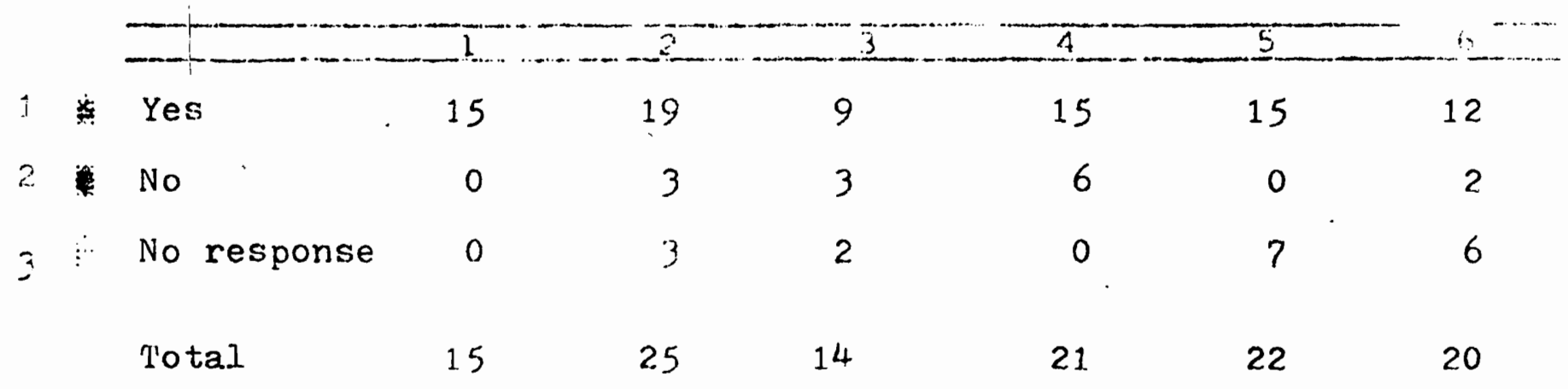

GRAPHIC ILLUSTRATION (number code above)

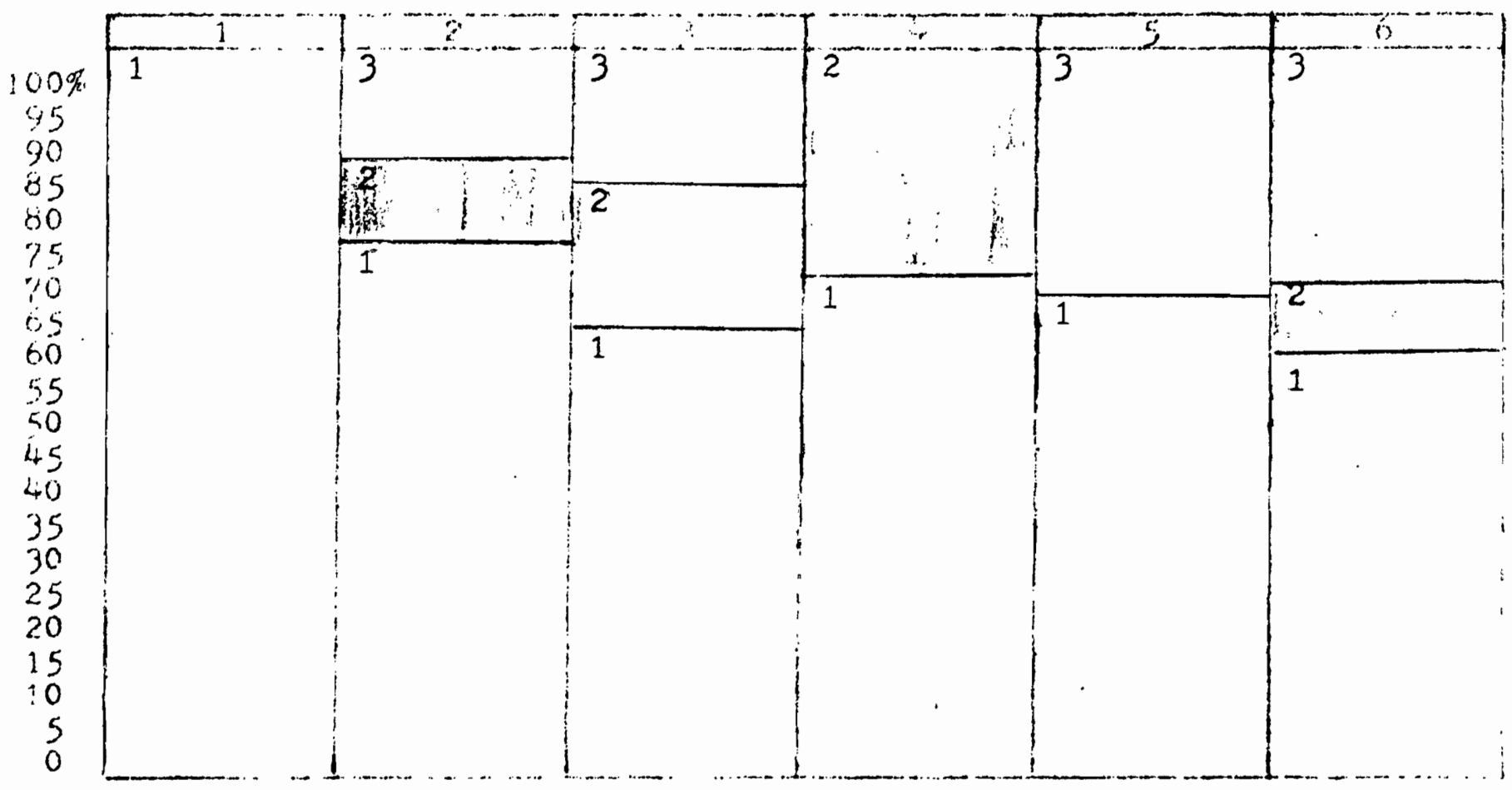


GLETION

would you support the Community Attention Home in The Dalles?

RESULTS 1 Interagency Council

2 Immediate Neighborhood

3 Carpenters' Union
4 Kiwanis Club

5 Hot Line Youth Group Police

\begin{tabular}{lrrrrrrr}
\hline Yes & 15 & 16 & 8 & 18 & 16 & 11 \\
No & 0 & 6 & 3 & 0 & 0 & 2 \\
No response & 0 & 3 & 3 & 3 & 6 & 7 \\
Total & 15 & 25 & 14 & 21 & 22 & 20
\end{tabular}

\section{GRAPHIC ILLUSTRATION (number code above)}

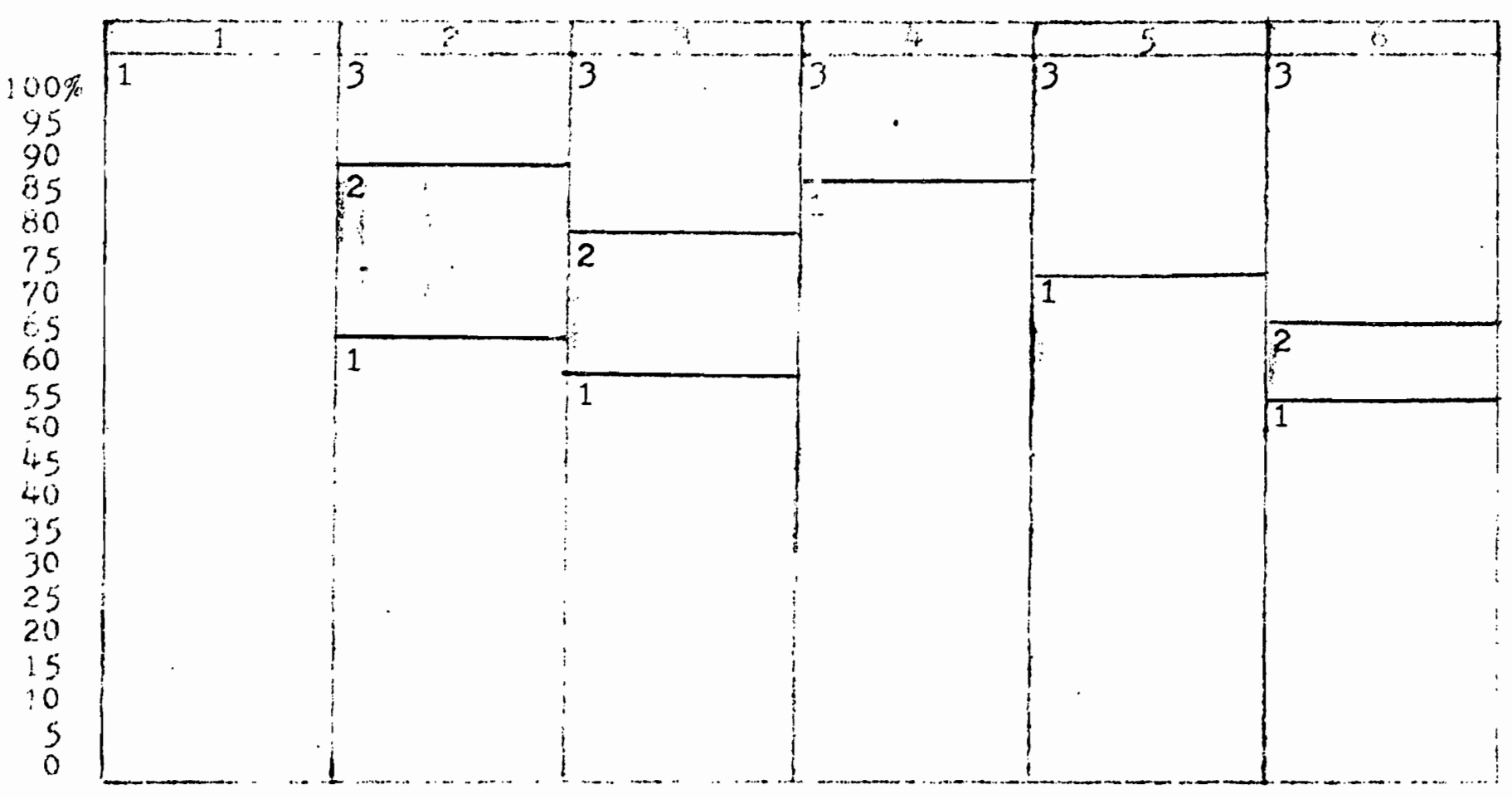


GUESTISN

Would you support the Community Attention Home in The DaJ.les? If yes, how? Cash donations

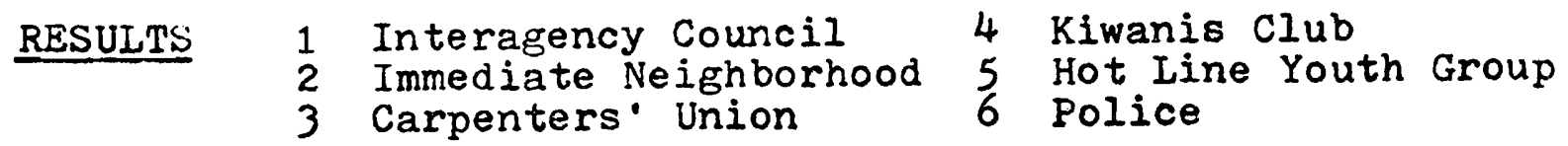

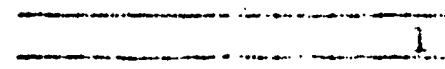

i : Yes

$2 . \quad$ No

No response

Total
11

4

0

15

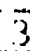

4

8

2

14
1

8

12

1

2.1
5

2

14

6

22 in 2 10 8

$\begin{array}{lllll}25 & 14 & 21 & 22 & 20\end{array}$

\section{GRAPHIC ILIUSTRATION (number code above)}

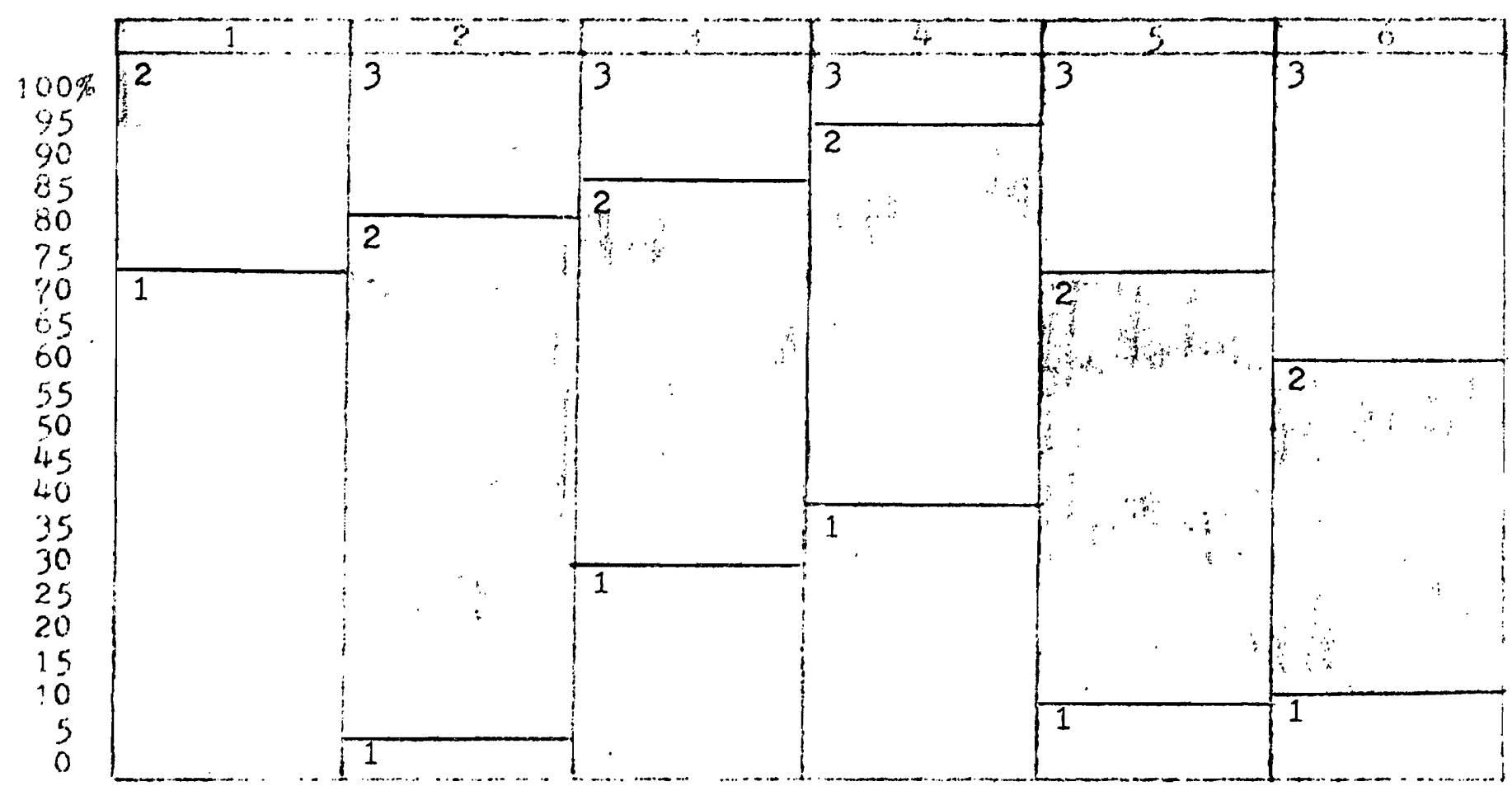


QUESTION

Would you support the Community Attention Home in The Dalles? If yes, how? Donations of goods or special services

RESULTS 1 Interagency Council 2 Immediate Neighborhood 3 Carpenters' Union
4 Kiwanis Club

5 Hot Iine Youth Group Police

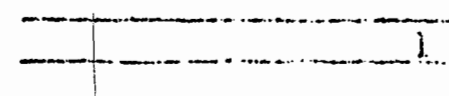

Yes

i. NO

3
No

No response

Total
9

6

0

15
7

13

5

25

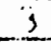

3

9

2

14

21
1.

9

1

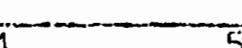


Quespin

Would you support the Community Attention Home in The Dalles? If yes, how? Donations of time (volunteer activities)

RESULTS 1 Interagency Council

2 Immediate Neighborhood

3 Carpenters' Union
4 Kiwanis Club

5 Hot Line Youth Group 6 Police

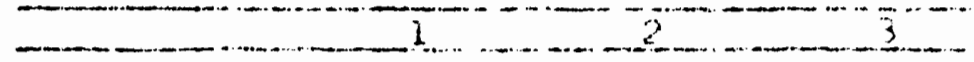

$\therefore \quad$ Yes

2 No

3. $\because:$ No response

T'otal
11

4

0

15
9

11

5

25

1 it

2

4

4

3
4

...... 1

.

15

5

15

1.5

7

21

6

5

1

21

22

20

\section{GRAPHIC ILLUSTRATION (number code above)}

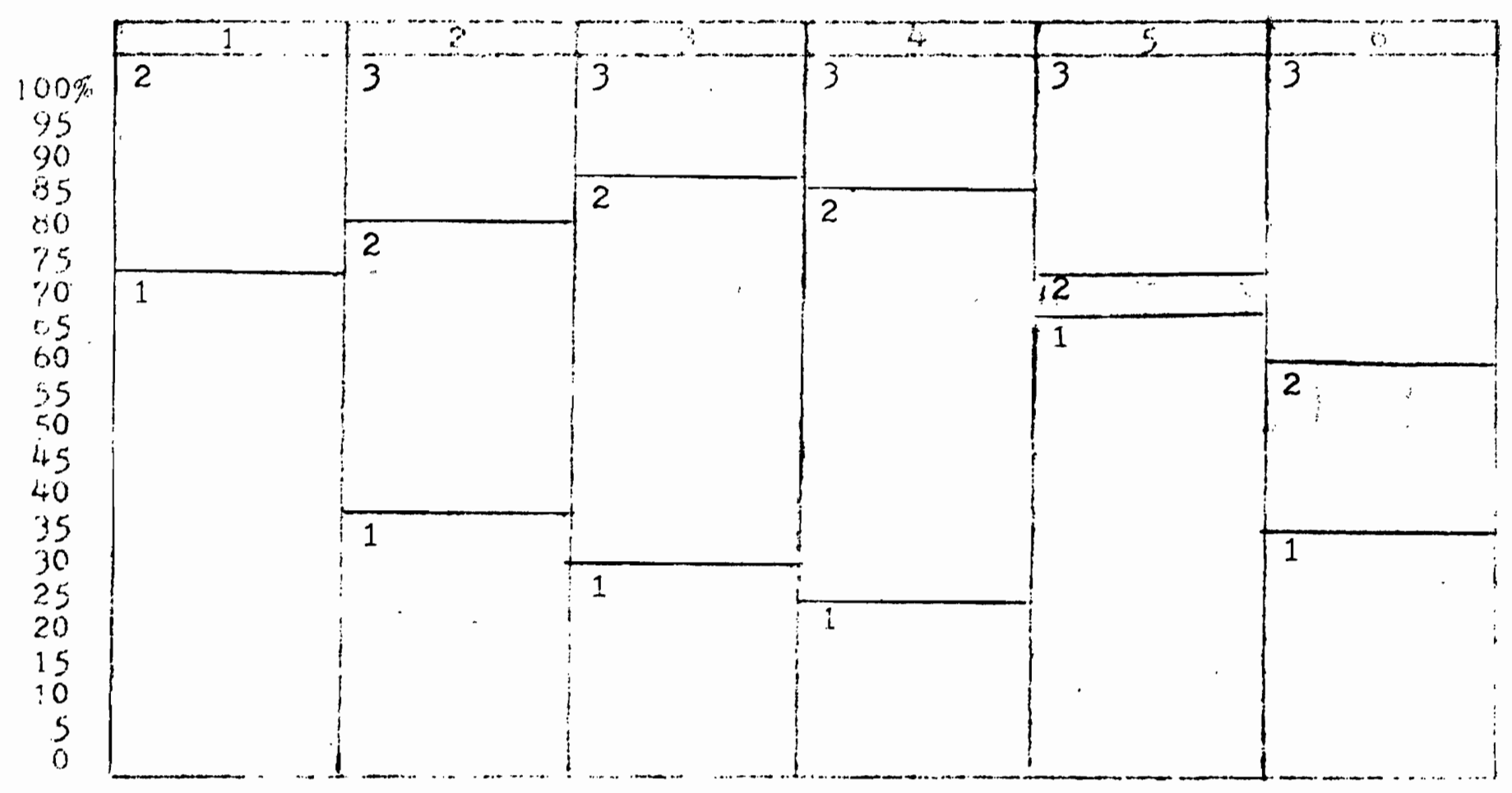


QUESTISN

Would you support the Community Attention Home in The Dalles? If yes, how? Extra taxes

RESULTS

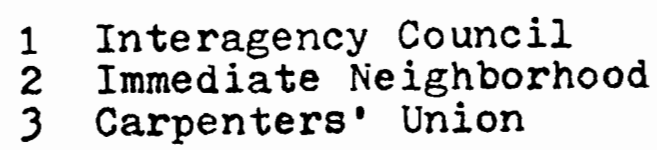

4 Kiwanis Club

5 Hot Line Youth Group 6 Police

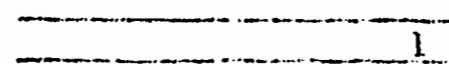

$1 \$$ Yes

5

$-2$

2 No

10

3

11

2

3 No response

17

11

9

14

9

Total

15

25

14

21

22.

20

\section{GRAPHIC ILLUSTRATION (number code above)}

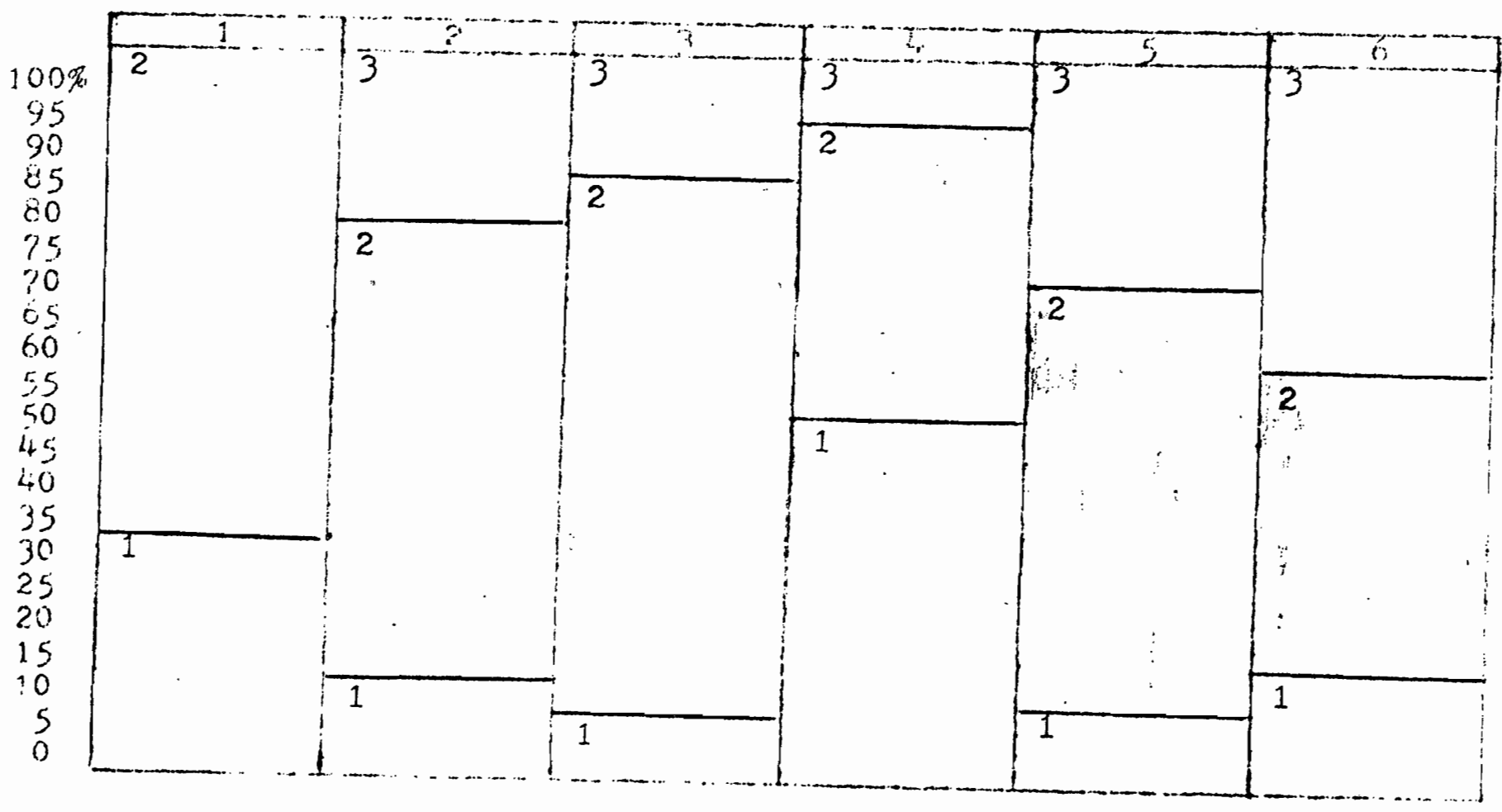


QUFSTISN

Would you support the Communjty Attention Home in The Dalles? If yes, how? In some way other than cash donations, donations of goods or special services, donations of time (volunteer activities), or extra taxes

RESULTS 1 Interagency Council

2 Immediate Neighborhood

3 Carpenters' Union
4 Kiwanis Club

5 Hot Iine Youth Group Police

\begin{tabular}{lrrrrrr}
\hline Yes & 1 & 3 & 0 & 1 & 5 & 1 \\
No & 14 & 17 & 12 & 19 & 15 & 12 \\
No response & 0 & 5 & 2 & 1 & 6 & 8 \\
Total & 15 & 25 & 14 & 21 & 22 & 20
\end{tabular}

GRAPHIC ILLUSTRATION (number code above)

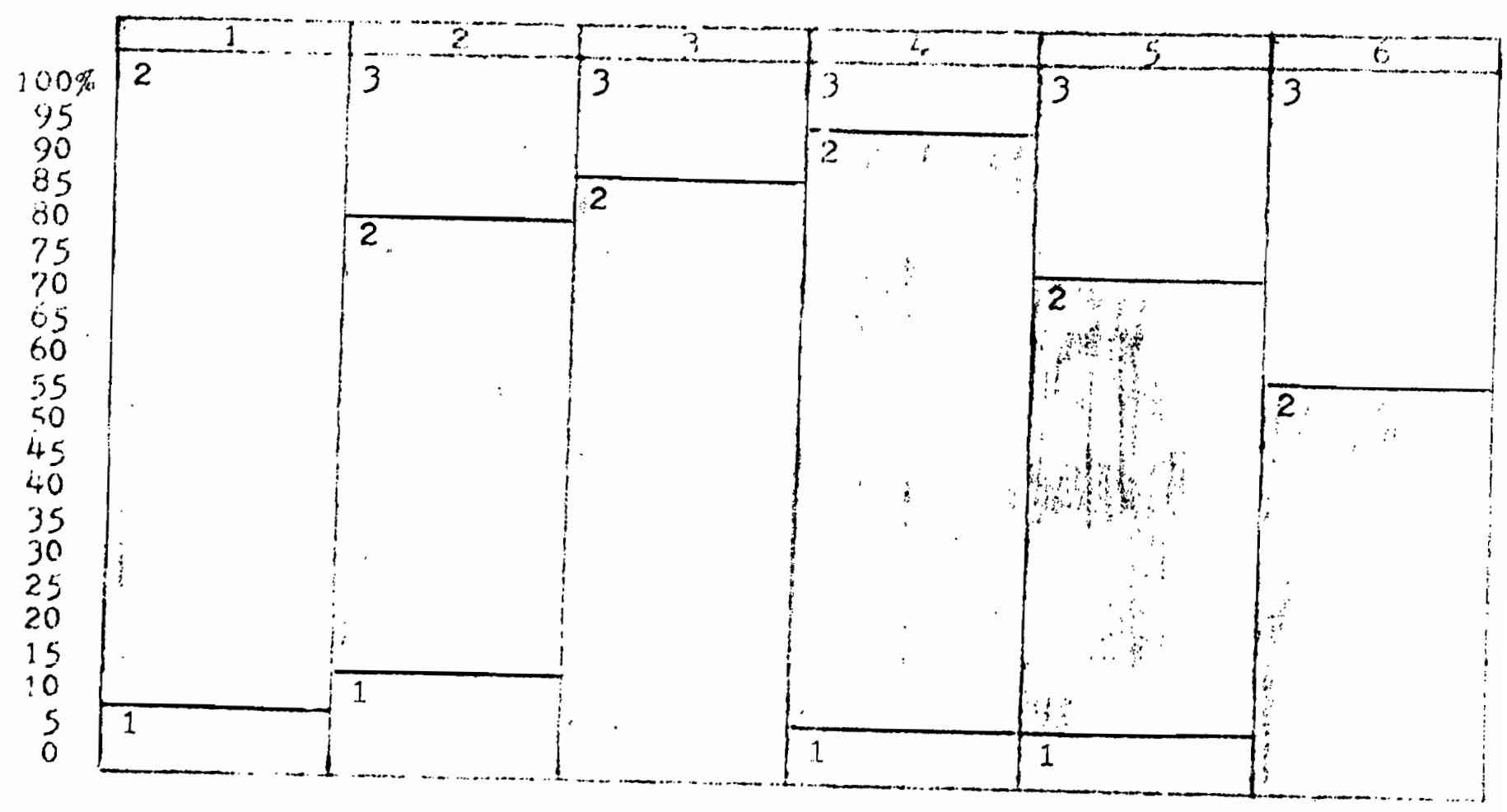


QUESTISN

How would you feel if the Community Attention Home were to be placed in your immediate neighborhood?

RESULTS

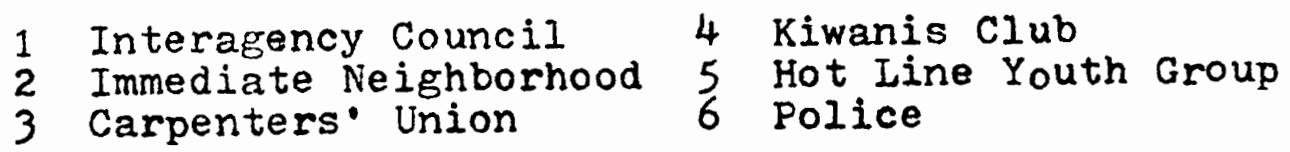

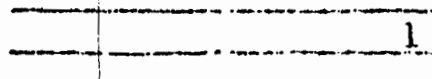

1..........

Strongly

in favor

7

8

4

2

6

3

2 Mildly

in favor

2

8

2

2

8

5

$3 \quad \therefore$ Undecided

4

2

6

9

0

1

6

4

1

2

3

0

$\begin{array}{cccc}\text { Total } & 15 & 25 & 14 \\ \text { GRAPHIC } & \text { ILLUSTRATION } & \text { (number code above) }\end{array}$

$\begin{array}{cccc}\text { Total } & 15 & 25 & 14 \\ \text { GRAPHIC } & \text { ILLUSTRATION } & \text { (number code above) }\end{array}$

$\begin{array}{cccc}\text { Total } & 15 & 25 & 14 \\ \text { GRAPHIC } & \text { ILLUSTRATION } & \text { (number code above) }\end{array}$

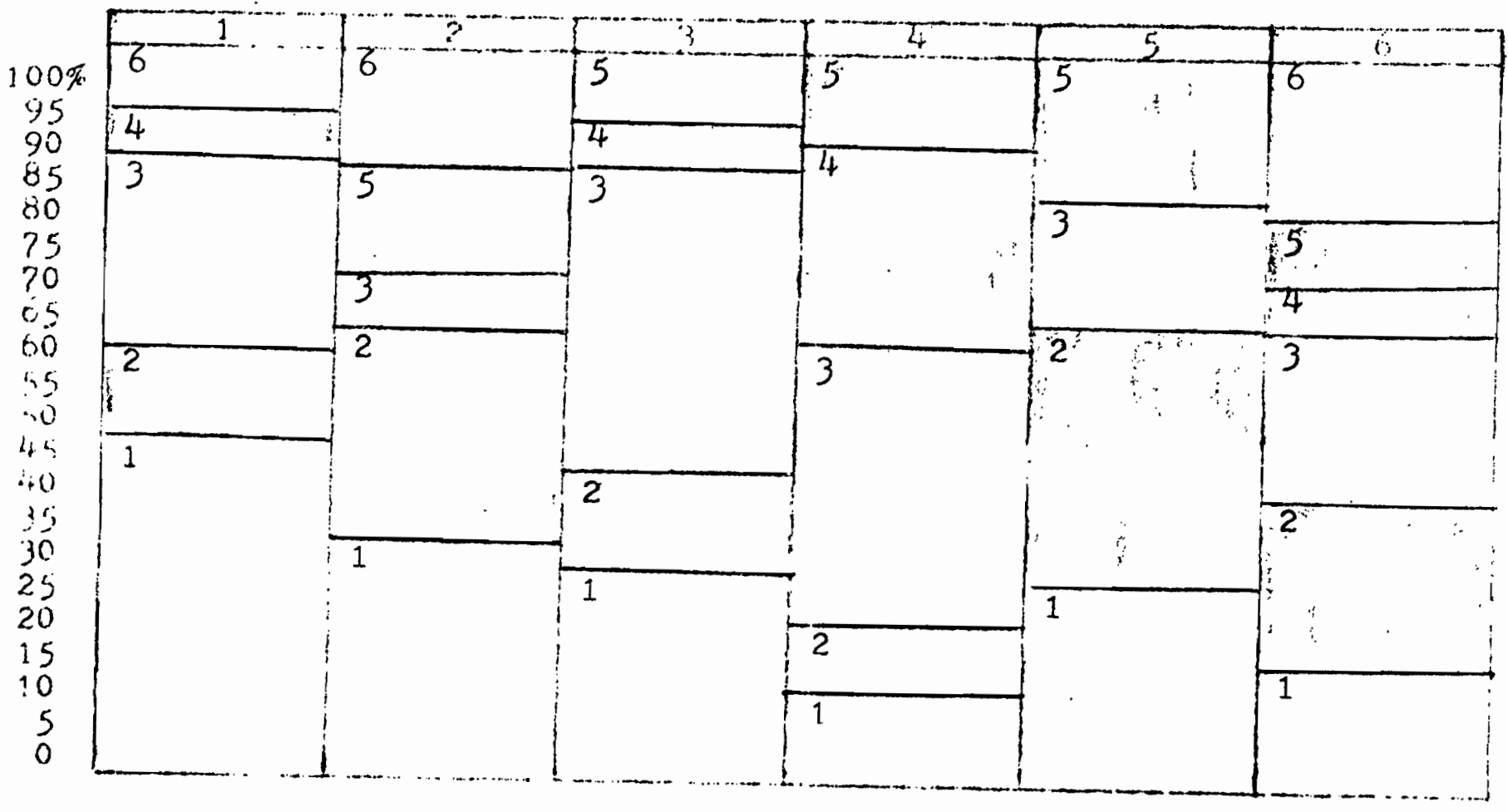


Gutsign

Do you know what facilities are presently available in The Dalles for youth who are in need of temporary shelter care?

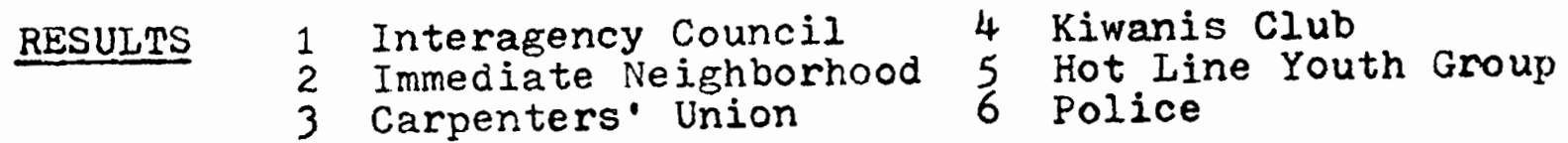

\begin{tabular}{|c|c|c|c|c|c|c|c|}
\hline ; & Yes & 15 & 6 & 3 & 4 & 9 & 12 \\
\hline 4 & No & 0 & 18 & 10 & 17 & 10 & 7 \\
\hline$\vdots$ & No response & 0 & 1 & 1 & 0 & 3 & 1. \\
\hline & Total & 15 & 25 & 14 & 21 & 22 & 20 \\
\hline
\end{tabular}

GRAPHIC ILIUSTRATION (number code above)

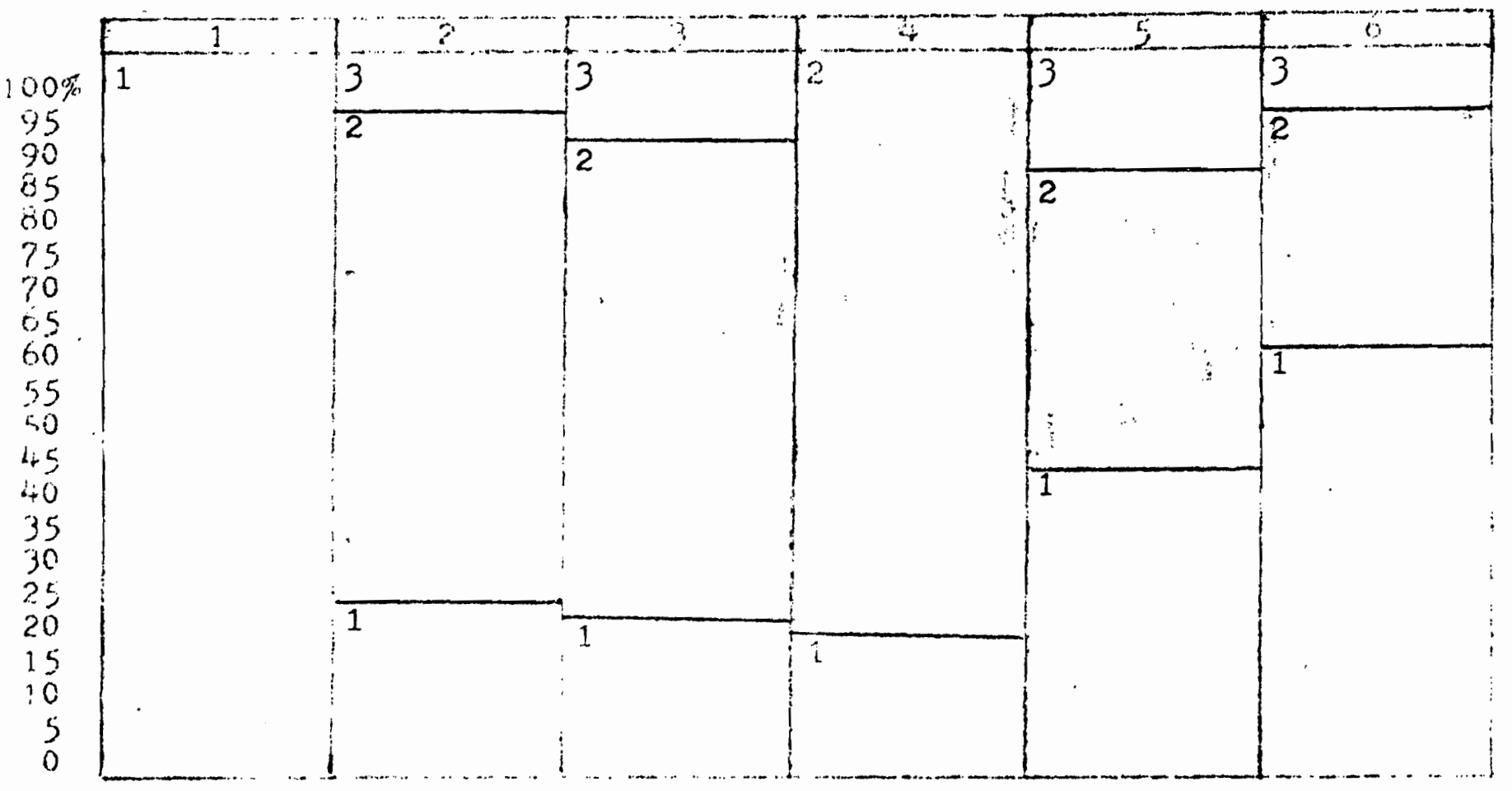


GutSques

What programs for troubled icuth veuld you like to see started in the Community Attention finme in The Dalles?

RESULTS

$$
\begin{aligned}
& 1 \text { Interagency Council } 4 \text { Kiwanis Club } \\
& 2 \text { Immediate Neighborhood } 5 \text { Hot Line Youth Group } \\
& 3 \text { Carpenters ' Union } 6 \text { Police }
\end{aligned}
$$

$-1$

H: Suggestion

$x$

11

14

25

$\mathrm{X}$

Total.

$1+$

21

13

3

13

22

GRAPHIC IILUSTRATION (number code above)

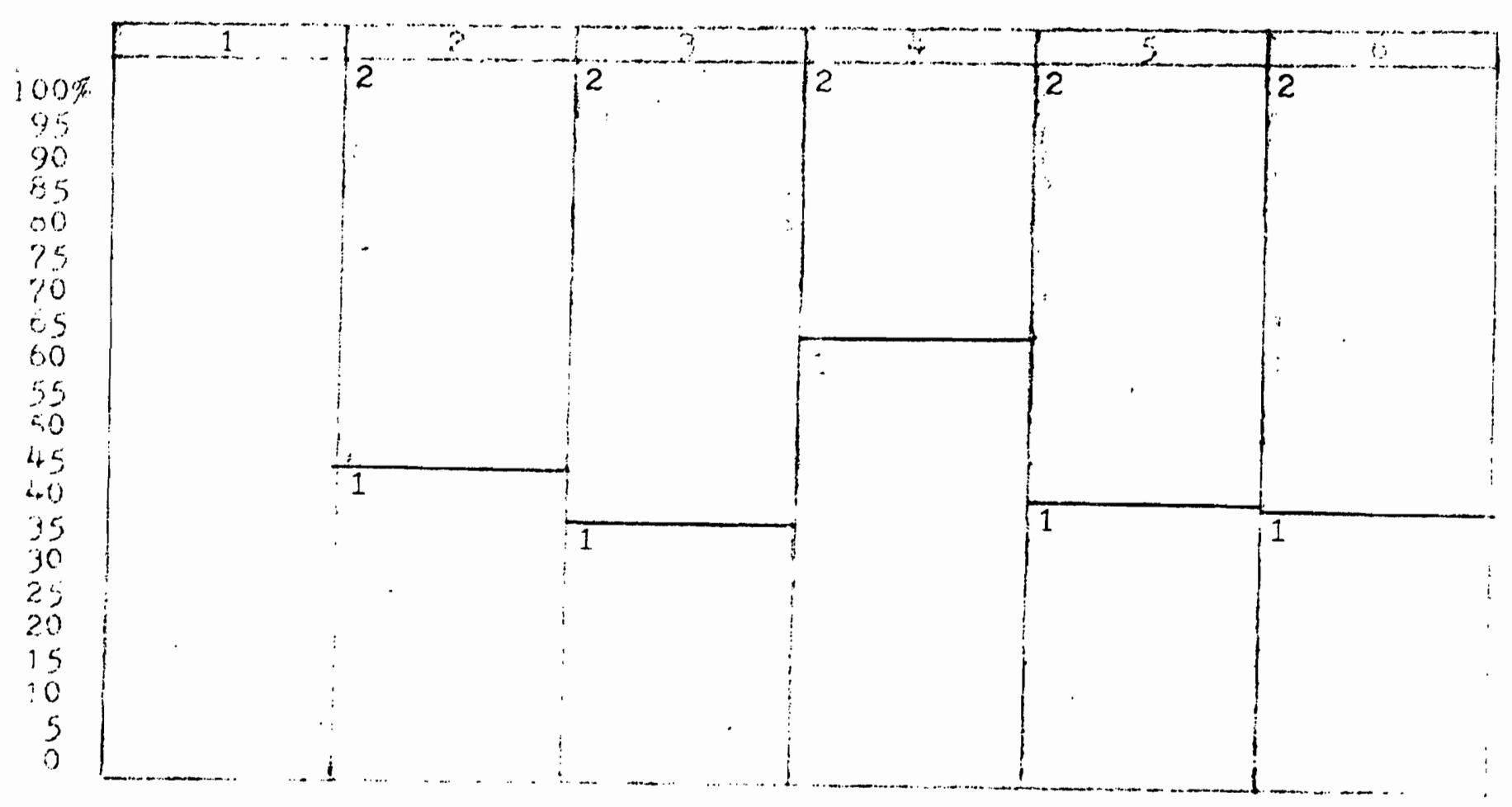


APPENDIX G 
Group Surveyed:

(Circle appropriate items)

Your age: $11-20 \quad 21-30 \quad 31-40 \quad 41-50 \quad 51-60,61-u p$ Sex: $M$ or $F$ Marital status: $S M$ N $M$ sep. No. of children: under 13

$$
13-21 \ldots \text { over } 21
$$

\section{COMMUNITY ATTITUDE QUESTIONNAIRE}

1. Do you feel there should be alternative methods for handling the following youths other than placing them in jail or detention facilities?
A.
NO
Youthful offenders
B. $\longrightarrow$ YES $\longrightarrow$ NO
Adolescents removed from their home because of family conflict
C. YES NO
Dependent or neglected youths

If yes, can you give suggestions?

2. Please indicate whether you agree or disagree with the following statements, and why.

A. Community volunteers should be involved in the handing of adolescents in need of temporary shelter care (as

opposed to only paid officials). (circle one)

STRONGLY AGREE MILDIY AGREE MILDLY DISAGREE STRONGLY DISAGREE Why?

B. Generally speaking, delinquent youth should be isolated from non-delinquent youth. (circle one)

STRONGLY AGREE MILDLY AGREE MIIDIY DISAGREE STRONGLY DISAGREE Why?

C. Jail or detention facilities should be used for temporary shelter care facilities for dependent or neglected youth. (circle one)

STRONGLY AGREE MILDLY AGREE NILDLY DISAGREE STRONGLY DISAGREE Why?

D. It is a poor plan to house youth who have broken the law and youth who are neglected by their parents, together in the same facility. (circle one)

STRONGLY AGREE MILDLY AGREE MILDLY DISAGREE STRONGLY DISAGREL' Why? 
E. The major responsibility for providing facilities for the youth in the community who need temporary shelter care lies with the community rather than the state or federal government. (circle one)

STRONGLY AGREE MILDLY AGREE MILDLY DISAGREE STRONGLY DISAGREE Why?

F. Funding for programs such as the Community Attention Home should come mainly from within the community rather than from outside the community. (circle one)

STRONGIY AGREE MILDLY AGREE MILDLY DISAGREE STRONGLY DISAGREE Why?

3. Have you heard of the Community Attention Home planned for The Dalles? YES NO

If yes, how did you hear of it? (check the appropriate blanks) T.V. Radio

Newspaper

other (describe)

4. Which of the following items apply to the Community Attention Home? (check yes or no)

A. Y_ YES NO Serves delinquent and non-delinquent

B. YES NO Profit making organization

C. YES NO Nlows youth to remain in the community (public school, etc.)

D. __ YES _ NO Relies partially on volunteer services from community

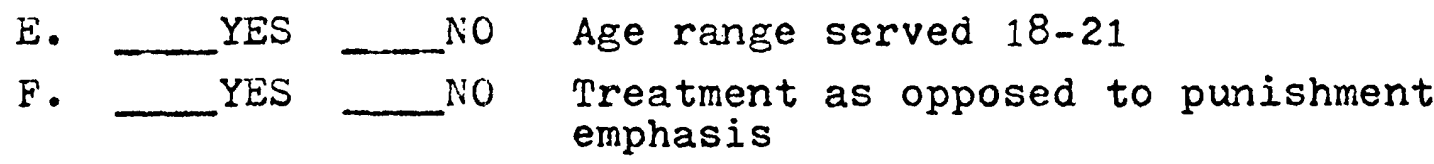

G. YES NO Isolates youth from his peers

H. YES NO Controlled by government agency

5. Are you in favor of the Community Attention Home type of program? (circle one)

STRONGLY IN. FAVOR MILDLY IN FAVOR NO OPINION NOT IN FAVOR Nhy? 
6. Do you feel there is a need for the Community Attention Home in The Dalles?

iny?

YES NO

7. Would you support the Community Attention Home in The Dalles? YES NO

If yes, how? (check those that apply)

Cash donations

Donations of goods or special services Donations of time (volunteer activities)

Extra taxes

Other (specify)

If no, why?

8. How would you feel if the Community Attention Home were to be placed in your immediate neighborhood? (circle one)

STRONGLY IN FAVOR MILDLY IN FAVOR UNDECIDED MILDLY OPPOSED STRONGLY OPPOSED

Why?

9. Do you know what facilities are presently available in The Dalles for youth who are in need of temporary shelter care? YES iio

If yes, describe briefly

10. What programs for troubled youth would you like to see started in the Community Attention Home in The Dalles? 